\title{
Cleft Lip
}

\author{
Pritham N. Shetty, Jaideep Singh Chauhan, \\ Mamatha Patil, Neha Aggarwal, and Dipesh Rao
}

\subsection{Introduction}

A cleft lip [CL] is defined as a congenital defect in lip continuity due to an embryological malformation. Cleft lip and palate [CLP] have an overall incidence of 1 in 1000 live births [1]. For different ethnicities, the incidence varies. Like other facial deformities, cleft lip and palate produce a considerable degree of disfigurement and functional impairment. A comprehensive treatment involving a cleft surgeon, otolaryngologist, geneticist, speech pathologist, orthodontist and others are required at multiple stages right from infancy to adulthood. A successful lip repair requires careful consideration of presentation of the cleft, the availability of tissues or the lack thereof and effect of intervention on growth and function. We have tried to simplify this concept, keeping certain key points in mind necessary for comprehension of the subject. In this chapter, we have discussed embryology, anatomy and clinical presentation of cleft as an integrated phenomenon for better understanding of cleft lip. The author's technique of cleft lip is discussed in a stepwise manner.

Electronic Supplementary Material The online version of this chapter (https://doi.org/10.1007/978-981-15-1346-6_72) contains supplementary material, which is available to authorized users.

P. N. Shetty $(\bowtie)$

OMFS, Bangalore Institute of Dental Science, Bangalore, India

J. S. Chauhan

Department of Maxillofacial Surgery and the Smile Train, CHL Hospital, Indore, India

M. Patil

Sparsh Hospital Bommasandra Industrial Area, Bangalore, India

N. Aggarwal

Cleft and Craniofacial Surgery, Meenakshi Cleft and Craniofacial

Centre, Chennai, India

D. Rao

Bhagwan Mahaveer Jain Hospital, Bangalore, Karnataka, India

\subsubsection{History of Cleft Lip Repair}

The enigma of cleft lip and the historic journey to repair the defect has been well described in the narrative book by Millard [2].The excerpts from it illustrates the documentation of the first cleft lip repair in the year 390 AD where an unidentified Chinese physician cut the edges of the cleft and stitched it together with a postoperative order of limited lip movements for the next 100 days. The need to identify an ideal technique was derived on the basis of the anatomical outcome of the repair and also the postoperative scarring. The concepts of cleft lip repair have evolved from straight line repairs to a variety of techniques using various cutbacks, triangles, z-plasties and other flaps.

The techniques for cleft lip can be broadly classified into:

- Straight line repairs.

- Geometric designed techniques.

- Rotational advancement techniques.

We will discuss certain techniques to explain the evolution from a historical point of view. The rotation-advancement technique with its modifications will be discussed later in this chapter.

\subsection{Embryology}

\subsubsection{Development of the External Face}

The face is derived from two sources: the frontonasal process that covers the forebrain (neural crest origin) and the tissues of first pharyngeal arch (mixed mesoderm and neural crest origin). These tissues surround the oropharyngeal membrane. From the frontonasal process, two medial nasal processes and lateral nasal processes arise [3]. The first pharyngeal arch gives 
rise to a pair of mandibular processes and a pair of maxillary processes from which palatal processes arise [3]. The maxillary prominences continue to grow medially, compressing the medial nasal prominences towards the midline, subsequently meeting the lateral nasal processes and then the lower part of the medial nasal processes (Figs. 72.1, 77.1). This lower part is known as the globular or premaxillary process. The components derived from various parts are given in Table 72.1.

Abnormalities throughout this complicated developmental process occur in the most severe congenital forms if they develop early in facial embryogenesis (4-8 weeks) to the relatively minor problems developing later (8-12 weeks). Cleft lip varies from a notch in lips red border to extending into the floor of nostril and the alveolar ridge. It may be unilateral or bilateral (Fig. 72.2). Some other forms of facial clefts have also been described in a pictorial form as a result of failure of fusion of the same processes but in a different trajectory and various permutations and combinations (Fig. 72.3).

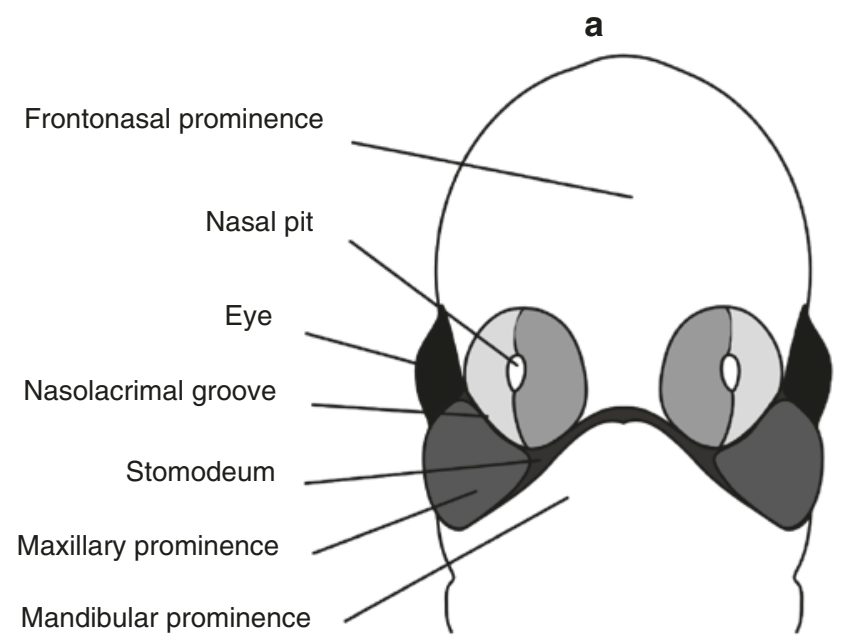

C

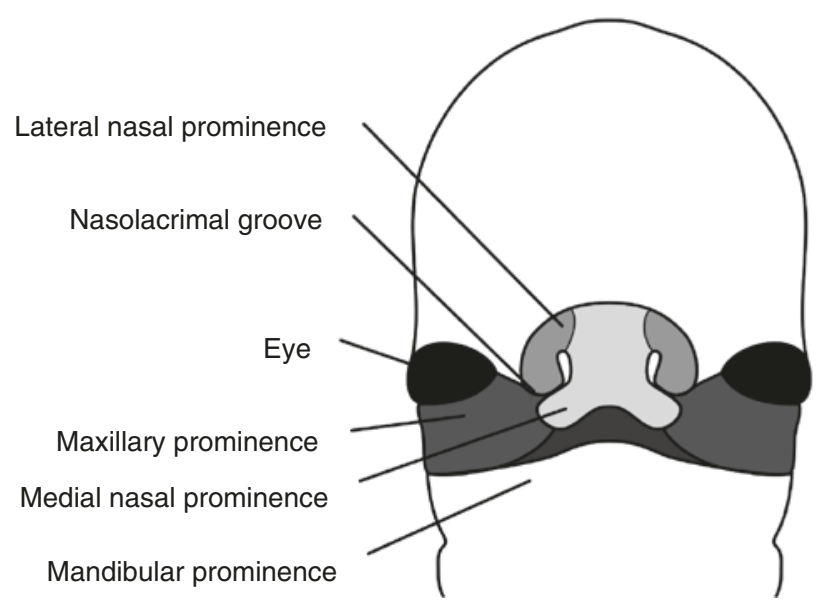

CAssociation of Oral and Maxillofacial Surgeons of India

Fig. 72.1 (a-d) Development of the face. (a) Lateral nasal and medial nasal swellings that surround the nasal placodes appear on the frontonasal process (b) Paired maxillary processes grow medially, compressing
1. Unilateral cleft lip-due to the failure of the maxillary prominence to join with the merged median nasal prominences which results in a cleft.

2. Bilateral cleft lip-due to failure of fusion of the maxillary prominences with merged nasal prominences bilaterally. The extent of clefting may or may not be similar on both sides.

Table 72.1 Components of face derived from various prominences

\begin{tabular}{|c|c|}
\hline Prominence & External face derivatives \\
\hline Frontonasal & $\begin{array}{l}\text { The forehead, the bridge of nose, } \\
\text { median and lateral nasal processes }\end{array}$ \\
\hline Medial nasal & $\begin{array}{l}\text { The philtrum of the upper lip, crest and } \\
\text { tip of the nose }\end{array}$ \\
\hline Lateral nasal & Alae of the nose \\
\hline $\begin{array}{l}\text { Maxillary process (first } \\
\text { pharyngeal arch) }\end{array}$ & Lateral portion of the upper lip \\
\hline $\begin{array}{l}\text { Mandibular process (first } \\
\text { pharyngeal arch) }\end{array}$ & The lower lip \\
\hline
\end{tabular}

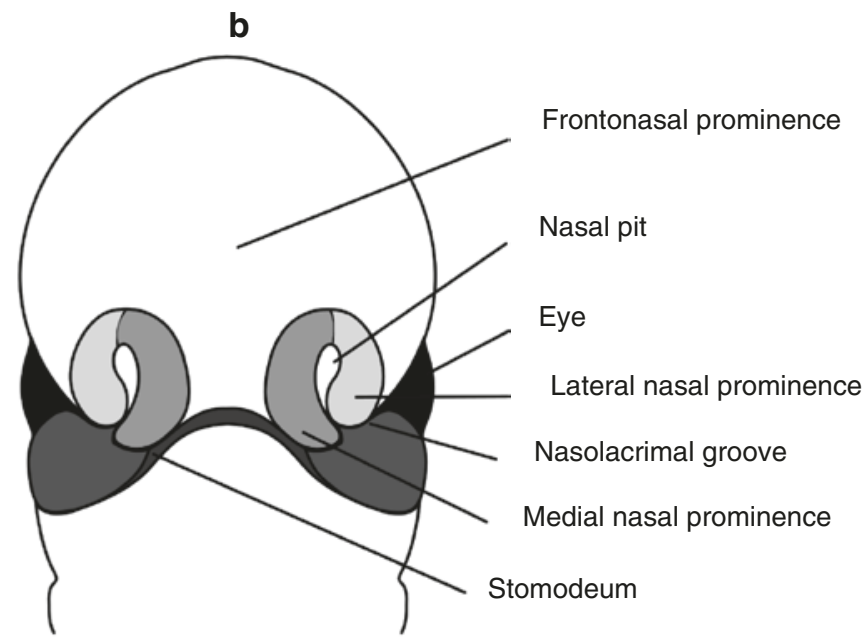

d

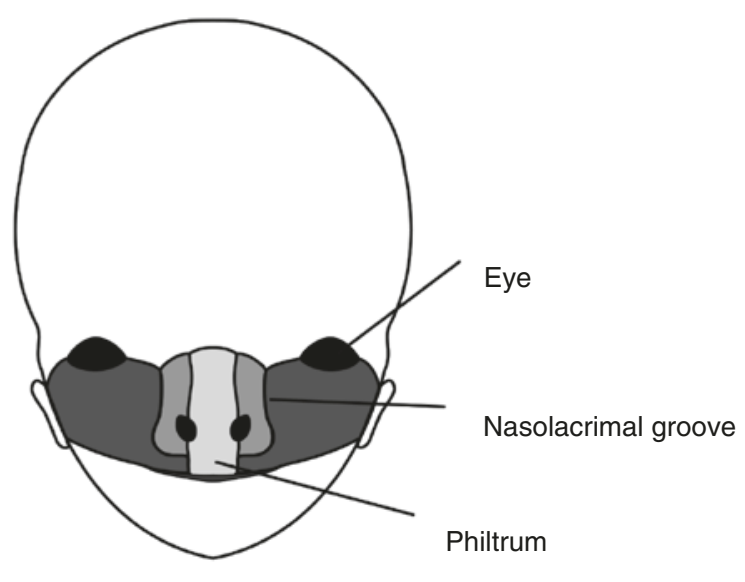

the medial nasal prominences towards the midline. (c) Medial nasal processes fuse with each other, lateral nasal processes and the maxillary processes. (d) Complete development of the nose and upper lip 

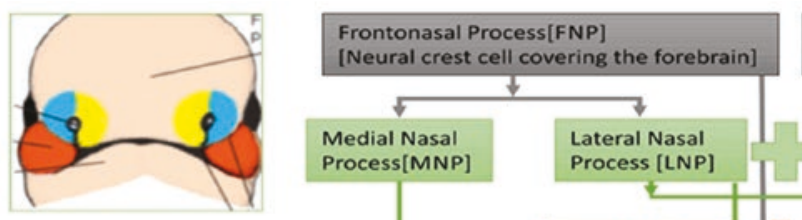

First Pharyngeal arch

[ mesoderm + neural Crest cells]
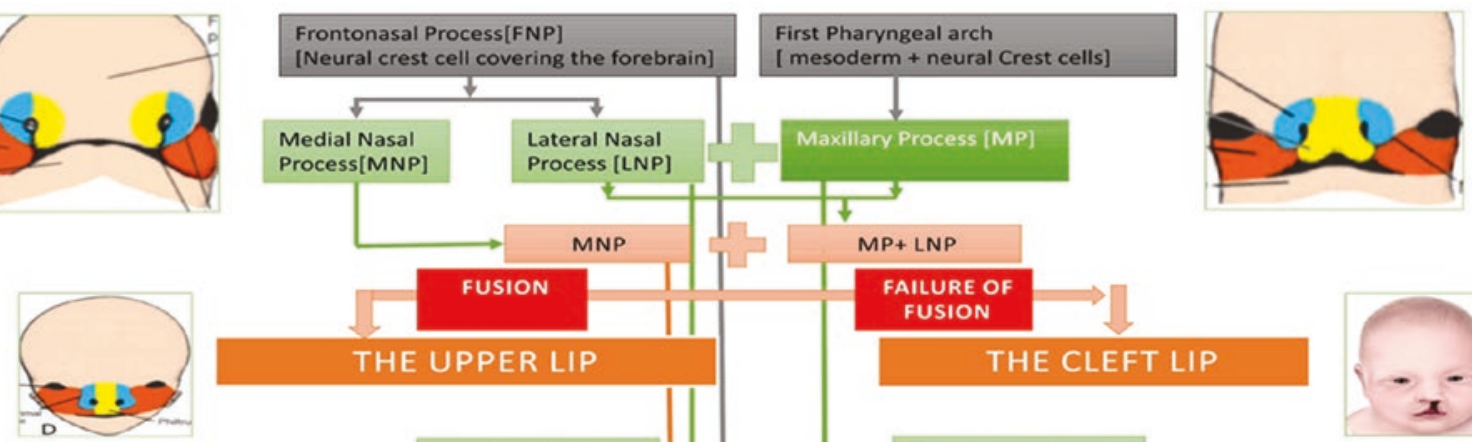

FAILURE OF
FUSION
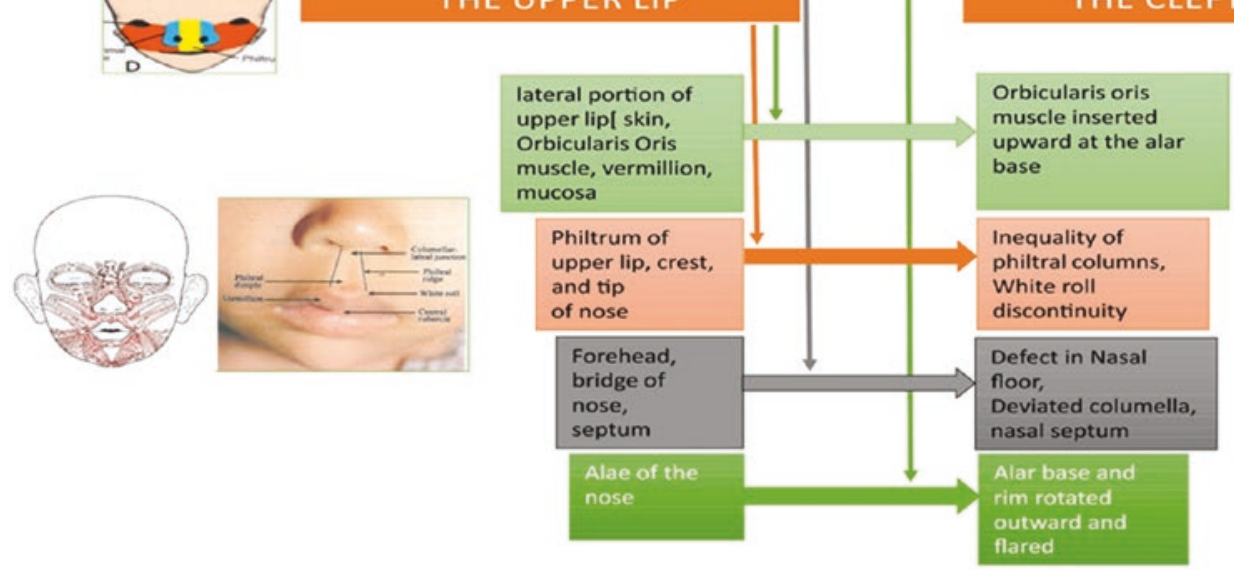

THE CLEFT LIP
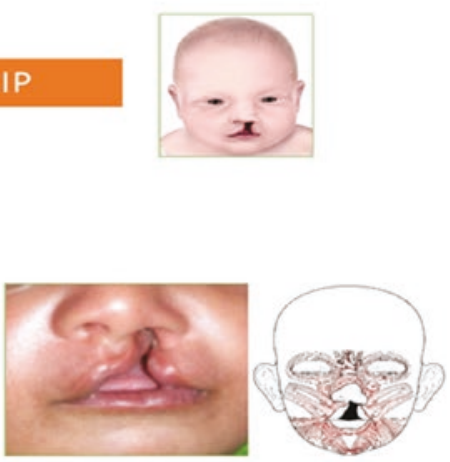

CAssociation of Oral and Maxillofacial Surgeons of India

Fig. 72.2 Relation of embryological derivative to the anatomical and clinical description of cleft lip

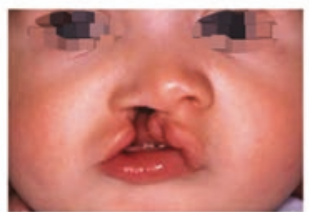

Failure of fusion of maxillary process and lateral nasal process with medial nasal process [ Tessier 1/2]

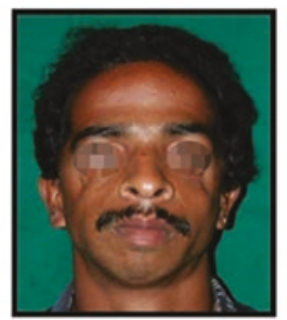

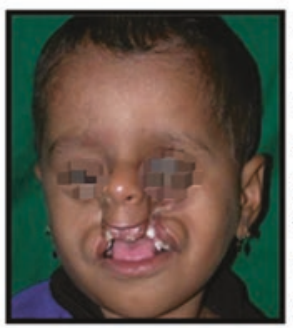

Failure of fusion of maxillary process with lateral nasal process and medial nasal process. There is fusion of medial nasal and lateral nasal process [ Tessier 4]

Component of Treacher

Collins Syndrome [Tessier 6]

(C)Association of Oral and Maxillofacial Surgeons of India
Failure of fusion in midline of the medial nasal process [Tessier 0 \& 1]
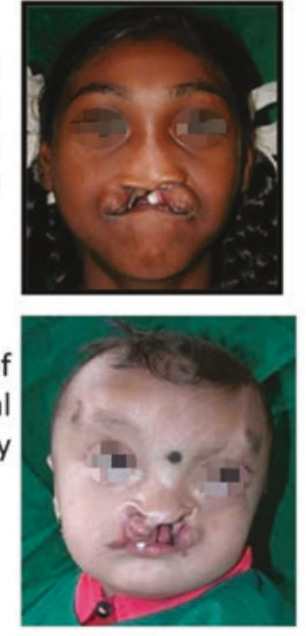

Failure of of

Maxillary and mandibular prominences [Tessier 7]

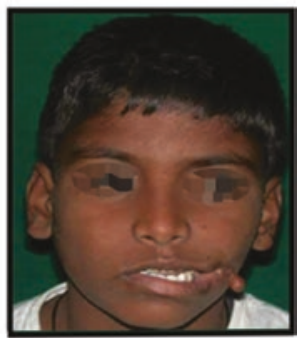

Fig. 72.3 Embryology of various facial clefts 
3. Median cleft lip-a very rare condition. Occurs due to the partial or complete failure of fusion of the two medial nasal prominences to form the intermaxillary segment. It is the characteristic feature of Mohr's syndrome.

\subsubsection{Embryology of Cleft and its Surgical Implications}

1. Mesodermal Migration: There are various theories to describe how a cleft occurs. These theories explain that cleft rises as a result of failure of fusion of the five processes. These processes are formed as a result of mesodermal migration resulting in heaping under the ectodermal layer. Insufficient or late migration of mesoderm leads to partial or total cleft as a result of epithelial breakdown.

Mesoderm gives rise to the fibromuscular layer of the lip. The importance of mesodermal migration carries in itself an important principle of cleft repair, i.e. muscle approximation. The author's technique presented later in this chapter describes this step as an important step in functional cleft repair. Also the mesoderm has chondrogenic potential which explains the accompanying deficit in the development of nasal capsule [4].

2. Vascular Supply: The philtrum and premaxilla derive their blood supply from the posterior septal artery and ter- minal branches of the ethmoidal artery (Fig. 72.4). Knowledge of this embryological vascular supply is important while designing the incision on the prolabium in a bilateral cleft lip repair. As the prolabium derives its blood supply solely from the frontonasal process, no back cuts are given during dissection of prolabial flap (Fig. 72.4). This is discussed again in surgical technique.

3. Premaxilla: In complete bilateral cleft lips, the labial artery fails to unite with its counterpart on the other side. In addition the arcade made by anastomosis of the posterior septal branch with the greater palatine artery through the incisive foramen is absent. Thus the blood supply of the premaxilla is derived from three sources: periosteal supply from the vomer, branches of the sphenopalatine and ethmoidal artery. This principle is used in anterior palate repair with concomitant lip repair in bilateral clefts. It is postulated that anterior palate repair using the vomerine flap can lead to premaxillary necrosis due to cutoff of blood supply from the posterior septal arteries. However, in author's opinion and experience, the premaxilla has a robust blood supply even after using vomerine flaps for anterior palate repair [5].

4. The maxillary process carries within itself the superior labial artery which supplies the orbicularis oris muscle. During muscle dissection, the artery is encountered within the muscle going upward. This vessel should be identified throughout the length of incision and muscle dissection and should be carefully cauterised.
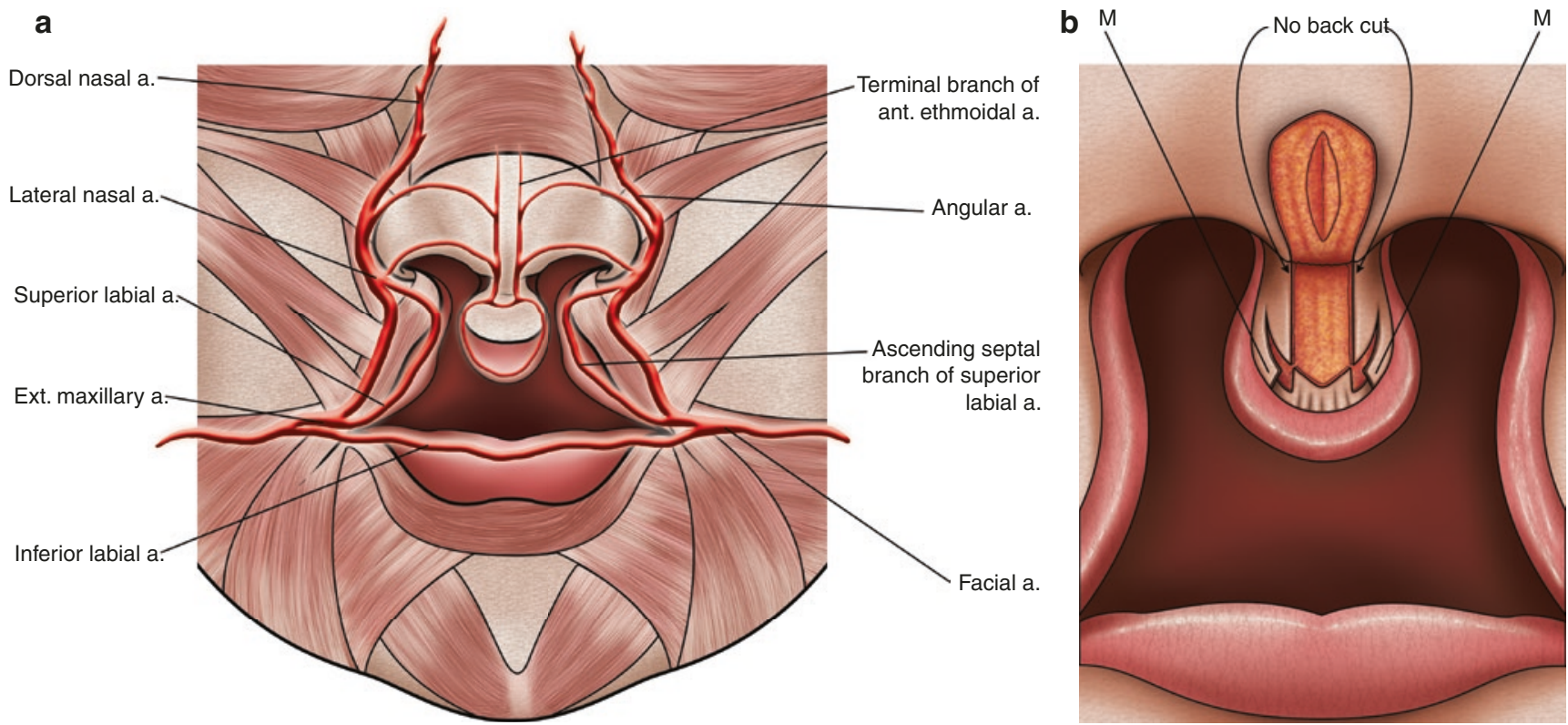

Fig. 72.4 (a, b) As the philtrum and premaxilla are derived from the frontonasal process, their blood supply is from the posterior septal artery and terminal branches of the ethmoidal artery (a). As the prola-

bium derives its blood supply solely from the frontonasal process, no back cuts are given during dissection of prolabial flap (b) 


\subsubsection{Prenatal Diagnosis in Cleft Lip}

Cleft lip can be diagnosed in the intrauterine stage with the help of routine ultrasound scanning at different intervals of gestation. The prenatal diagnosis is usually established during the second and third trimester [6]. Recent data suggests that during the 11-13 gestational weeks, a midsagittal view of the fetal head, face and brain, in addition to certain measurable abnormalities, such as a smaller palatino-maxillary diameter, can make grounds for an underlying CLP. 3D sonography can construct a computerized volumetric rendering of the foetus, similar to 3D CT volumetric reconstructions. Detection rates of up to $75 \%$ have been described by specialist maternal-fetal medicine [MFM] physicians and radiologists. Thus, prenatal counselling continues to be important with evolving diagnostic procedures. Although there is currently no intrauterine treatment of cleft lip and palate, research has indicated that both mother and child benefit from early diagnosis and counselling. Prenatal counselling has positive psychological implications on the parents of a child with cleft as they are better prepared and motivated for treatment.

\subsection{Surgical Anatomy}

Anatomy of the cleft lip patient includes two major components: the lip and the nose. Both the structures vary greatly in a unilateral and bilateral cleft lip deformity and are discussed individually here.

The upper lip is attached above to the nose and blends laterally into the cheek, curving into the lower lip at the commissures. It is formed of muscles and glands covered superficially with skin and lined internally with mucous membrane. These layers are tightly adherent to the muscles and are sealed along the free margin (Box 72.1).

\section{Box 72.1 Components of an Upper Lip}

Normal upper lip anatomy

1. Skin, mucous membranes and vermillion with lbial mucosal glands.

2. Muscles: orbicularis oris insertion is displaced in unilateral and bilateral cleft patients.

3. Vascular supply: superior labial artery, inferior labial artery and septal arteries are the major blood supplies of the lips and the nose.

\subsubsection{Surface Anatomy}

The following anatomical surface components of the upper lip are to be kept in mind when assessing a patient with cleft lip (Fig. 72.5). Anatomical equal repositioning of these features is essential for an aesthetic and functional outcome (Box 72.2).

\section{Box 72.2 Anatomic Landmarks}

Philtral columns: They are paired bilateral vertical lip bulges created by the dermal insertion of orbicularis oris fibres into the skin of the upper lip.

Philtral dimple: It's a concavity between the philtral columns created by relative deficiency of muscle fibres.

White roll: The white roll is a prominent ridge just above cutaneous-vermillion border. It appears very distinct and white/light in colour due to reflection of light off the skin. This is due to insertion of pars maginalis of orbicularis muscle and absence of hair in this region.

Vermillion: It's the red mucosal portion of lip divided into dry (keratinized) and wet (nonkeratinized) mucosa.

Red line: It's the junction between wet and dry vermillion mucosa.

Cupid's bow: A curvature of central white roll, formed by the two lateral peaks as the philtral columns extend inferiorly.

Tubercle: Vermillion fullness at central inferior apex of Cupid's bow.

In the normal lip, the columella is a central straight column reaching up to the nasal tip. At its base the columella blends into the nostril sill in front of the nasal floors laterally towards the alar bases. The arches of the alae are symmetrical with equal bulges of the alar cartilages. The eversion of the upper lip places it slightly out in front of the lower lip at the mucocutaneous junction of the upper lip. There is a continuous $1-2 \mathrm{~mm}$ rounded roll from commissure to commissure which tops the vermilion and picks up white light it coincides in its curves with the peaks of the Cupid's bow of the vermilion which has central tubercle flanked by, each arch of the bow. The abundance of eleidin in the epithelial cell layers increases the translucency, and the numerous rich capillaries of the papillae create the red colour of this area [5]. 


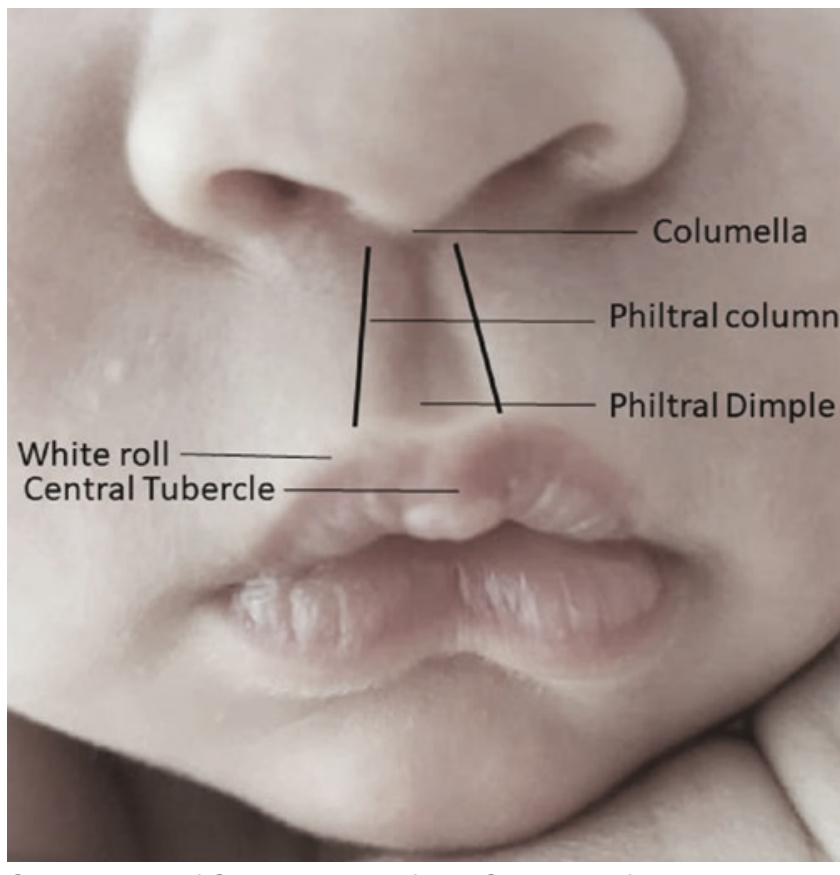

CAssociation of Oral and Maxillofacial Surgeons of India

Fig. 72.5 Surface landmarks of a normal lip and nose

\subsubsection{Muscles}

The orbicularis oris consists of numerous layers of muscle fibres surrounding the rima oris traversing in different directions. It is partly derived from muscle fibres of the other facial muscles which are inserted into the lips and partly fibres of its own inserted into the skin near the midline. The main fibres of the lips are oblique and pass from the skin to the mucous membrane, throughout the lip thickness. In the upper lip, these fibres group into two bands bilaterally, lateral and medial [total of four bands]: the lateral band originating from the alveolus of the lateral incisor tooth and the medial band connecting the upper lip to the septum of the nose. The area between the two medial bands forms the philtrum, below the septum of the nose. The additional fibres for the lower lip arise on either side of the midline lateral to the mentalis and merge with the other muscles at the commissure [7].

Orbicularis oris derives from eight muscle components with their origins in the modiolus at each angle of the mouth. Orbicularis fibres of one side end by decussating in the median line with fibres from the opposite side. The orbicularis is composed of four pars peripheralis extending from the rima oris on the right and left side. Intimately associated with the pars peripheralis is the pars marginalis with its two right and left components lying in a plane superficial to the pars peripheralis and confined to the area beneath the vermil- lion. Pars marginalis is responsible for fine movement (speech) and pars peripheralis for gross movement of the lips (Fig. 72.6a-c). In the presence of cleft, the orbicularis oris muscle fibres do not decussate transversely across the midline but tend to go parallel to the cleft edges towards the base of the nose with their integrity divided. In addition, the transverse nasalis muscle, levator labii superioris and depressor septi do not insert and are prolapsed laterally. They often contract abnormally which has a ripple effect of the lip and the nose. Muscles make the most of their advantage exerting unnatural lateral lifting and distortion of the lip elements in both incomplete and complete clefts. They play a role in displacement of alar base to the side of cleft and the nasal septum on non-cleft healthy side.

\subsubsection{Vascular Supply}

The major vascular supply to the lip and nose area is derived from the facial artery, branch of the external carotid artery. Other additional sources are from the ophthalmic and the infraorbital arteries. The facial artery gives off inferior and superior labial branches which arise near the corner of the mouth and course as the coronary vessels beneath the free border of the lips deep to the muscle and close to the mucous membrane. The right and left labial arteries freely anastomose to form a circle surrounding the oral aperture. The facial artery then proceeds upwards along the nasolabial fold and gives off the lateral nasal branch and then becomes the angular artery proceeding up to anastomose with the dorsal nasal branch of the ophthalmic artery. The posterior septal artery arising from the sphenopalatine artery in the roof of the nasal cavity courses down the vomerine groove to the incisive foramen anastomosing with the major palatine and ascending septal branches of the superior labial arteries (Fig. 72.7a, b).

Near the inferior lateral attachment of the ala, the lateral nasal artery divides to run one branch along the lower border and another along the superior margin of the lower lateral cartilage. These branches anastomose in the midline with the terminal branches of the anterior ethmoidal artery. It enters the nose and passes along the undersurface of the nasal bone continuing distally over the upper lateral cartilages to the tip of the nose. It joins the lateral nasal branches to continue into the columella anastomosing with the ascending septal branches of the superior labial artery [5].

Vascular anatomy in a cleft lip has been described pictographically in Fig. 72.8. There is an interruption in the usual arcade in the upper lip in unilateral clefts. However, there is sufficient blood supply to both lip elements and the nose to ensure adequate healing. 

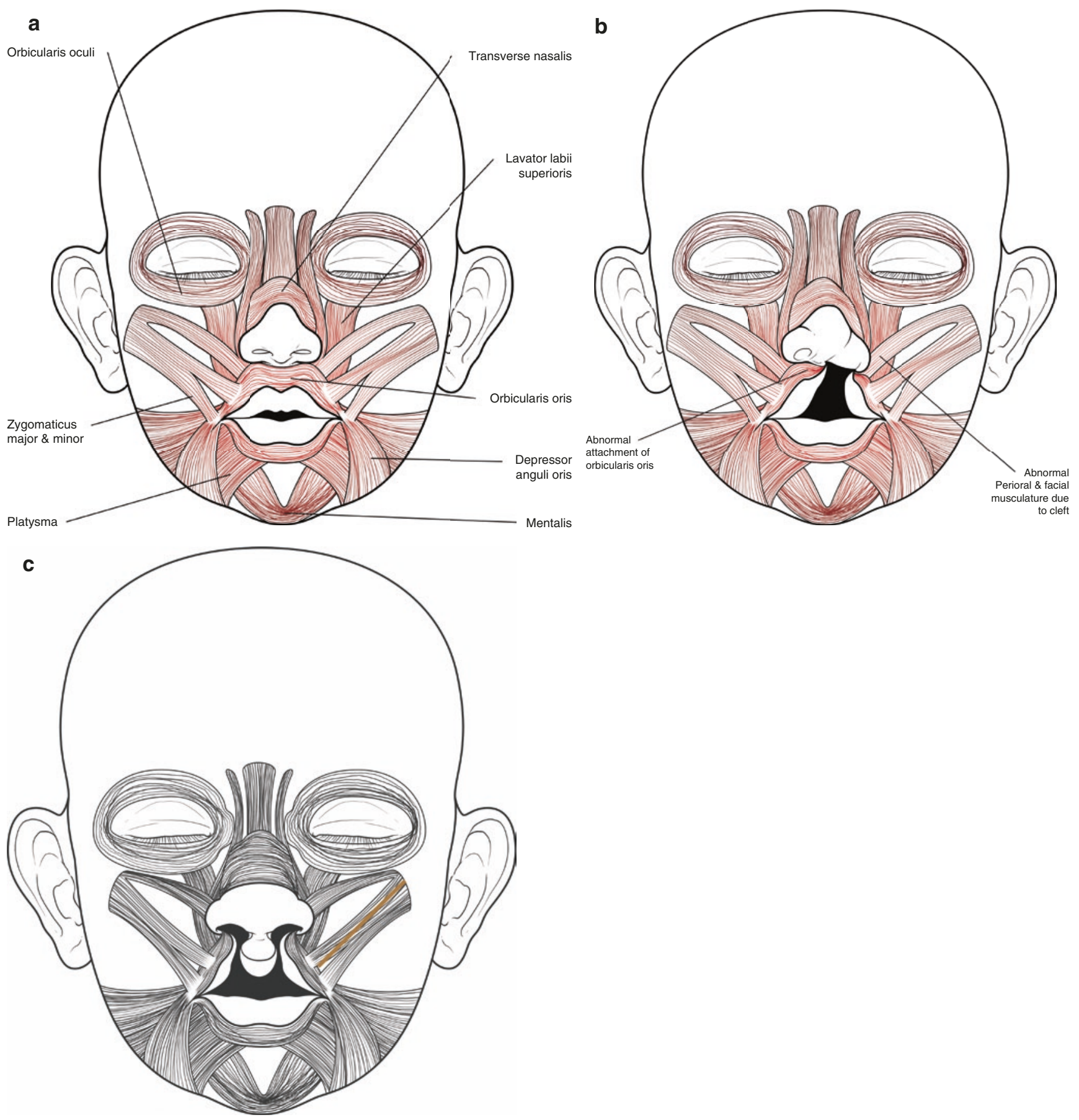

(C)Association of Oral and Maxillofacial Surgeons of India

Fig. 72.6 (a-c) Concentric band of orbicularis oris forming oral sphincter. Upper and lower fibres arise from each modiolus and decussate in the midline. Superficial fibres upper lip criss-cross at midline to attach to the dermis of the overlying skin at the philtrum. Deeper fibres attach to the anterior nasal spine [left]. Note the abnormal attachments in unilateral and bilateral clefts [middle and right] 
Fig. 72.7 (a, b) Vascular anatomy of a complete lip (a) and a unilateral cleft lip (b)

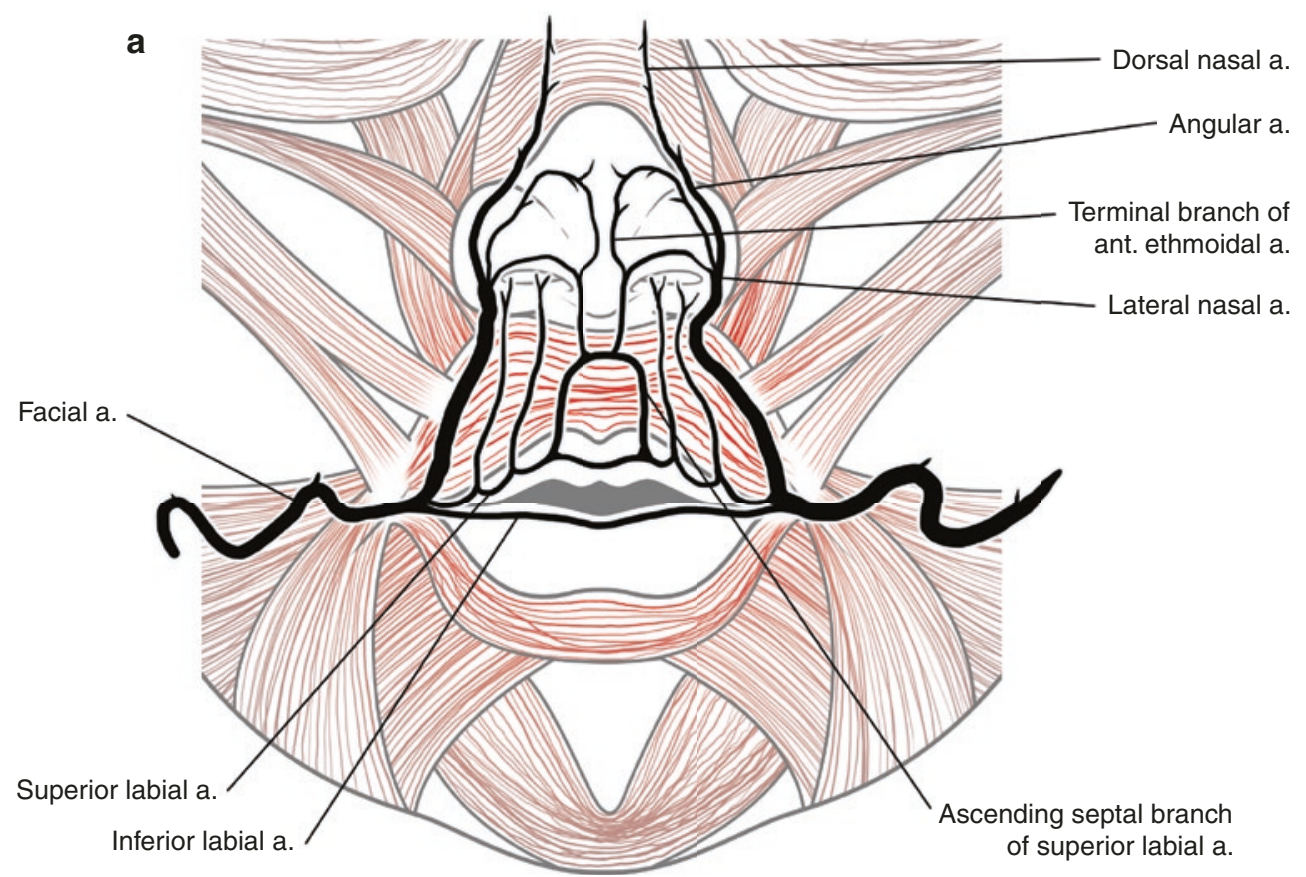

b

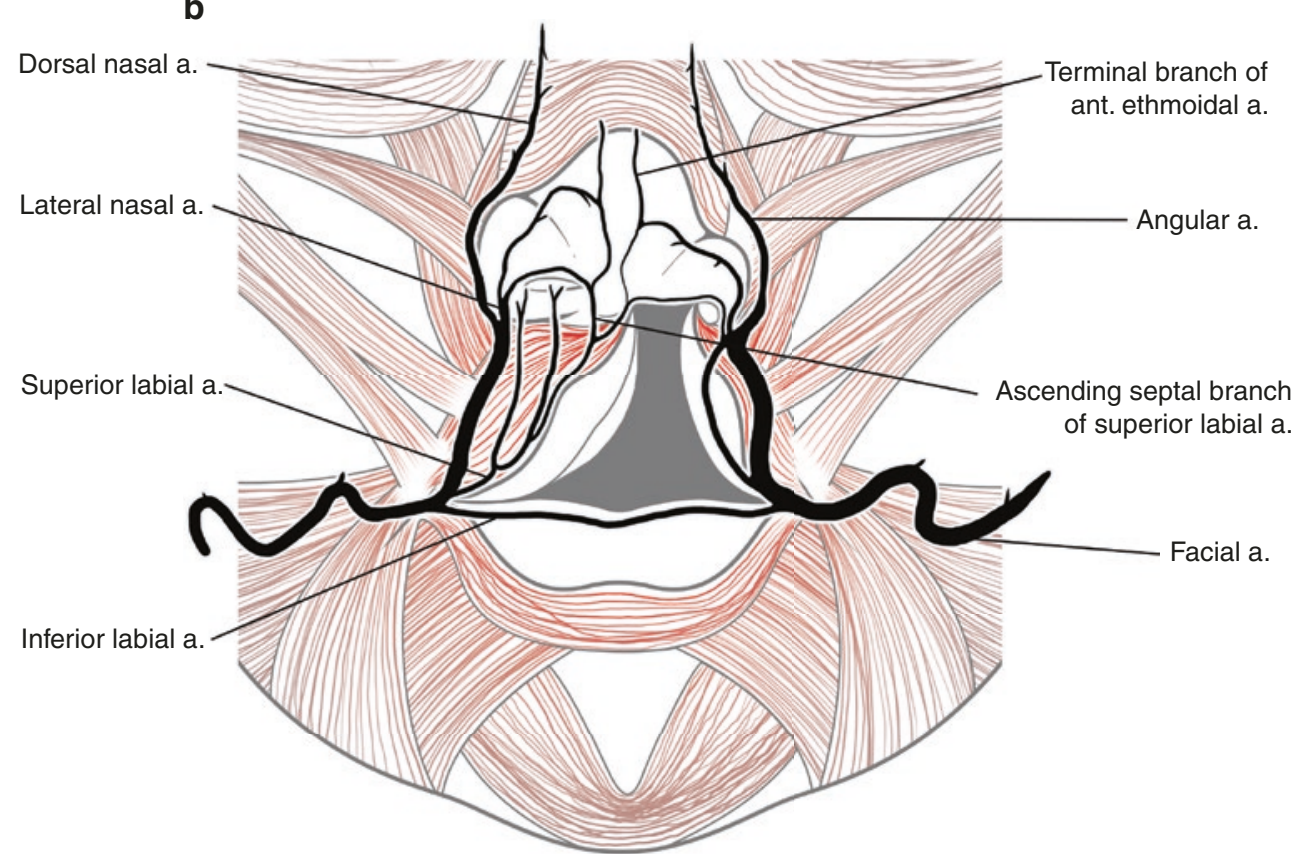

(CAssociation of Oral and Maxillofacial Surgeons of India

\subsubsection{Nerve Supply}

The sensory nerve supply to the involved areas of the lips and nose comes from branches of the fifth cranial nerve, trigeminal nerve surfacing through the infraorbital foramen as the infraorbital nerve and through the mental foramen as the mental nerve The motor nerve supply to the muscles of the lips and nose comes from the seventh or facial nerve through its zygomatic, buccal and mandibular branches.

\subsubsection{Anatomy of the Unilateral Cleft Lip}

A thorough knowledge of the normal lip anatomy can help us understand the abnormal anatomy in cleft. Displacement of muscle insertions and deformation and functional hypotrophy leading to paucity of tissues result in a distorted anatomy of labial clefts (Fig. 72.9). The following are the characteristics of the cleft lip and nose deformity (Table 72.2): 


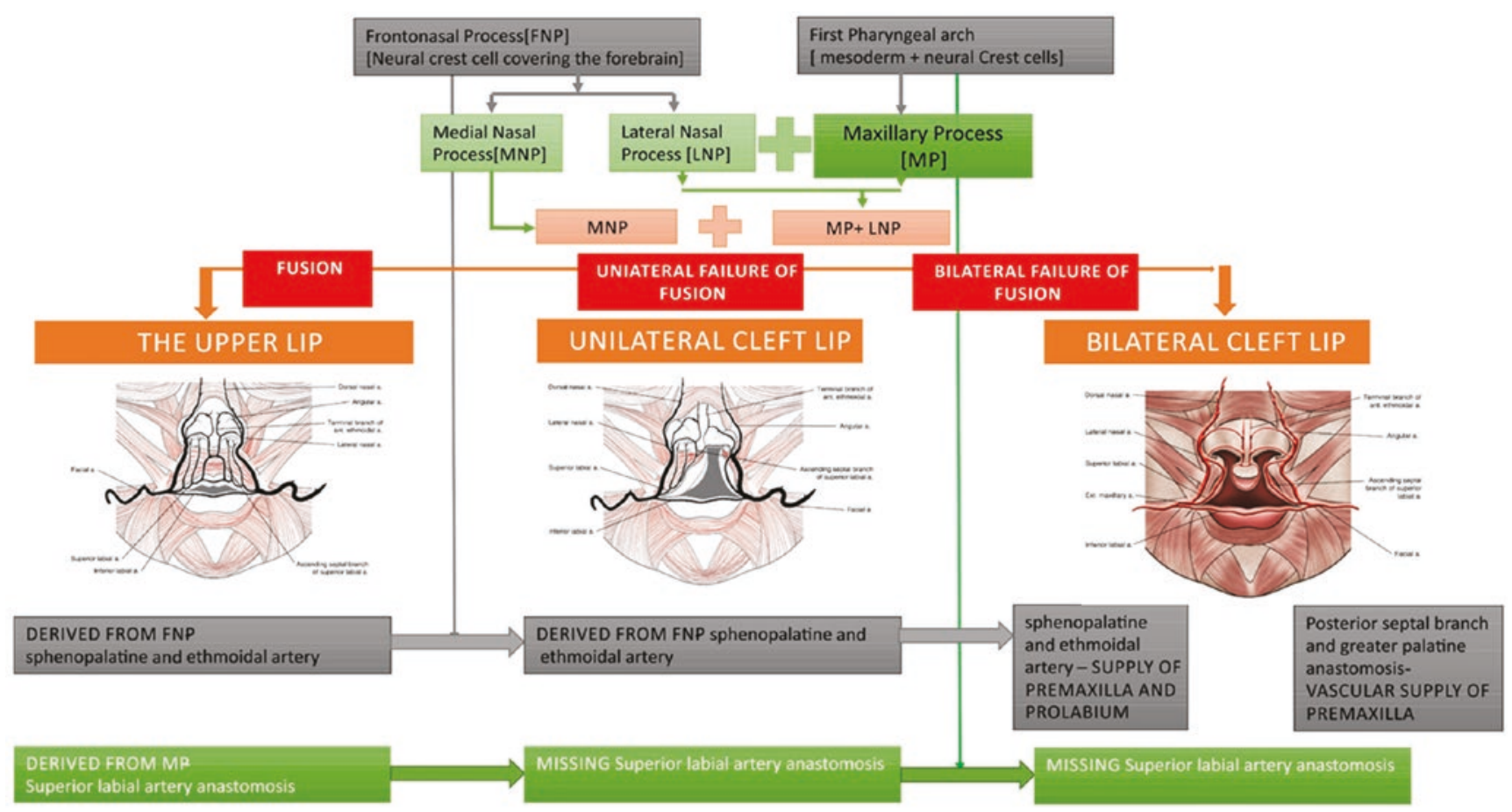

CAssociation of Oral and Maxillofacial Surgeons of India

Fig. 72.8 Embryological basis of vascular anatomy in unilateral and bilateral cleft lip

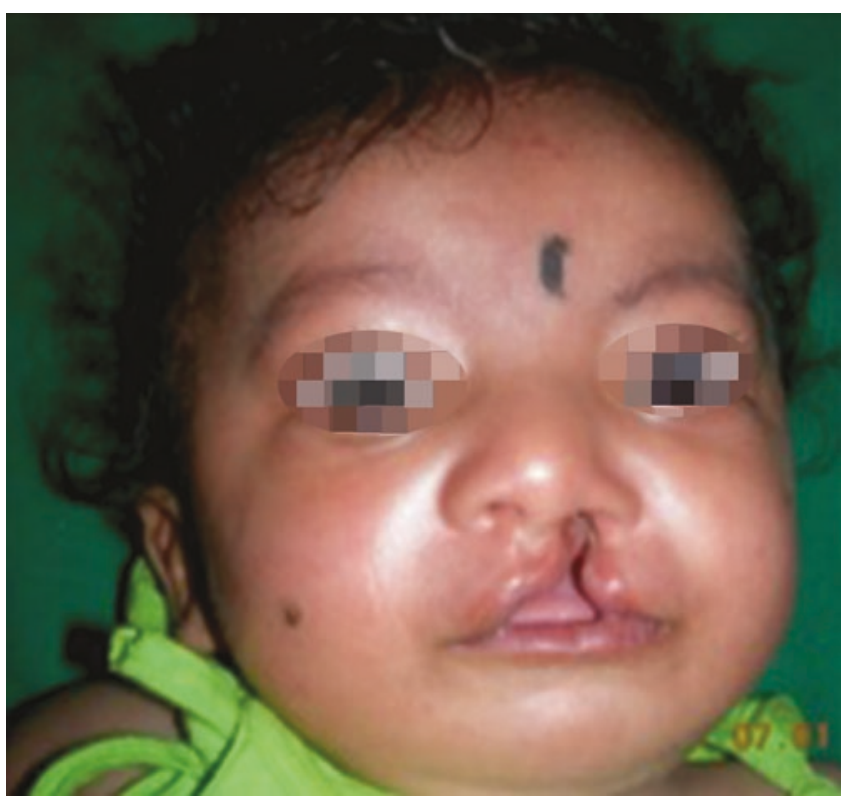

CAssociation of Oral and Maxillofacial Surgeons of India

Fig. 72.9 Presentation of a unilateral cleft lip. Note the abnormal anatomy of the lip and nose compared to the non-cleft side
Table 72.2 Comparison of normal and cleft anatomy

\begin{tabular}{|c|c|c|}
\hline $\begin{array}{l}\text { Normal } \\
\text { anatomy }\end{array}$ & Unilateral cleft anatomy & $\begin{array}{l}\text { Bilateral cleft } \\
\text { anatomy }\end{array}$ \\
\hline Labial skin & $\begin{array}{l}\text { Non-fusion of the lip, the skin } \\
\text { on both sides of the lip is less } \\
\text { projected or drawn out }\end{array}$ & $\begin{array}{l}\text { One prolabium and } \\
\text { bilateral lip elements. } \\
\text { The prolabium is the } \\
\text { central lip element } \\
\text { that has severe } \\
\text { paucity of tissues }\end{array}$ \\
\hline $\begin{array}{l}\text { Philtral } \\
\text { columns }\end{array}$ & $\begin{array}{l}\text { Philtral columns are on the } \\
\text { non-cleft side, obliquity and } \\
\text { discrepancy in their length }\end{array}$ & $\begin{array}{l}\text { No philtral columns } \\
\text { present on any } \\
\text { element }\end{array}$ \\
\hline White roll & $\begin{array}{l}\text { Lateral side, the white roll } \\
\text { gradually diminishes to about } \\
2-3 \mathrm{~mm} \text { before it disappears. } \\
\text { On the medial side, the } \\
\text { demarcation of the white roll is } \\
\text { less clear }\end{array}$ & $\begin{array}{l}\text { The white roll on the } \\
\text { prolabium is rounded } \\
\text { and indistinct }\end{array}$ \\
\hline Mucosa & $\begin{array}{l}\text { Absence of a labial glandular } \\
\text { bed, paucity of compressor } \\
\text { muscles, thinner and finer } \\
\text { mucosa }\end{array}$ & $\begin{array}{l}\text { Absence of a labial } \\
\text { glandular bed, paucity } \\
\text { of compressor } \\
\text { muscles, thinner and } \\
\text { finer mucosa }\end{array}$ \\
\hline $\begin{array}{l}\text { Orbicularis } \\
\text { oris }\end{array}$ & $\begin{array}{l}\text { No muscle decussating in the } \\
\text { midline. Abnormal attachment } \\
\text { at alar base }\end{array}$ & $\begin{array}{l}\text { Muscle runs } \\
\text { bilaterally up into the } \\
\text { alar bases, no muscle } \\
\text { on the median lip } \\
\text { element }\end{array}$ \\
\hline
\end{tabular}


1. Labial skin: Apart from the non-fusion of the lip, the skin on both sides of the lip is less projected or drawn out. This leads to a hypoplastic or decreased cutaneous length of the skin. However, the skin is thicker than in normal individuals. The lip consists of the skin, orbicularis oris muscle, minor salivary glands and the labial mucosa. These anatomical planes are important to identify while dissecting the muscle layer. Only 1-2 $\mathrm{mm}$ of subdermal dissection should be done, whereas on the mucosal side, the plane of dissection is between the muscle on one side and minor salivary glands and mucosa as a single layer.

2. Unequal philtral columns: The philtral columns are on the non-cleft side, with an obliquity due to discrepancy in their length leaning towards the contralateral sides.

Matching of the philtral columns of both sides is central to a successful lip repair. The philtral columns are the paired elevated soft tissue structures of the face which make an important aesthetic subunit. Various surgical manoeuvres have been used to achieve symmetry of the philtral columns. The surgical design of rotationadvancement technique is also based on making the philtral columns of the same height.

3. White roll abnormality: From the lateral side, the white roll gradually diminishes to about $2-3 \mathrm{~mm}$ before it disappears. On the medial side, the demarcation of the white roll is less clear. Identifying the white roll is pivotal in making incision markings during surgery. A practical tip is to identify maximum width of the dark/dry mucosa; it is generally the most pertinent area to mark the point where the white roll starts diminishing. This is discussed again in the surgical technique.

4. Mucosa: In cleft lip, due to absence of a labial glandular bed and the paucity of compressor muscles, the mucosa of the cleft side is thinner and finer. Also, the mucosa merges with the skin closer to the nose and rolls inward. This mucosa of the cleft region is considered redundant and excised frequently. However, in author's clinical judgement, this tissue can be converted into a flap to close the nasal floor, thus precluding the need for any vestibular releasing incision.

5. Nostril skin on the lip: The skin of the lateral alar part, the columella and part of nasal vestibule intrudes onto the lip in the upper part. Distinction can be made between nostril skin and labial skin as the former is finely stippled while the latter is finely striated and has hair.

\subsubsection{Nose}

1. Platform: The base, i.e. the premaxilla, is projected and rotated outwards, whereas the lateral maxillary segment is retropositioned. Consequently, there is nasal asymmetry at the base.
2. Septum: Lower border of the septum is dislocated out from the vomerine grove, thus twisting the nasal tip and columella.

3. Columella: Unilateral shortness in vertical dimension is seen with deflection towards the non-cleft side.

4. Nasal floor: Has a defect in the skin, muscle and bone.

5. Lower lateral cartilage: The cleft alar cartilage is flattened and more horizontal in its long axis and stretched at an obtuse angle.

6. Alar crease: Due to the absence of alar cartilage bulge, alar crease continues across the tip to produce a disjointed effect.

7. Alar base: Rotated outwardly in a flare.

8. Alar rim: There is a skin curtain of ala that is without cartilage further reducing the apparent length of the columella on the cleft side (Fig. 72.9).

\subsubsection{Anatomy of the Bilateral Cleft}

The following are the salient anatomical features of a bilateral cleft:

- Prolabium and premaxilla: The prolabium and premaxilla isolated from lateral segments (lip and maxilla). The premaxilla is not found in the alveolar arch and either protruded or deviated or rotated. This is probably because of the excessive forward growth of the premaxillaryvomerine suture and uninhibited forward growth of the cartilaginous nasal septum (Fig. 72.10).

- The prolabium is the central lip element that has paucity of tissues. The prolabium has no muscle, is non-mobile and has a limited blood supply. The white roll on the prolabium is rounded and indistinct.

- Nasal deformity depends on the premaxilla and size and position of the prolabium. The columella is very short or absent. The base of the ala is positioned laterally and posteroinferiorly. There is a wide nasal base. The deformity in LLC is presented by the elongated lateral crus and shorter medial crus. The nasal tip is flat with increased distance between alar domes. Only in cases of asymmetric bilateral clefts, the septum is deviated.

- The orbicularis oris muscle runs bilaterally up into the alar bases. There is no muscle on the median lip element (Fig. 72.4).

- In complete bilateral cleft lips, the labial artery fails to unite with its counterpart on the other side. In addition the arcade made by anastomosis of the posterior septal branch with the greater palatine artery through the incisive foramen is absent. The philtrum and premaxilla therefore derive their blood supply from the posterior septal artery and terminal branches of the ethmoidal artery. 


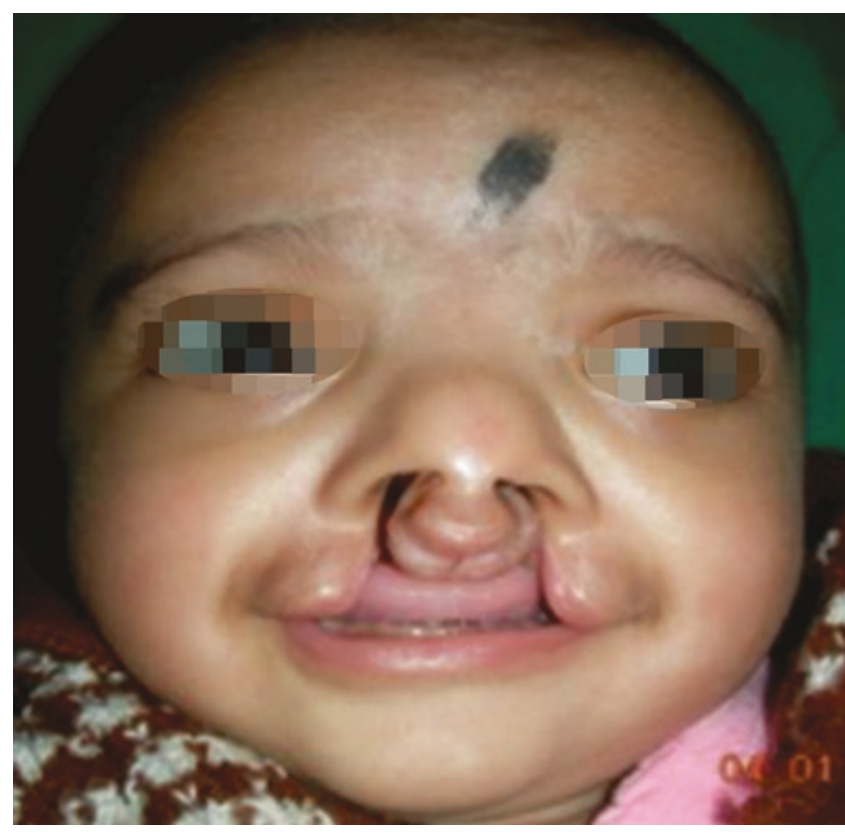

CAssociation of Oral and Maxillofacial Surgeons of India

Fig. 72.10 Presentation of a bilateral cleft lip

\subsection{Classification and Presentations of Cleft}

As we discussed in embryology, insufficient or late migration of mesoderm leads to epithelial breakdown resulting in a cleft. Thus, a cleft lip presents in various forms, and the management differs slightly for all forms of cleft. The basic classification is based on the side of presentation, i.e. left and right and complete and incomplete (Figs. 72.11 and 72.12). The incomplete cleft lip can be further classified into various types (Box 72.3).

\section{Box 72.3 Presentation of Incomplete Clefts}

Incomplete clefts can be further divided on the basis of extent of involvement of the mucosa, skin and nasal floor.

1. Incomplete cleft lip with mucosal notch not extending into the skin.

2. Incomplete cleft lip with mucosal and skin notching.

3. Incomplete cleft lip involving the mucosa and skin extending upwards but not up to the nasal floor.

4. Incomplete cleft lip with Simonart's band. Simonart's band is a bridge of tissue between the premaxilla and the lateral lip element. Its prevalence is approximately $20 \%$.

Similarly, bilateral cleft lip can be divided into complete and incomplete clefts. Complete clefts can be further divided on the basis of status of the premaxilla. The premaxilla can be severely, moderately or mildly protruded. However, this is a clinical classification and helps in deciding treatment of a bilateral cleft lip.

\subsubsection{Classification}

Throughout history, many surgeons have attempted to classify cleft lip and palate in their own ways. Classifications made have been on three bases: laterality, severity and morphology of the cleft. At the least any classification system should be able to specify the laterality, extent and severity of

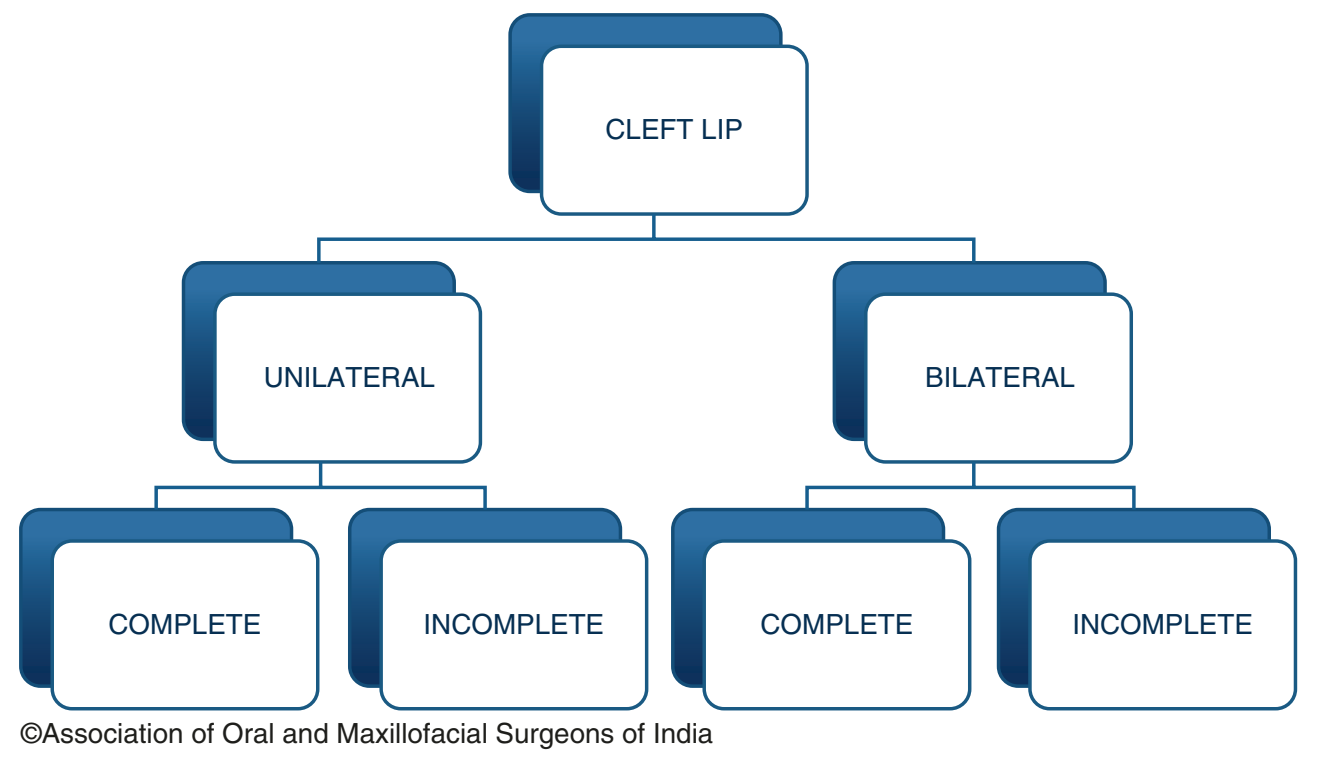

Fig. 72.11 Basic classification of cleft lip 
Fig. 72.12 Incomplete cleft lip with mucosal notch not extending into the skin. (a) Incomplete cleft lip with mucosal and skin notching. (b) Incomplete cleft lip involving the mucosa and skin extending upwards but not up to the nasal floor. (c) Incomplete cleft lip with Simonart's band
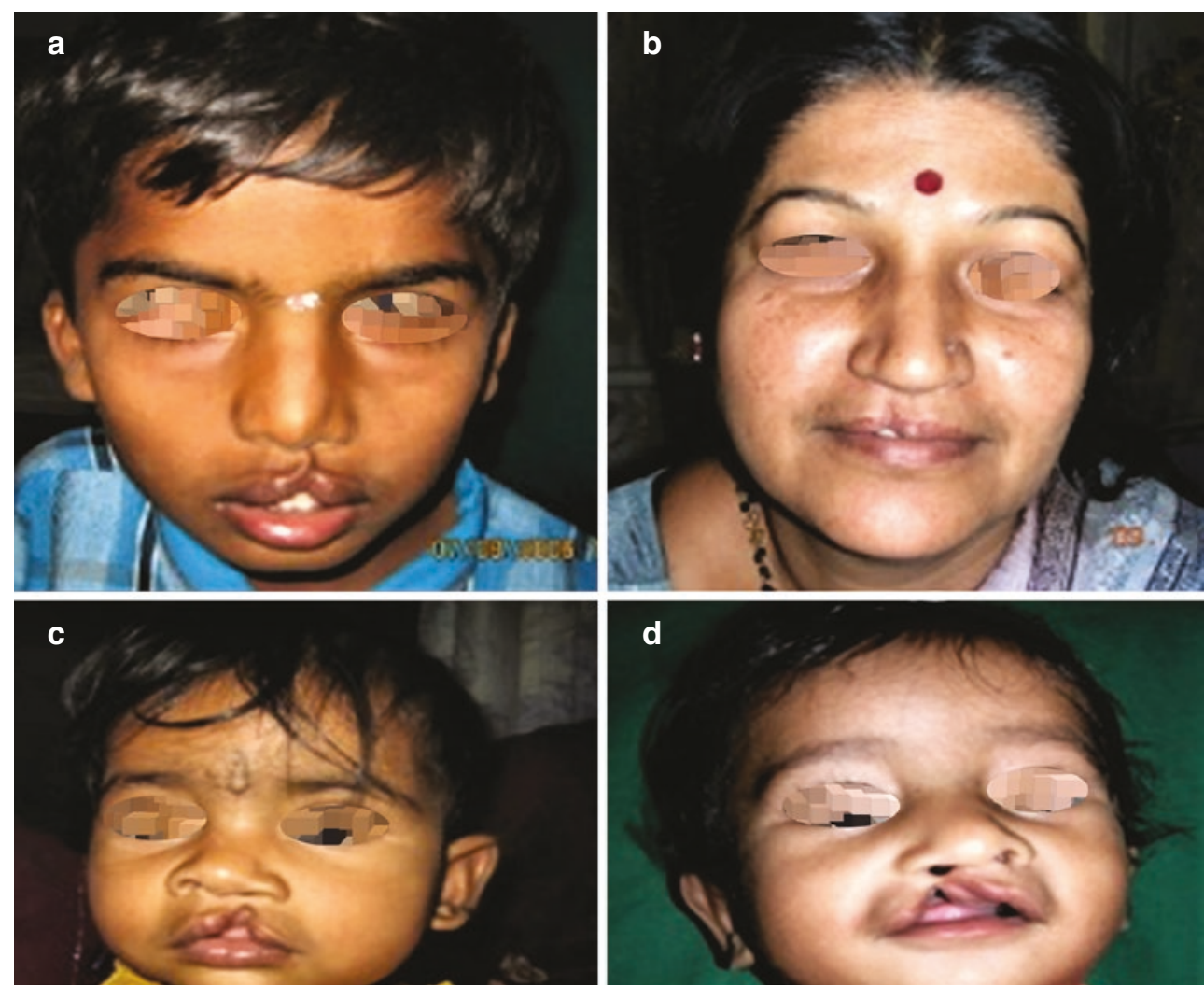

(CAssociation of Oral and Maxillofacial Surgeons of India the labial cleft and the palatal cleft necessary for treatment planning or outcome assessment (Tables 72.3 and 72.4).

Apart from the above-mentioned classifications, there are various reports of individual classifications by many international and Indian surgeons based on their experience and perspective. An ideal classification should be simple, clear and universally acceptable for purpose of communication and documentation.

\subsection{Treatment of Cleft Lip}

\subsubsection{Timing of Intervention}

Cleft lip repair constitutes the first surgical step in cleft lip and palate. Each cleft protocol team advocates different timings for lip reconstruction, with slight variations from the neonatal period to 6 months and later. Timing of intervention can be broadly categorised based on chronological age of the cleft patient or based on certain dental age milestones and status of dentition (Tables 72.5 and 72.6). There are a number of protocols adopted by various centres around the world. Proponents of traditional repair at the chronological age of 10-12 weeks argue that it poses a decreased risk of anaesthesia-related complications and provides improved aesthetic outcomes and positive psychological assurance to the parents. Surgery was traditionally delayed for several weeks based on the "rule of tens", i.e. infant weighing a min- imum of 10 pounds, having a haemoglobin level of $10 \mathrm{~g} / \mathrm{mL}$ and reaching an age of 10 weeks. This rule was based on the fact that the musculature of the lip is more evolved by this age and thus allows for proper reconstruction [23]. Another important milestone is the neck holding capacity of the baby. It is generally present at 3-4 months of age. It is prudent to wait till this milestone is achieved. This is crucial in cautious transfer of the infant as he/she is transferred to the operating room, recovery or intensive care unit and is handled by various healthcare personnel.

\subsubsection{Basic Treatment Algorithm}

We have devised a basic treatment algorithm for unilateral and bilateral cleft lip repair that we follow at our centre. Due to lack of awareness, prenatal and postnatal counselling and the social taboo, many patients in India do not report at the correct age for surgery. As a result, the treatment methods have been modified based on the age of presentation of the cleft patient to provide the optimal outcome (Figs. 72.13 and 72.14).

\subsubsection{Presurgical Nasoalveolar Moulding}

Wider, extensive clefts and bilateral clefts are associated with significant deformities of nasolabial complex, presenting a greater surgical challenge in approximating anatomic struc- 


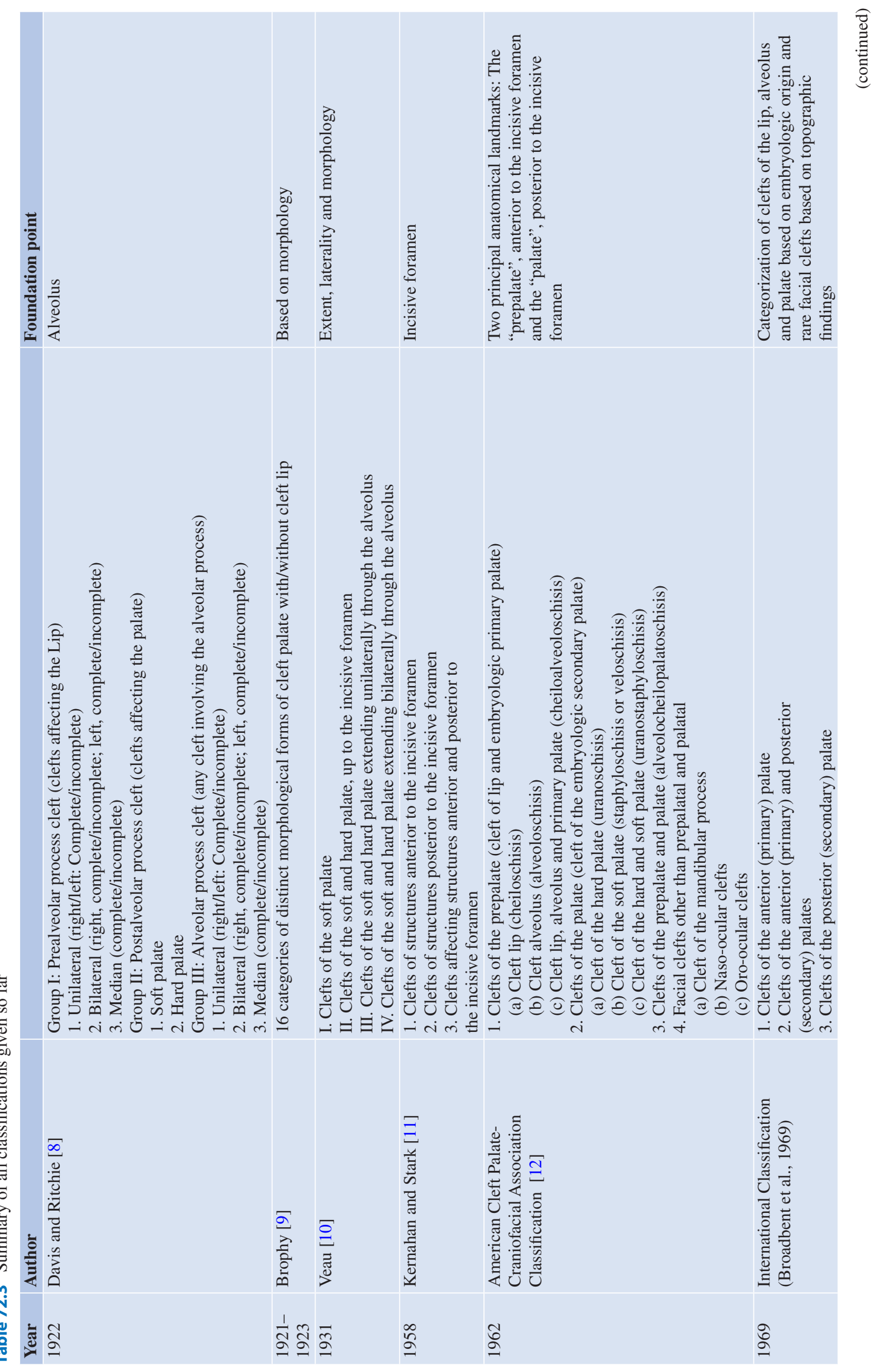



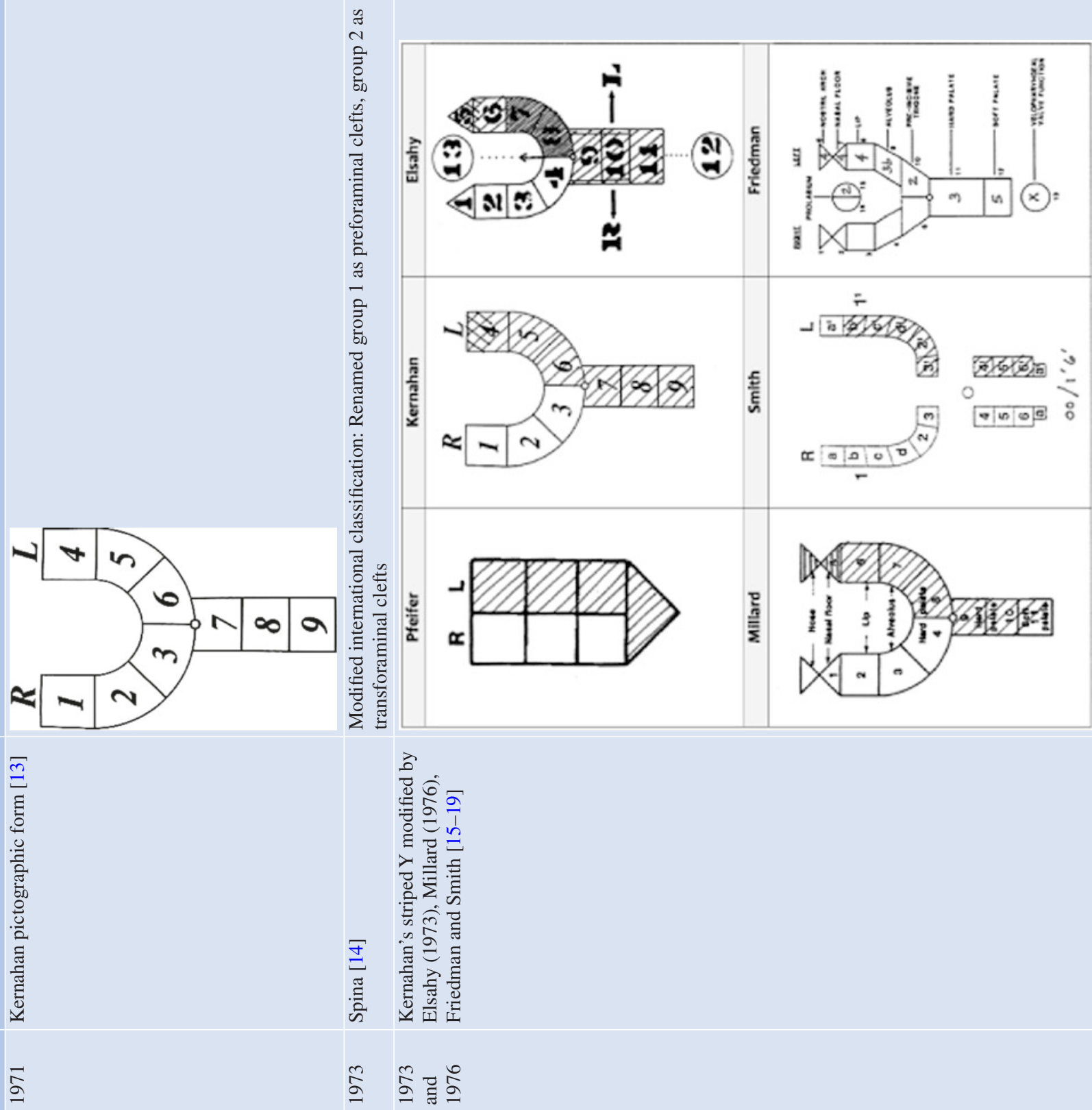


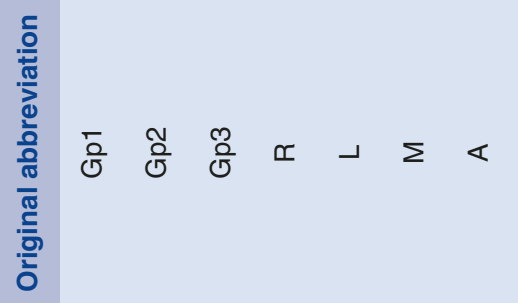

- $\infty$ के $\frac{\circ}{\frac{0}{E}}$

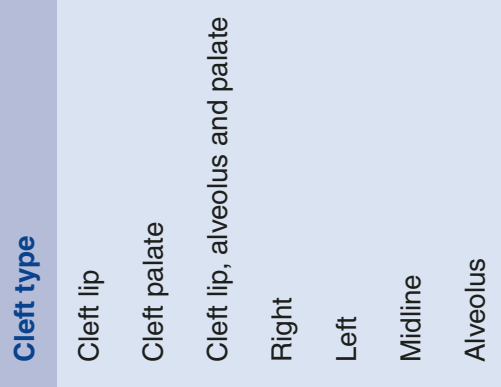

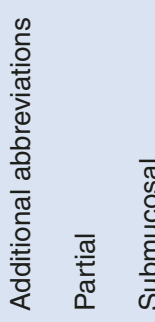<smiles>CCC</smiles>

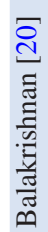
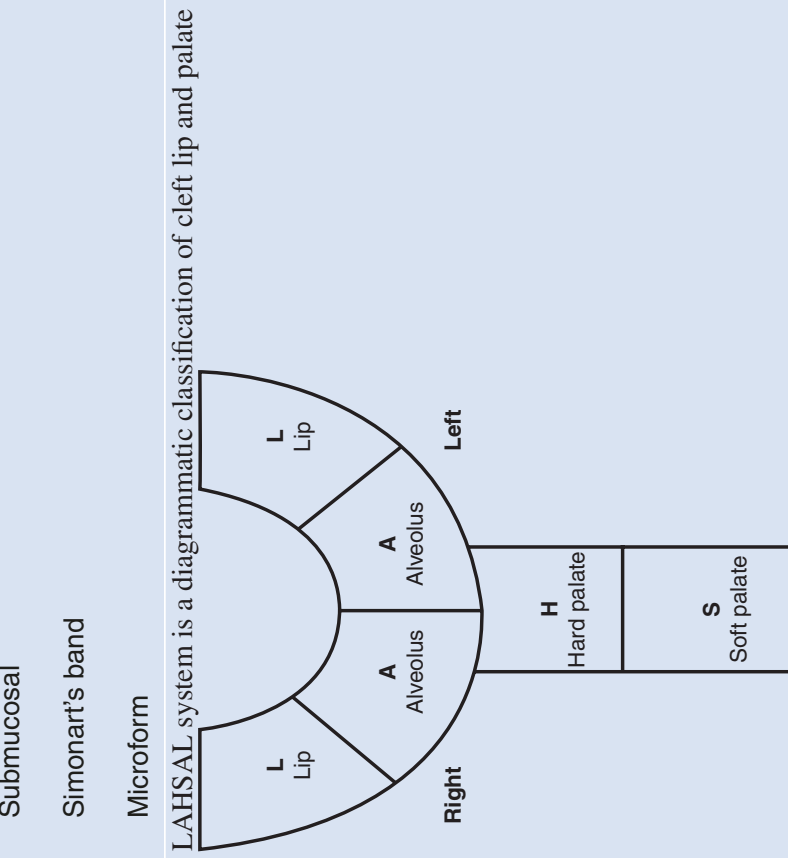

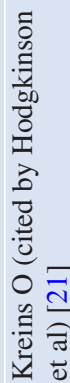

ڤุ

$\stackrel{\infty}{\mathscr{\infty}}$ 
Table 72.4 Incomplete cleft lip can be further divided into minor-form, microform and mini-microform [22]

\begin{tabular}{|c|c|c|}
\hline Minor-form & Microform & Mini-microform \\
\hline $\begin{array}{l}\text { 1. Notched vermilion-cutaneous junction } \\
\text { extending } 3 \text { mm or more above the } \\
\text { normal Cupid's bow peak } \\
\text { 2. Deficient vermilion on the medial cleft } \\
\text { side } \\
\text { 3. Cutaneous groove and muscular } \\
\text { depression that is evident on puckering } \\
\text { 4. Hypoplastic median tubercle } \\
\text { 5. Nasal deformity }\end{array}$ & $\begin{array}{l}\text { 1. Medial vermilion-cutaneous point less than } 3 \mathrm{~mm} \text { above } \\
\text { the normal Cupid's bow peak } \\
\text { 2. Deficient vermilion on the medial cleft side } \\
\text { 3. Lower cutaneous lip shows a variable glabrous strip } \\
\text { 4. Philtral line shows muscular depression, with a prominent } \\
\text { medial component of the philtral ridge } \\
\text { 5. Nearly normal length of the hemicolumella, the sill shows } \\
\text { a small depression, slight slump of the alar genu and } 1 \text { to } \\
2 \text { mm lateral displacement and outward flare of the alar } \\
\text { base }\end{array}$ & $\begin{array}{l}\text { 1. Discontinuous vermilion- } \\
\text { cutaneous junction } \\
\text { 2. Level Cupid's bow peaks } \\
\text { 3. Notched free mucosal margin } \\
\text { 4. Variable muscular depression } \\
\text { 5. Variable nasal deformity; mostly a } \\
\text { depressed sill }\end{array}$ \\
\hline
\end{tabular}

Table 72.5 Timing of intervention based on chronological age

\begin{tabular}{|c|c|}
\hline Timing & Procedure \\
\hline $\begin{array}{l}\text { After } 16 \text { weeks of } \\
\text { pregnancy }\end{array}$ & Cleft lip diagnosis by USG images \\
\hline Prenatal & $\begin{array}{l}\text { Discussion with surgeon } \\
\text { Consultation with a geneticist }\end{array}$ \\
\hline Neonatal & $\begin{array}{l}\text { Presurgical orthopaedics } \\
\text { Feeding instructions }\end{array}$ \\
\hline 12 weeks of age & Cleft lip surgery \\
\hline $6-12$ months of age & $\begin{array}{l}\text { Cleft palate repair with intravelar } \\
\text { veloplasty }\end{array}$ \\
\hline 14 years or later & Orthognathic surgery \\
\hline Adulthood & Secondary rhinoplasty \\
\hline
\end{tabular}

Table 72.6 Timing of intervention based on status of dentition

\begin{tabular}{|l|l|}
\hline Timing & Procedure \\
\hline $\begin{array}{l}\text { Prior to cleft lip repair } \\
\text { Primary dentition }\end{array}$ & $\begin{array}{l}\text { Presurgical orthopaedics [NAM] } \\
\text { Orthodontic maxillary expansion }\end{array}$ \\
\hline $\begin{array}{l}\text { Orthodontic maxillary expansion and } \\
\text { perotraction }\end{array}$ \\
\hline Permanent dentition & $\begin{array}{l}\text { Secondary alveolar bone graft using } \\
\text { iliac crest particulate cancellous bone } \\
\text { marrow }\end{array}$ \\
\hline $\begin{array}{l}\text { After full eruption of } \\
\text { permanent dentition }\end{array}$ & $\begin{array}{l}\text { Orthodontic treatment for dental arch } \\
\text { alignment }\end{array}$ \\
\hline $\begin{array}{l}\text { Orthognathic surgery for } \\
\text { maxillary advancement } \\
\text { Postsurgical orthodontics }\end{array}$ & $\begin{array}{l}\text { After orthognathic alignment } \\
\text { For space closure and final settling of } \\
\text { occlusion } \\
\text { Prosthetic rehabilitation }\end{array}$ \\
\hline
\end{tabular}

tures, thus obtaining an optimum functional and aesthetic result. The basic goal of any surgical technique is to restore normal anatomy and function. Thus in such cases, where it is difficult to achieve goals of primary repair due to wide discrepancies, presurgical maxillofacial orthopaedic appliances mould the nasolabial structures through specifically directed forces, thus reducing the deformity before surgery for an easy repair.

Currently, presurgical nasal alveolar moulding (PNAM) is a widely used orthopaedic technique for presurgical cleft deformity correction [23, 24]. PNAM theory is based on the theory that increased hyaluronic acid content is present in the infant cartilage, which makes the cartilaginous structure more pliable and plastic. By the age of 3 months, the cartilage becomes more rigid with less plasticity. PNAM can significantly improve the nasal symmetry, by elongating the columella, bolstering the alae, narrowing the cleft and restoring the alveolar arch form, thus demonstrating favourable immediate and long-term outcomes.

PNAM is based on the principles of negative sculpting and passive moulding of the alveolus, lip and nasal tissues. An initial impression is obtained, and custom-made plates are fabricated. A series of modifications are made to the surface of the appliances with the addition and deletion of materials in certain areas. This process is called negative sculpting [25]. The purpose of this is achieving approximation and symmetry of the two maxillary alveolar segments and addressing the nasal deformity by moulding the cartilage in anatomical position [26, 27] (Fig. 72.15). The process should be explained to the parents; insertion of the appliance should be carefully taught and made to practice. Parents should be explained the importance of this exercise through videos and photos of previous patients.

Impression Making A heavy-bodied polyvinyl siloxane impression material should be used for the first impression. The infant is held in prone position to keep the tongue forward and to allow any material or saliva to drain out of the oral cavity and prevent aspiration. This should be done in a hospital setting to manage any airway emergency in the presence of an anaesthetist available if needed. Once impression is made, the mouth should be examined for any residual material.

Device Fabrication The moulding plate is made with clear methyl methacrylate lined with a soft denture material on the dental stone model. The borders should be trimmed and smoothened to prevent any ulceration. The oral surface should be smooth and polished with good retention and no extensions into the cleft area.

Insertion and Moulding The moulding plate is to be worn full-time by the patient. It should be removed for cleaning and routine hygiene practices to prevent infection and check for any ulceration. Suckling should be checked with the plate in position and to check gagging. The plate is secured to the 
Fig. 72.13 Basic treatment algorithm for unilateral cleft lip

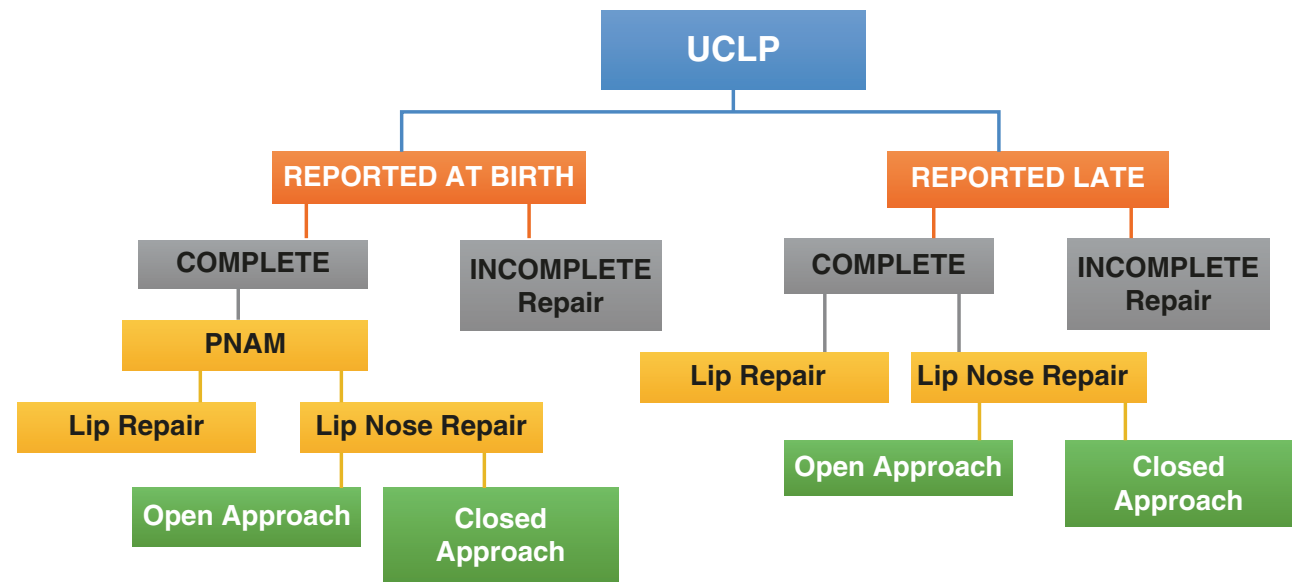

Note: Authors suggest use of nasal conformers

(C)Association of Oral and Maxillofacial Surgeons of India
Fig. 72.14 Basic treatment algorithm for bilateral cleft lip

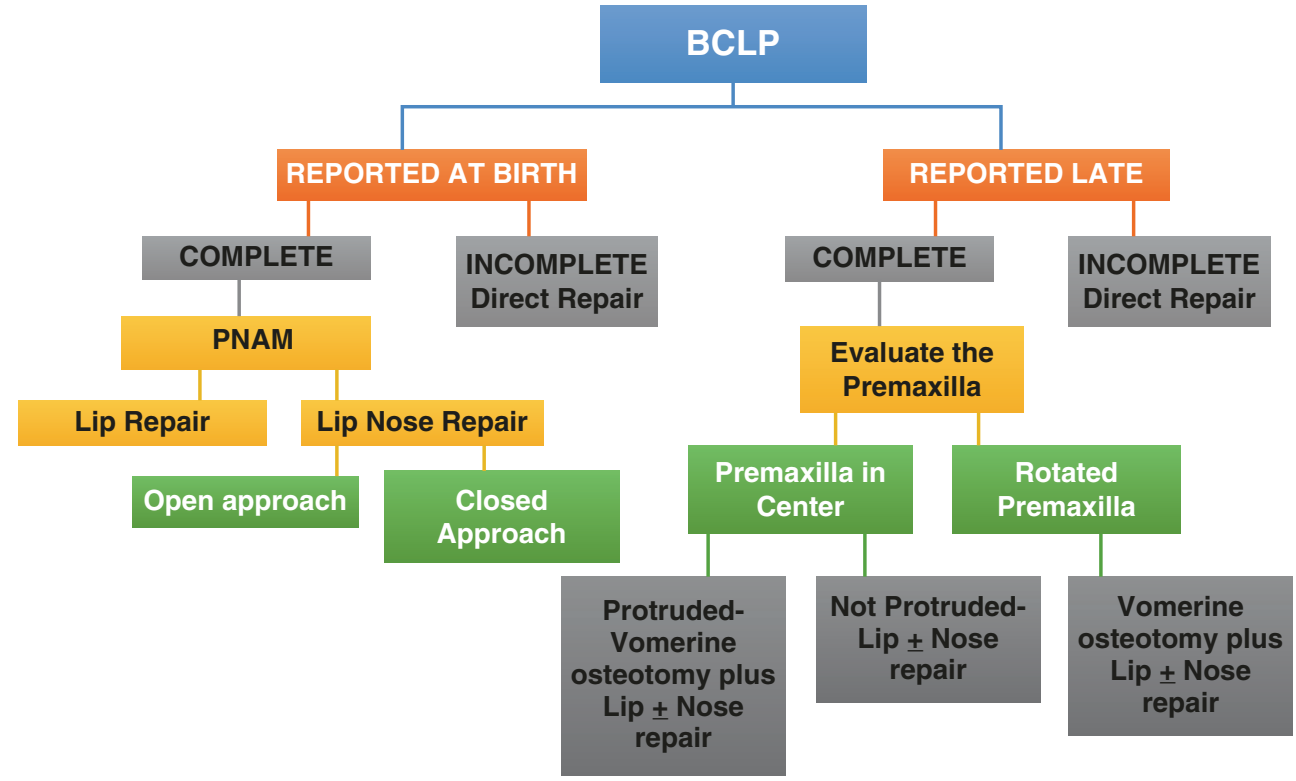

(CAssociation of Oral and Maxillofacial Surgeons of India cheek bilaterally using orthodontic elastics going to the opposite side and secured with surgical tapes. The elastic loop extends from the retention arm approximately in a 40-45 degree angle, thus pulling the anterior flange of the plate posterosuperior vector for activation. 2 ounces of traction force is given by stretching the elastic to twice its original. The surgical tape is applied to a layer of wound dressing material like micropore tape and not the skin directly. The tape is to be changed once a day. The tape should be applied to the noncleft side first and then pulled over to the cleft side. Weekly follow-ups should be made to evaluate the moulding plate for retention and changes in the alveolar segments.

Moulding Plate Modification Selective grinding of acrylic material is done from the region into which the alveolar segments are to move. At the same time, soft denture lining material is selectively added to the plate to direct the alveolar segments to the midline, as desired. In a patient with bilateral cleft, the premaxilla is retracted and derotated, to bring to a normal maxillary arch alignment. An ideal surgical result may be obtained when 1-2 mm gap remains between alveolar segments.

Nasal Stent When the maxillary alveolar segment approximation has been achieved, the nasal moulding should begin. The nasal stent is added to the existing moulding plate in the form of a stainless steel wire projecting out of the plate outwards going into the nose like a "swan neck". A small wire loop can be made on which a bilobed intranasal acrylic component is made with a layer of soft denture liner. Nasal stent is placed $3-4 \mathrm{~mm}$ inside the ala and gently lifted towards dome until slight blanching is noted. 
Fig. 72.15 PNAM treatment in a case of bilateral lip. (a and b) Pre- and postoperative PNAM. Note the changes in the nasal tip, alar cartilages and position of the premaxilla. (c and d) PNAM device with the nasal stent and lip taping
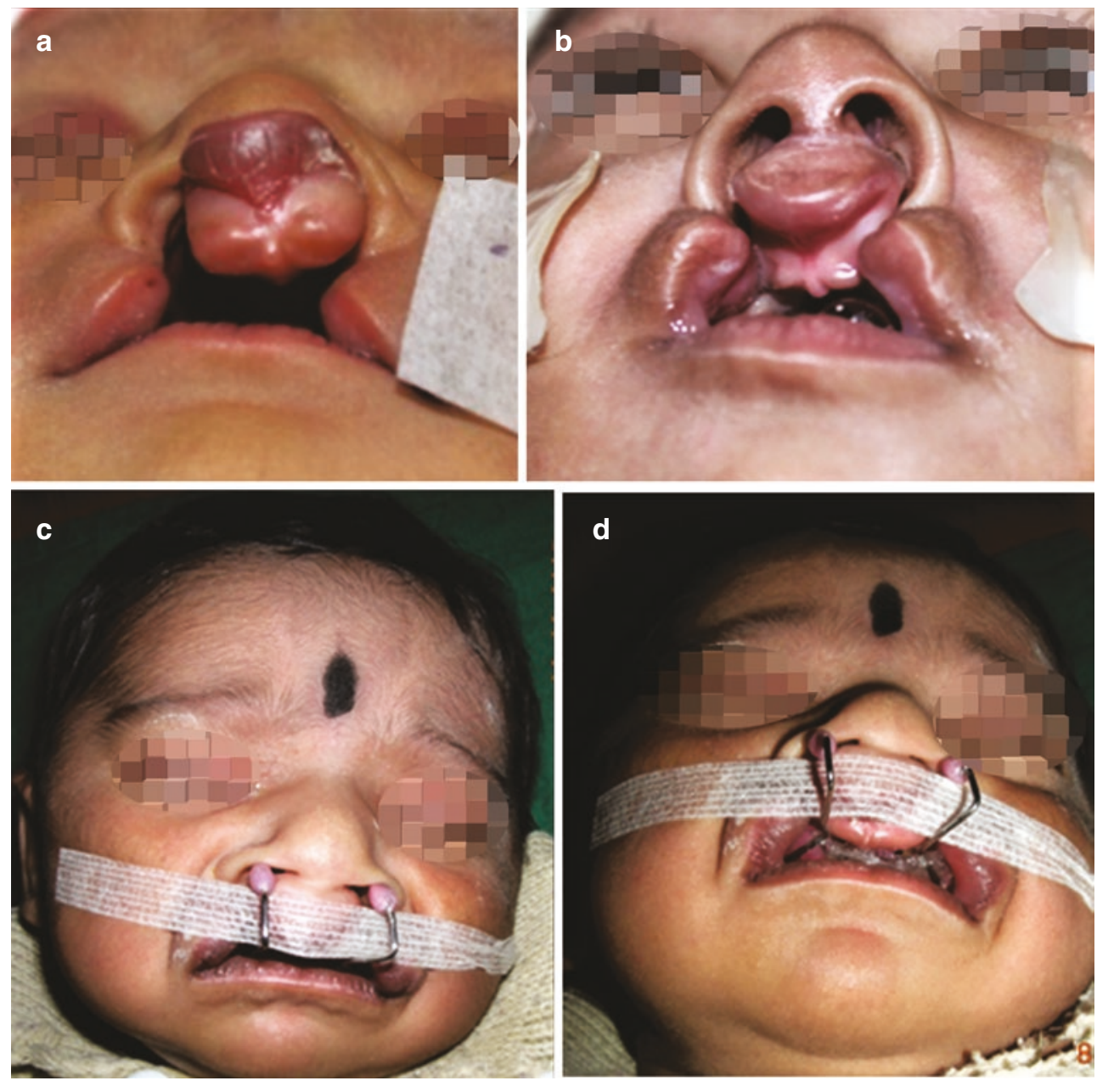

(C)Association of Oral and Maxillofacial Surgeons of India
Blanching of the nasal tip as the baby suckles activates the appliance. Lip taping is continued after the nasal stent appliance is added.

In a follow-up study over 6-9 years, Bennum et al. observed that patients treated with PNAM within 15 days after birth maintained satisfactory nasal symmetry [28]. Ezzat et al. compared 12 unilateral cleft lip and palate patients with PNAM treatment and found narrowing of the alveolar cleft, increased posterior width of the dental arch, uprighting of the columella and improved nasal symmetry [29]. Yang et al. reported similar results from 45 unilateral complete cleft lip and palate patients [30]. In a large multicentre study sample, Ross argued that orthopaedic correction of the premaxilla failed to stimulate maxillary growth and thus was not necessary [31].

The authors conducted a study to evaluate the nasolabial aesthetics on two-dimensional photographs at 6 months post cheiloplasty. Cupid's bow, vermilion symmetry, vermilion notching, premaxillary show at rest, scar aesthetics, columella height and bialar width were all significantly better in the PNAM group [32].

\subsubsection{Protocols}

There is no universal protocol for management of cleft lip, and there is a striking diversity of clinical practice. There is a paucity of higher-level evidence (i.e. systematic reviews and randomized controlled trials) on cleft lip and palate. There have been few RCTs comparing individual treatment steps. The Eurocleft study showed that among the 201 European centres, 194 different treatment protocols existed for unilateral clefts [33]. Listed below are some standard protocols followed worldwide.

- Rule of tens.

- IOWA Protocol [34].

- Dallas Protocol [35].

- Warsaw Protocol [36].

- Oslo Protocol [37].

- Malek Protocol [38].

- American Cleft Protocol [39].

- Australian Cleft Craniofacial Society Protocol [40].

- European Studies and results [41, 42]. 
Discussion of each protocol is beyond the scope of this chapter. However, we have tried to compare and discuss in detail few protocols for a comprehensive understanding of cleft lip and palate repair

The basic protocols of cleft lip repair can also be classified as follows:

1. Primary cleft lip repair.

2. Primary cleft lip and anterior palate repair.

3. Primary cleft lip and soft palate repair.

4. Primary cleft lip and palate repair.

Primary Cleft Lip Repair Only: This protocol of early lip repair at 3-4 months of age following the rule of tens is followed popularly at various centres. The author's centre also follows the same protocol. The timing of intervention has been discussed previously in the chapter.

Primary lip and anterior palate repair: was proposed by Abyholm in Oslo protocol [37]. In the first operation, cleft

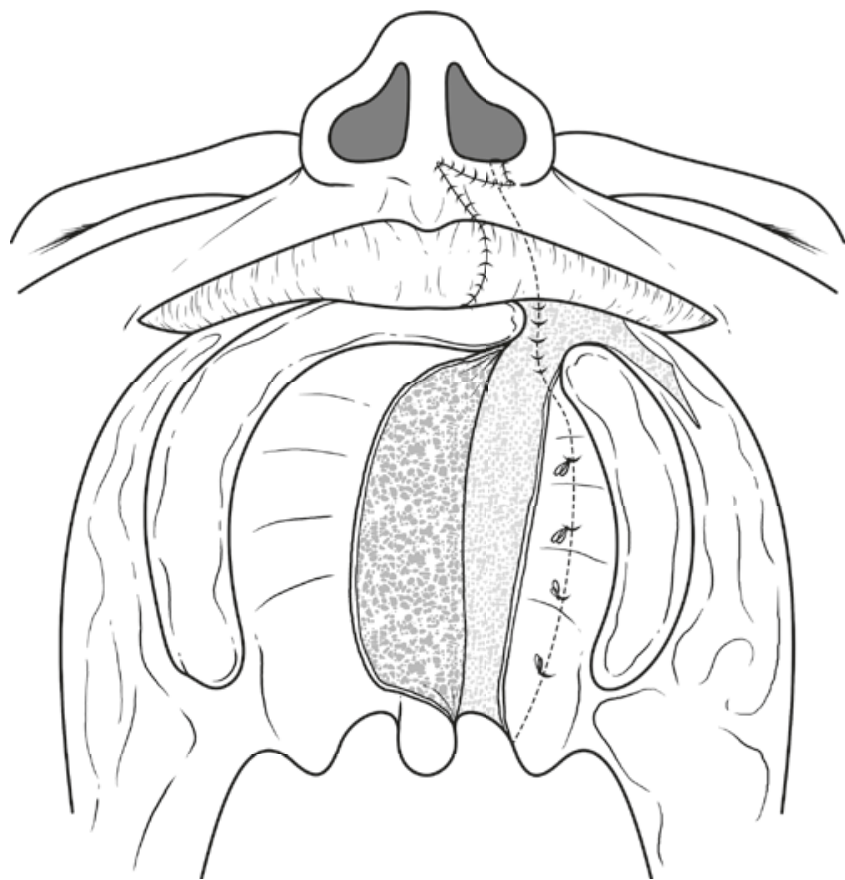

(CAssociation of Oral and Maxillofacial Surgeons of India

Fig.72.16 Cleft lip and anterior palate repair: Veau's vomer flap (Veau. 1931). An incision was made on the medial side of the cleft along the border line between oral and nasal mucosae or in bilateral clefts, along the free edge of the vomer. A mucoperiosteal flap is raised from the vomer and turned across the cleft. The lateral edge of the cleft is incised, and the palatal mucoperiosteum is elevated, allowing the vomer flap to be put under the mucoperiosteum and fixed with mattress sutures. In the alveolar area, and in continuity with the vomer flap plasty, the nasal mucoperiosteum is mobilised on both sides and joined across the cleft to complete the nasal floor anterior to the vomer flap. Towards the oral cavity, the raw surfaces of the vomer and of the flap are left uncovered lip repair using Millard technique with simultaneous anterior hard palate closure using a single layer vomer flap. The mean age for first surgery was 3.3 months. The soft palate was closed at a mean age of 17.2 months (Fig. 72.16).

Primary lip and soft palate repair: It is a well-established early palatal closure which causes maxillary hypoplasia. Because of this reason, many surgeons used to perform palate repair in two stages, i.e. soft palate first followed by hard palate. At the time of introduction of this protocol, the soft palate was repaired along with the lip at around 4-6 months of age, and the hard palate was repaired at the age of $10-12$ years. This was later reduced to $4-5$ years.

Complete Lip and Palate Repair: one-stage simultaneous repair of the entire cleft is a simple and economic treatment of complete unilateral cleft lip and palate [43]. The concept of one-stage repair was first introduced in 1958, when Farina (1958) described the surgical technique. A decreased risk associated with general anaesthesia, better healing, lower incidence of fistulae and reduced hospitalization costs has been the rationale for performing such repair. This repair performed in children above 10 months of age has been claimed by surgeons with extremely good results without any complications. Overall, the cleft teams from Brussels, Belgium; Konya and Zonguldak, Turkey; and Warsaw, Poland, found that their protocols employing one-stage closure of UCLP produced favourable morphological results [36, 37, 44, 45].

\subsection{Unilateral Cleft Lip Repair}

\subsubsection{Techniques of Cleft Lip Repair}

The evolution of cleft repair was bound to happen mainly due to the nature of the aesthetics that had to consider the anatomical parameters, namely:

(a) Cupid's bow.

(b) White roll continuity.

(c) Vermillion continuity.

(d) Muscle continuity.

(e) Philtral columns and equality of length on both cleft and non-cleft sides.

(f) Minimizing scarring on the anatomical unit of the lip, i.e. philtral column, philtral dimple and nasal base.

Broadly over the period of cleft history, lip repair can be divided into three basic types depending on the design of flap used (Fig. 72.17). These are straight line repairs (Box 72.4), geometric flap repairs (Box 72.5) and rotation-advancement flap. 


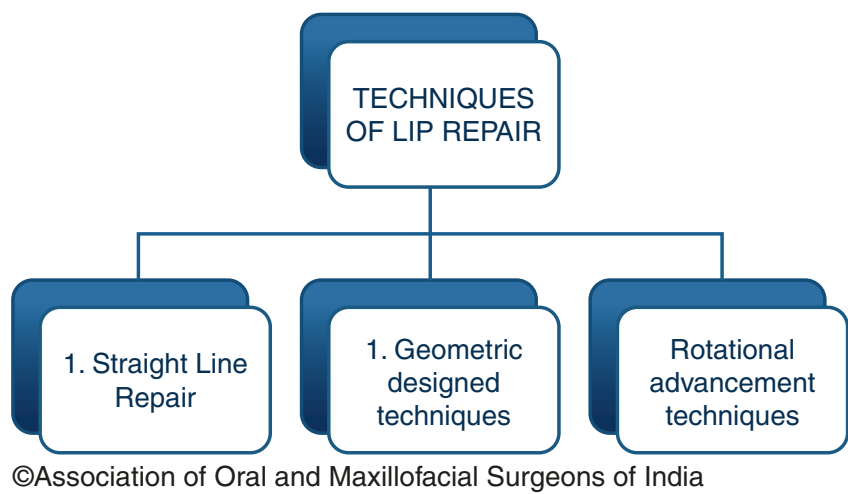

Fig. 72.17 Basic techniques of lip repair

Box 72.4 Straight Line Repairs

- Rose [1981] [46].

- Thompson [1912] [47].

- Veau [1925] [48].

- Pfeifer [1970].

- Delaire [1975] [49].

- Chaid [2007] [50].

- Nakajima [2008] [51].

Box 72.5 Geometric Flap Repairs

- Joseph Malgaigne [1843] [52].

- G Mirault [1844] [52-54].

- Triangular flap.

- Le Mesurier [1849] [55, 56].

- Tennison [1952] and Randall [1959] [57, 58].

- Skoog [1969] [59].

\section{Millard's Rotation-Advancement Flap.}

Ralph Millard (1957) [2] revolutionized the cleft repair technique with most of its principles applicable and widely used in current day practice. His innovation was in designing the incisions without disrupting the aesthetic subunits. The cut as you go technique was simplified further by understanding the anatomy of the lip. He realized that two thirds of the Cupid's bow, complete with tubercle, white roll of the mucocutaneous junction, one column and the dimple of the philtrum, were all present in the non-cleft side but askew and thus had to be rotated down to normal position [60].

\subsubsection{Basic Components of Millard's Repair} (Video 72.1)

\section{Labelling of the Flaps}

A-Non-cleft side (with Cupid's bow and dimple-rotation). In Millard's original description, the incision for the rotation flap begins at the peak of the Cupid's bow [cleft side], marked along the cleft edge up to the junction with the columella, and curves under the base, crossing the midline, but doesn't cross the contralateral philtral column. Millard later added a back cut at the end of the incision, to allow for adequate rotation of the medial lip element and less tension on the repair [61, 62].

B-Cleft side (advancement).

The incision on the lateral lip element of cleft forms the advancement flap. It is made along the cleft edge, extending up to the nasal floor. This incision should match the length of the incision on the medial side of the cleft.

C-A small triangular flap attached to the columella from the non-cleft side left after the incision.

\subsubsection{Points Marked: The Following Points are Marked in a Classic Millard's Technique (Fig. 72.18a, b)}

1. Deepest point on the Cupid's bow.

2. Bow peak on the non-cleft side (distance usually $4 \mathrm{~mm}$ ).

3. Bow peak on the cleft side (equal to distance between point 1 and 2 from point 1 ).

4. The alar base on normal side.

5. Final extent of the incision following a rotational curve, skirting the columella-lip junction and extending past the midline of columella base almost as far as the philtrum column on the normal side but no farther.

6. Commissure of the lip on the non-cleft side.

7. Commissure of the lip on the cleft side.

8. Equidistant point from 6 to 2 marked on the mucocutaneous junction (usually $20 \mathrm{~mm}$ ), and distance between 10 and 8 is equal to 4 and 2 .

The vertical distance from the alar base on the normal side 4 to the height of the non-cleft peak of the bow 2 gives the distance that must be matched ultimately on the cleft side from its alar base 10 to its peak 8 (usually around $10 \mathrm{~mm}$ ).

9. Most medial point or leading point of the advancement flap.

10. The alar base on the cleft side.

Despite being seemingly complicated, a simple exercise of carrying out the points over an illustration of complete cleft lip shall allow the reader to completely understand the simplicity of the description (Fig. 72.19). Complete surgical technique of Millard's cleft lip repair with the author's modification is discussed later in this chapter.

Once the markings are made, the rotation and advancement flaps are designed. The basic aim is to achieve symmetry of the philtral columns. This can be achieved by the following methods in a Millard's repair: 

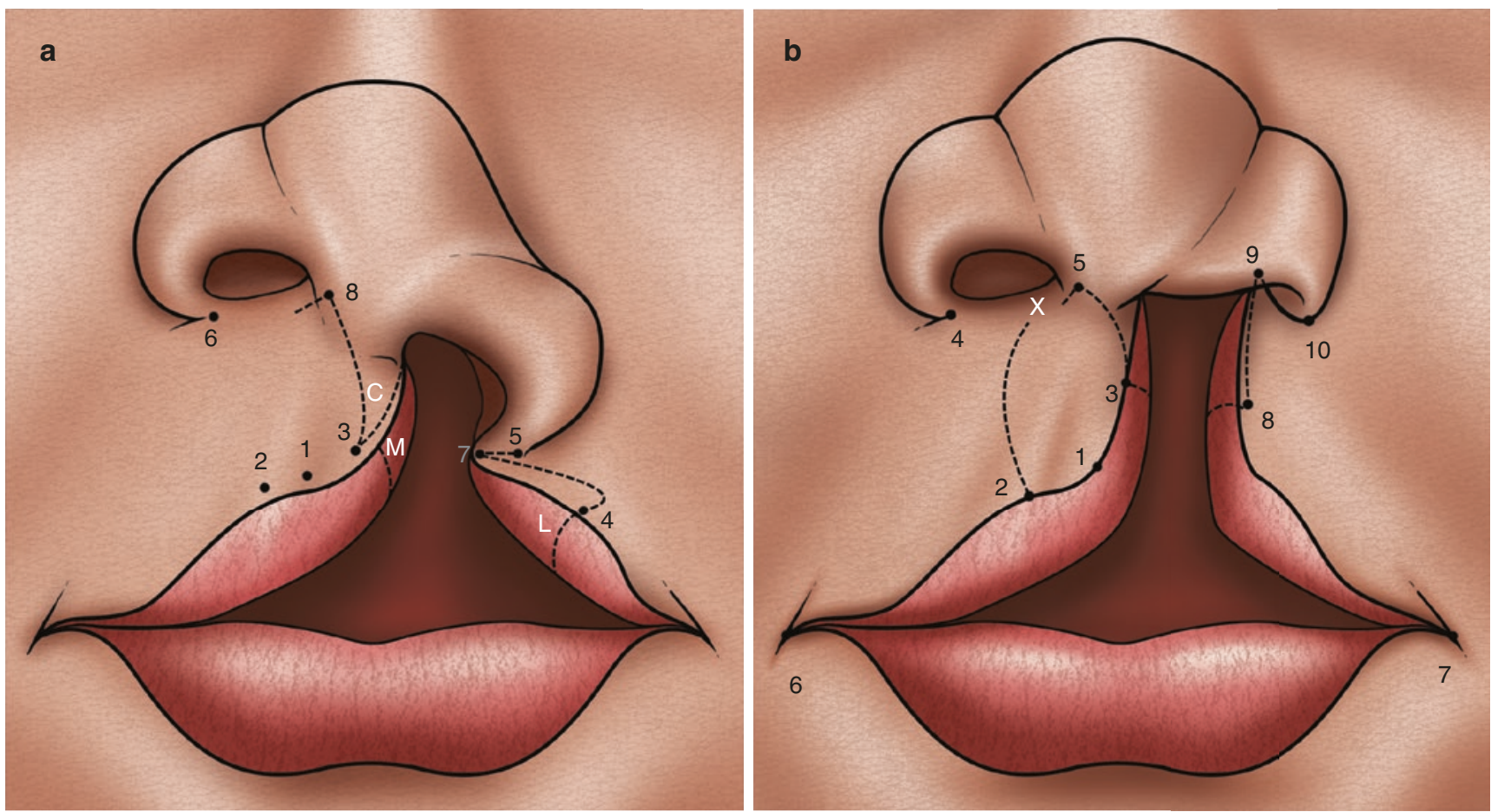

CAssociation of Oral and Maxillofacial Surgeons of India

Fig. 72.18 (a, b) Basic design of Millard's technique
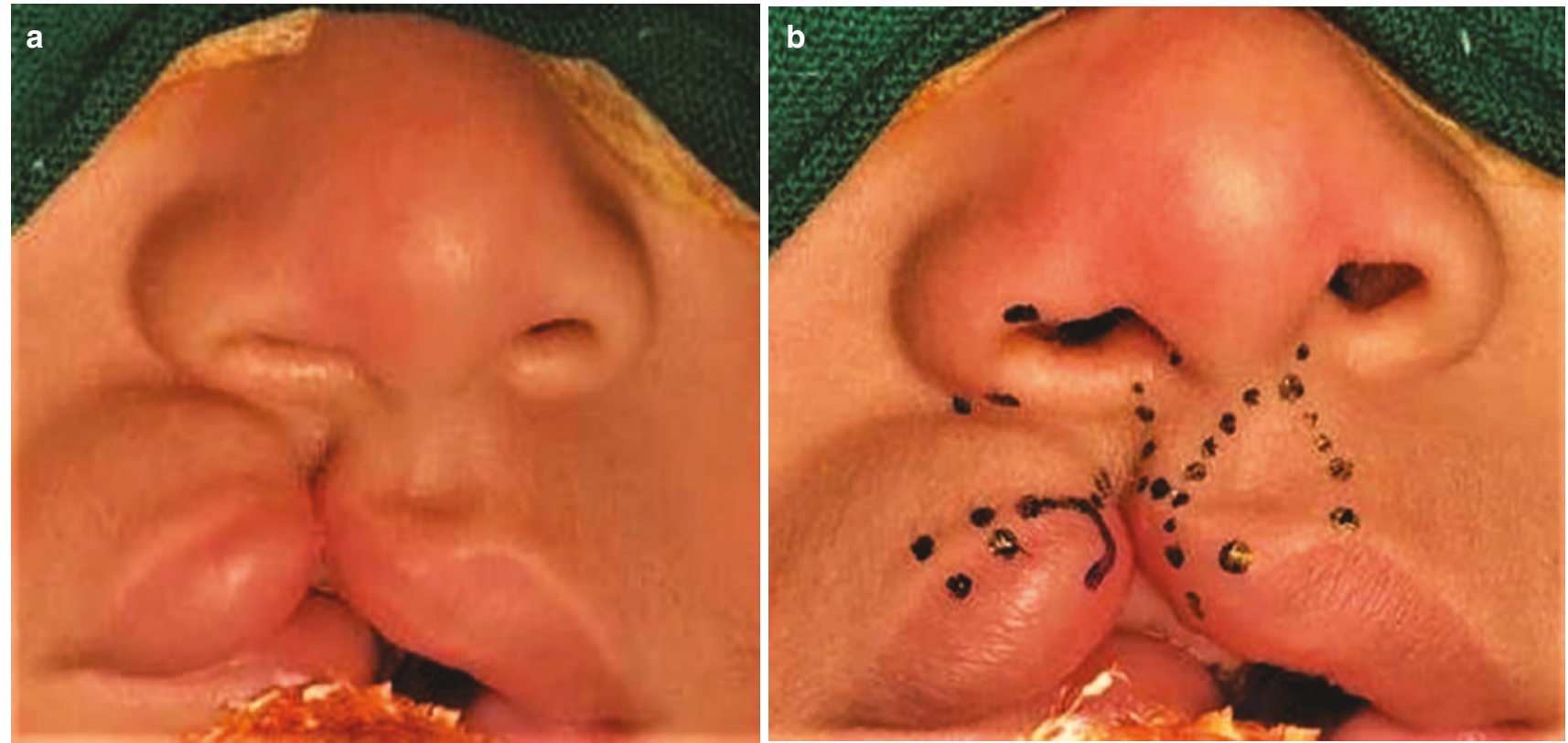

CAssociation of Oral and Maxillofacial Surgeons of India

Fig. 72.19 (a, b) Marking of incisions

1. Curve the incision on the rotation side; this helps in gaining length on the cleft side philtral column.

2. Back cut: The role of the back cut comes into force when the rotation is not adequate to provide enough length to match the normal philtral column. It can be made to cross the midline or made parallel to the normal side philtral column as in Mohler's modification.
3. Role of "C" flap: The "C" flap can be designed to accomplish either of the following goals: closure of nasal sill, columellar lengthening or back into the defect created by rotation of the flap [63]. 
a

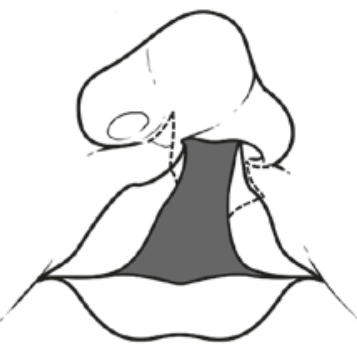

b

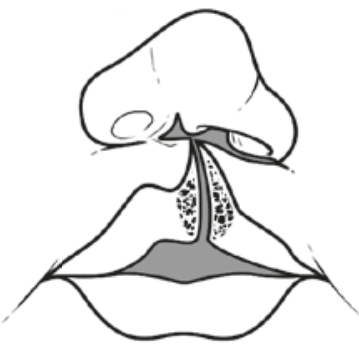

c

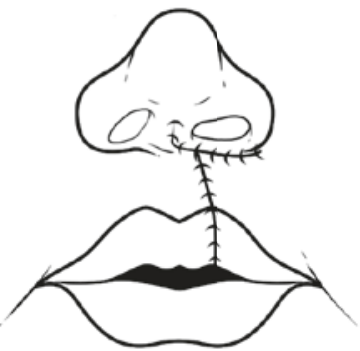

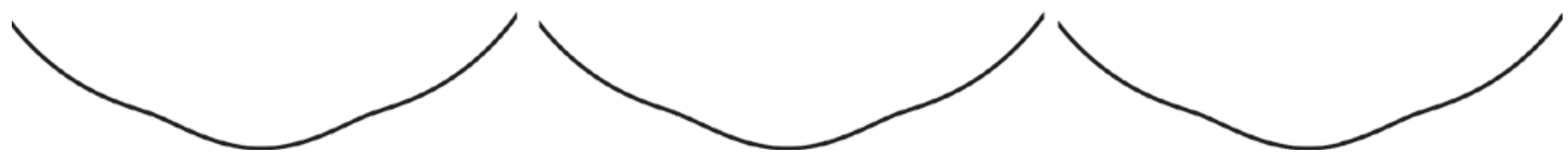

CAssociation of Oral and Maxillofacial Surgeons of India

Fig. 72.20 (a-c) Mohler's modification of Millard's technique
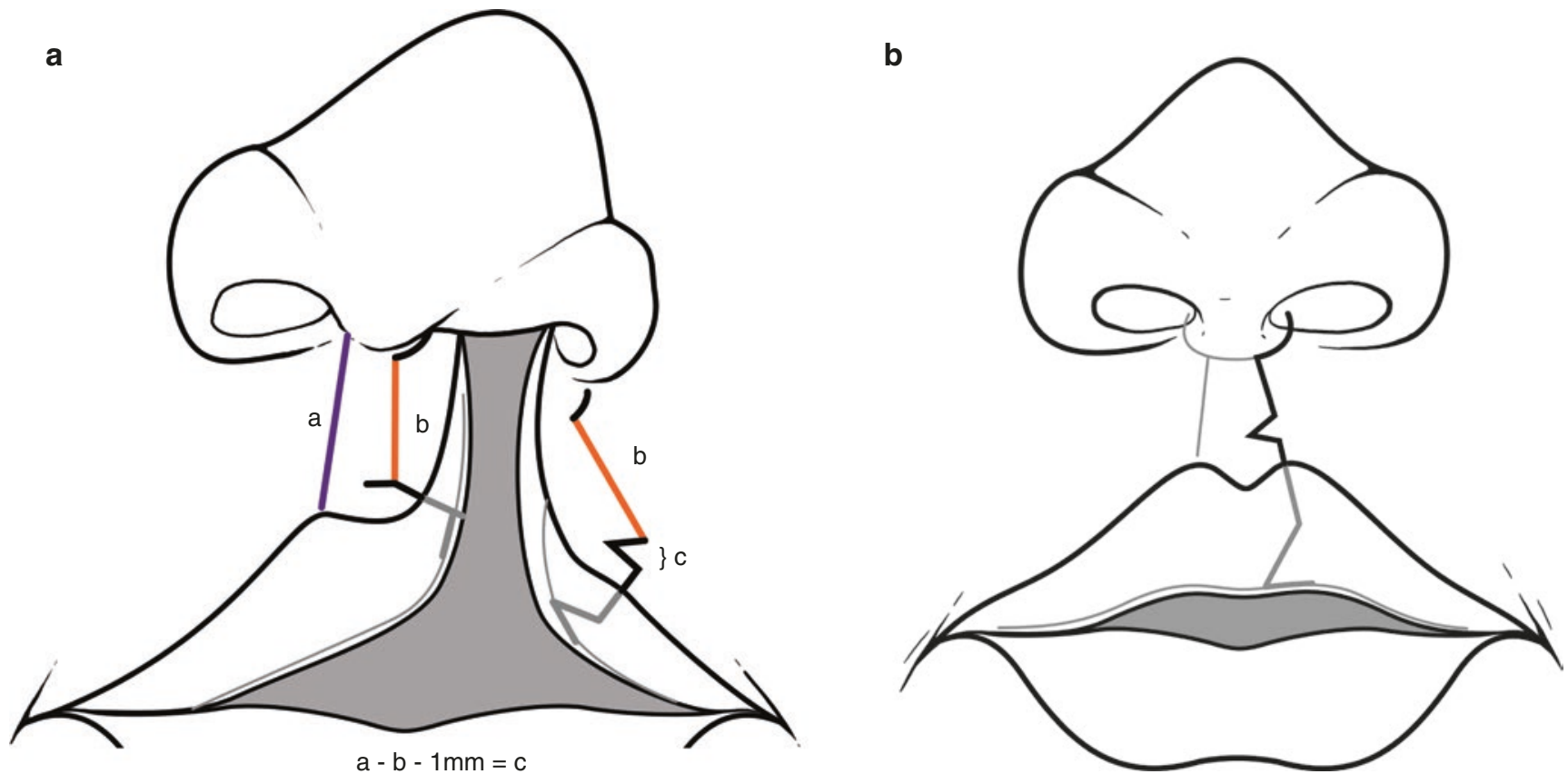

CAssociation of Oral and Maxillofacial Surgeons of India

Fig. 72.21 (a, b) Fischer's modification

\subsubsection{Modifications to Millard's Technique}

In the original Millard's technique, the advancement flap often disrupts the upper third of the cleft side philtral column. Also, in wider clefts the advancement flap results in an unaesthetic scar around the alar base. This led to a series of modifications to the conventional Millard's rotational advancement technique:

\section{External Scar Placement}

1. Mohler (1987) [64]: The medial lip rotation incision was modified to extend onto the columella. The back cut was added which was confined to the columella. The $\mathrm{C}$ flap is used to fill the defect created by rotating the medial lip element at the base of the columella. Thus it is used for lengthening the shortened columella (Fig. 72.20).

2. Fisher (2005) [65] merged techniques of the Tennison triangle repair and rotation-advancement from Millard. It uses a small triangle above the white roll at the outset and avoids the use of rotation incision allowing most scar to be placed along the ideal philtral column (Fig. 72.21a, b).

3. Vermilion Repair/Noordhoff's [66] technique:

In Noordhoff's words the essential features of this technique are as follows:

(a) No dissection over the maxillary base.

(b) No "back cuts" in rotation flap. 
a

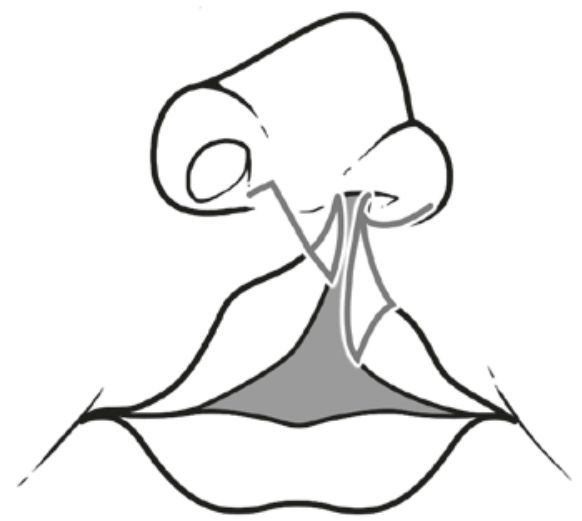

b

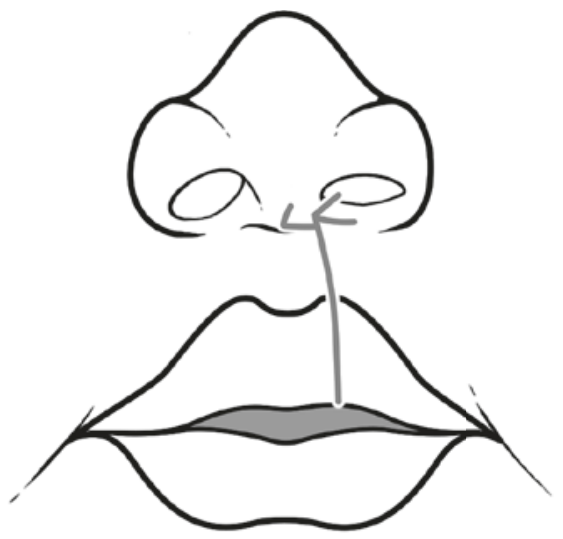

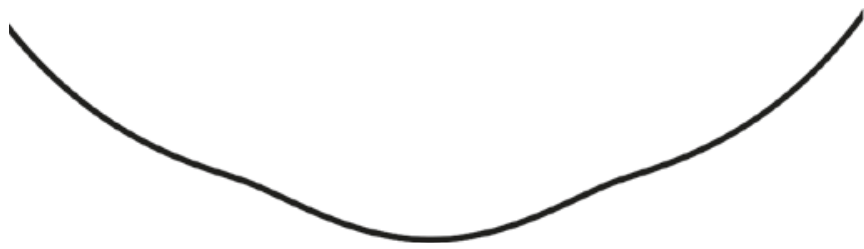

CAssociation of Oral and Maxillofacial Surgeons of India (c) In cases where the rotation is inadequate, the use of a small triangular flap of the skin above the "white roll" will be used to achieve adequate rotation without distorting the philtral column. These flaps heal well and are aesthetic.

(d) A lateral vermilion flap used for reconstruction of deficient vermilion on the cleft side Cupid's bow.

(e) Muscle reconstruction.

(f) Complete closure of mucosa of all areas using inferior turbinate mucosal flap that allows for repositioning of the lower lateral cartilage and adds mucosa wherever there is a deficiency.

(g) Fixation of the lower lateral cartilage to the upper lateral cartilage at its base and to the skin with alar transfixion sutures.

(h) Delayed upper limb rotation-advancement incisions limiting scars around the ala and nostril floor.

(i) The alar groove should be defined well.

(j) Postoperative splinting with a nasal silicone conformer to limit wound contracture.

4. Columella Flap/Cutting Repair: Cutting uses a technique that does not curve the incision towards the cleft and extends up onto the columella 1.5 to $2.0 \mathrm{~mm}$ slightly to the non-cleft side [67]. This yields a wider $\mathrm{C}$ flap thus filling the entire medial defect, allowing for a straight line closure (Fig. 72.22a, b).

\section{Muscle Repair:}

The following modifications have been made in muscle repair:

(a) Cutting [67]: Interposition orbicularis muscle repair. (b) Mulliken [68]: Vertical mattress sutures for end-toend muscle repair to evert the orbicularis.

(c) Fischer [65]: On both medial and lateral cleft elements, dissection of the overlying skin from the orbicularis. Dissection on the medial lip is limited to $1 \mathrm{~mm}$ from cut edge whereas of the lateral lip extends to the alar base to eliminate orbicularis bulge.

\subsubsection{Step-by-Step Technique of Unilateral Cleft Lip Repair: Author's Technique}

(Figs. 72.23, 72.24, 72.25, 72.26, 72.27, $72.28,72.29,72.30,72.31,72.32,72.33$ and 72.34)

Lip Repair:

The authors have presented their technique of lip repair in a stepwise manner.

The following steps have been described:

- Markings: The most important principle of cleft lip repair is to identify the normal and abnormal structures. This includes the length of the philtral columns and the width of wet and dry mucosa. All the soft tissues should be kept in mind while designing the flap. No soft tissue should be discarded or considered redundant.

\section{Non-Cleft Side.}

Deepest point on cupid's bow, peak on non-cleft side and normal philtral column. (To make the philtral column prominent, one may use a two-pronged nasal hook to pull and retract the columella.) 

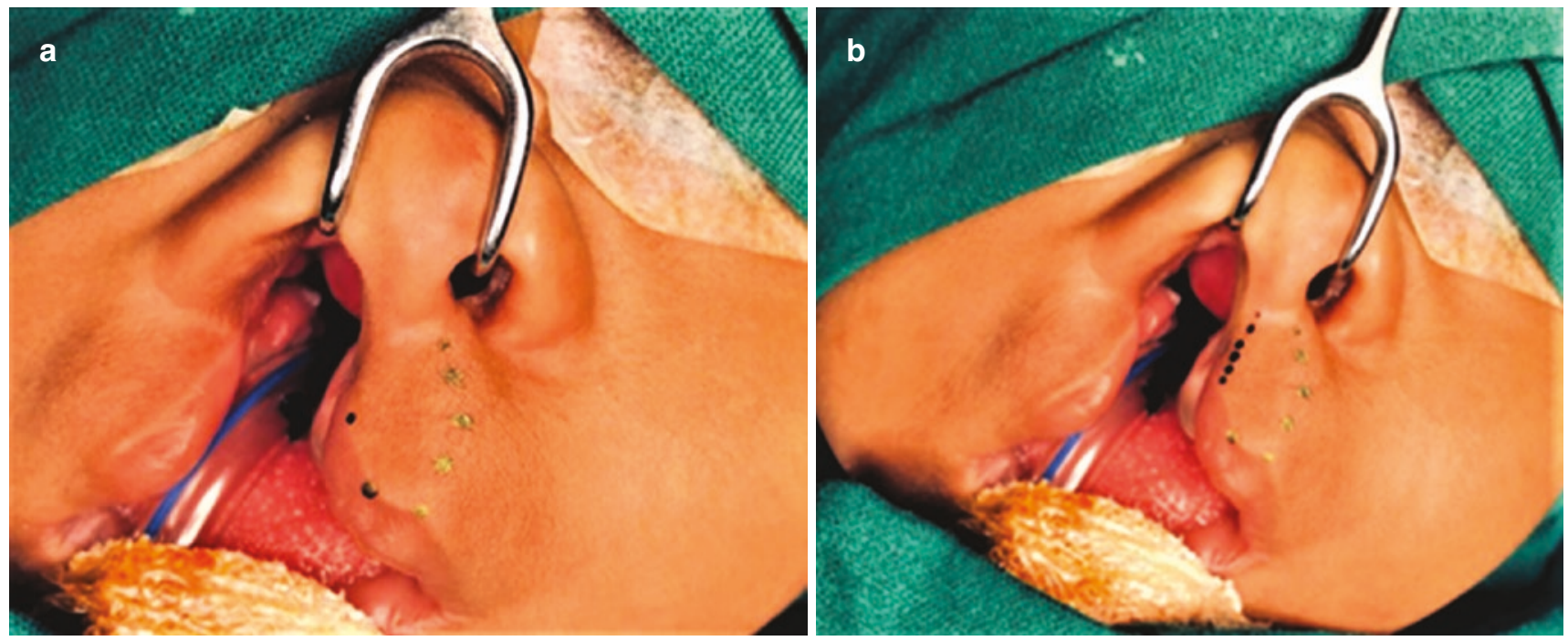

CAssociation of Oral and Maxillofacial Surgeons of India

Fig. 72.23 (a) Mark the highest point on the Cupid's bow (cleft side), and also notice the philtral dimple. (b) Mark the future philtral column, and continue it up to the columella without cutting across the columella

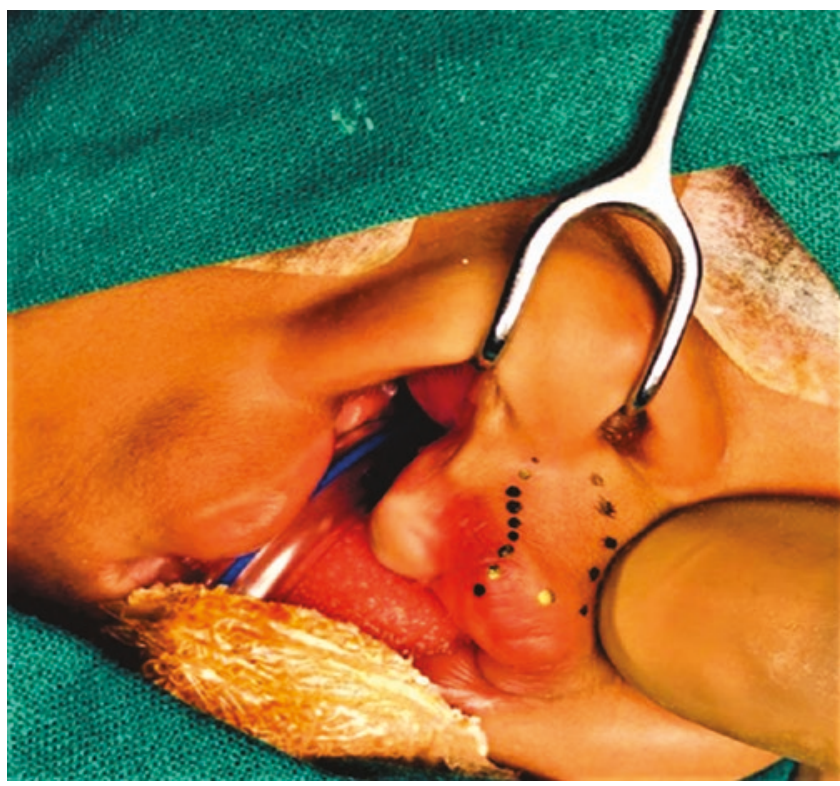

CAssociation of Oral and Maxillofacial Surgeons of India

Fig. 72.24 From the peak of Cupid's bow on the cleft side, mark the incision on the dry mucosa till the junction of wet and dry mucosa

- Mark the highest point on the Cupid's bow (cleft side), and also notice the philtral dimple (Fig. 72.23a).

- Mark the future philtral column, and continue it up to the columella without cutting across the columella (Fig. 72.23b).

- At this point the surgeon should compare the mark with the philtral column on the normal side. It might appear shorter; however, it will increase in length once the muscle is dissected from the abnormal attachment. The back cut discussed previously is used for adequate rotation of

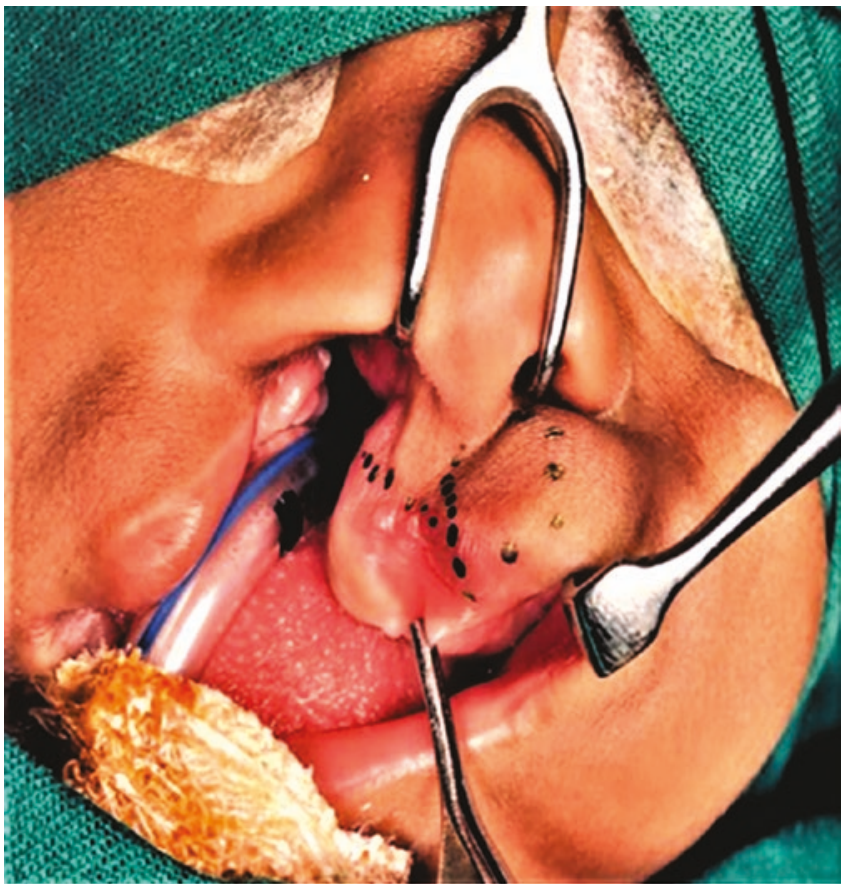

CAssociation of Oral and Maxillofacial Surgeons of India

Fig. 72.25 Marking of $C$ flap: A triangular flap between the mucosa and the future philtral column

the cleft side philtral column. The back cut should be made after the muscle closure.

- From the peak of Cupid's bow on the cleft side, mark the incision on the dry mucosa till the junction of wet and dry mucosa (Fig. 72.24).

- Marking of C Flap: A triangular flap between the mucosa and the future philtral column. Continue between the skin 


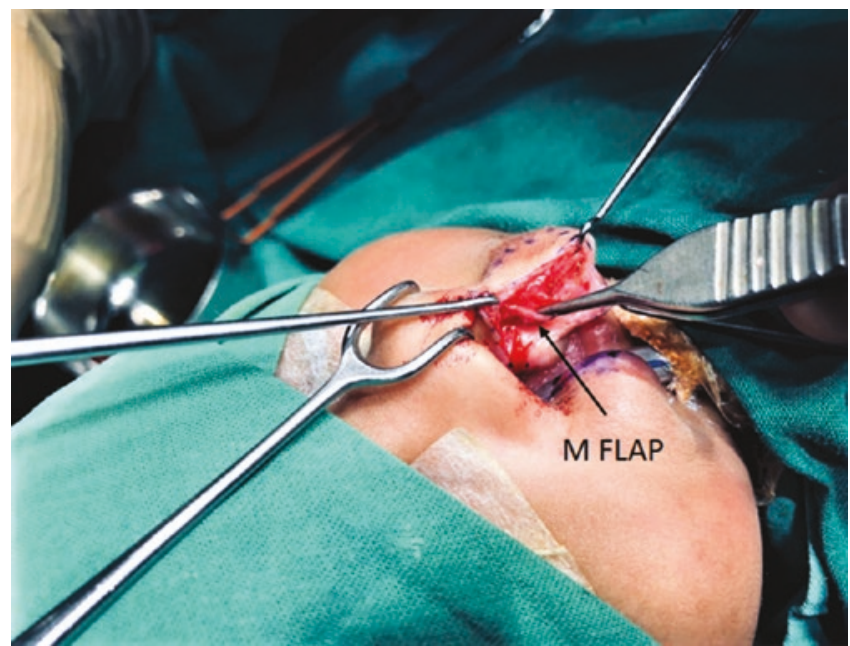

(C)Association of Oral and Maxillofacial Surgeons of India

Fig. 72.26 M flap: The mucosal element on the non-cleft segment after raising the $\mathrm{C}$ flap becomes the $\mathrm{M}$ flap and is raised to expose the underlying muscle

and mucosa junction down to the mucosa to keep enough mucosa for nasal layer closure (Fig. 72.25).

- C flap originally described by Millard was used to augment the lateral lip at the insertion of alar base. We use the C flap either to create the nasal sill or if a back cut is given; it can be used to reconstruct the columella-lip junction.

- M Flap: The mucosal element on the non-cleft segment after raising the $\mathrm{C}$ flap becomes the $\mathrm{M}$ flap and is raised to expose the underlying muscle (Fig. 72.26).

- Rotational Flap: The muscle is now exposed, and the preparation of the lateral element can be divided into three easy steps:

- Oral mucosal layer: Separation of this layer from the muscle bulk can be identified with the plane where the minor salivary glands exist. Bleeding is generally encountered in this plane and should be managed early to reduce blood loss and keep a good plane of dissection.

- Skin-muscle dissection: The incision between this plane is to ensure just adequate separation to provide room for suturing the muscle bulk. Overexposing the muscle not only leads to excessive swelling postoperatively but also distorts the natural anatomical curves of the non-cleft element. On the cleft side, only 1-2 mm of subdermal dissection should be done. Closure of the skin later reinforced by the underlying muscle gives better elevation of the future philtral column as compared to overzealous separation of the muscle from the overlying skin.

- Release of abnormal muscle attachment: The abnormal attachments are usually near the alveolus and the base of the columella. At this point blunt dissection can be done to straighten out the septum.

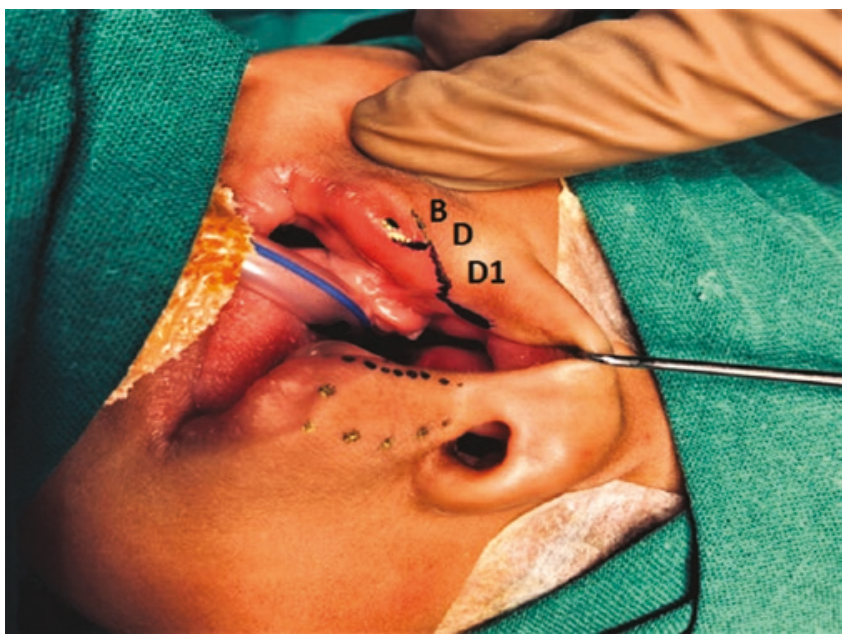

CAssociation of Oral and Maxillofacial Surgeons of India

Fig. 72.27 On the side of the cleft, mark the point B. From the B point, extend the incision along the mucocutaneous junction till point $\mathrm{D}$. From point $\mathrm{D}$, marking goes into the nose to separate the nasal mucosa and the skin [D1]

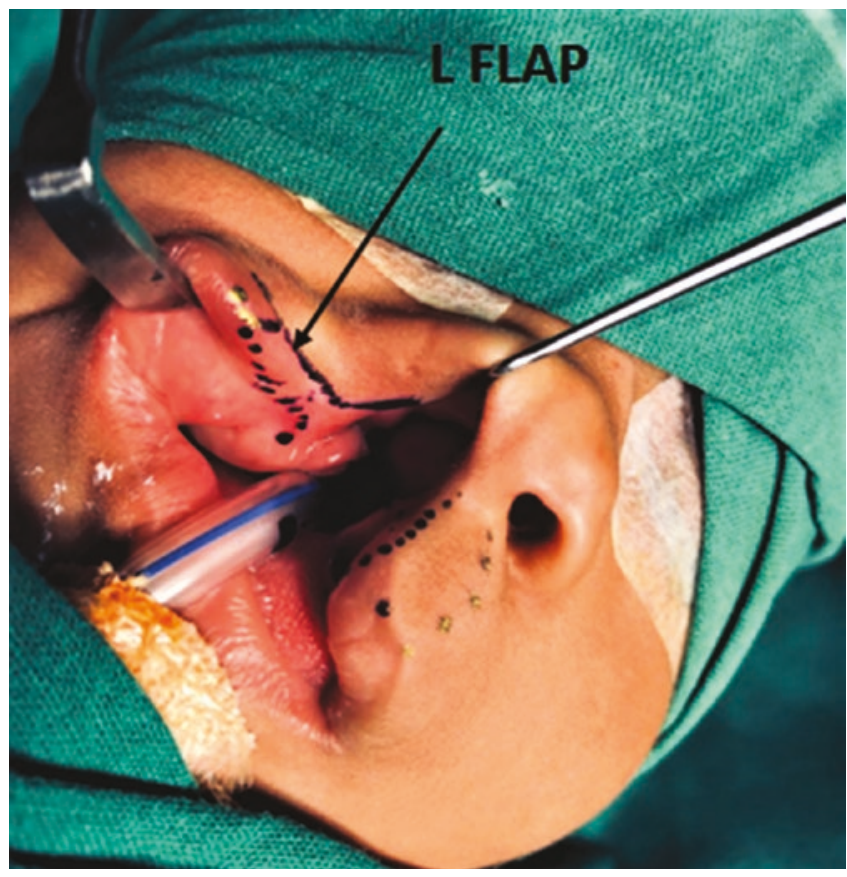

CAssociation of Oral and Maxillofacial Surgeons of India

Fig. 72.28 Marking of L flap

Cleft Side:

- On the side of the cleft, mark the point B. First identify the white roll, and look for the point where the white roll starts to diminish; that is the exact point to join the Cupid's bow. Drop an imaginary line from this point to the junction of dry and wet mucosa. The maximum mucosal width is present at this point. 


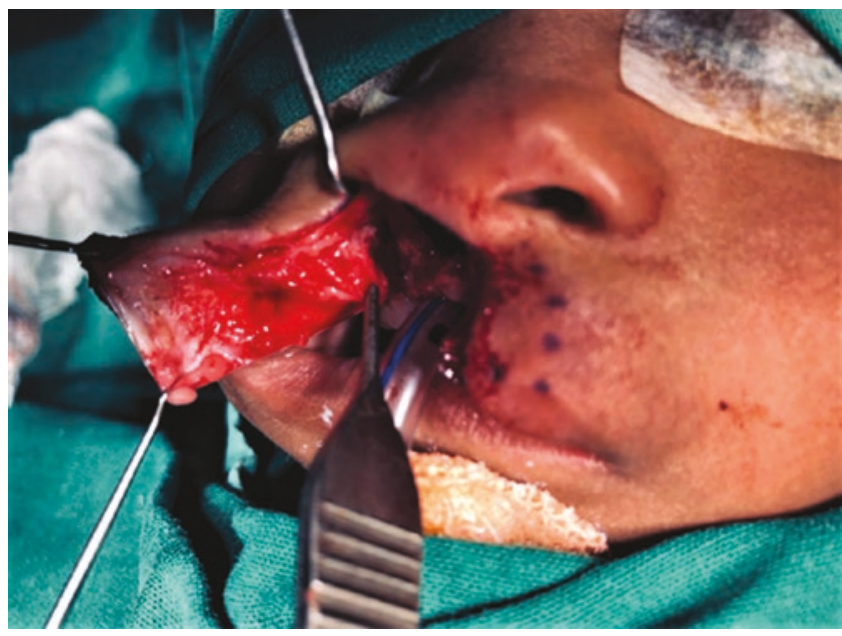

CAssociation of Oral and Maxillofacial Surgeons of India

Fig. 72.29 Incision starts from the deepest point of the Cupid's bow till the columella base. The plane of dissection is just above the muscle

- From the B point, extend the incision along the mucocutaneous junction till point $\mathrm{D}$. Point $\mathrm{D}$ is a point at the edge of the lip at the junction of the skin and mucosa. From point $\mathrm{D}$, marking goes into the nose to separate the nasal mucosa and the skin (Fig. 72.27).

- After marking the L flap, the incision is continued down to the alveolus, to free the abnormal muscle attachment at the base of the alveolus. In a classic Millard's technique, additional incision is given into the vestibule on the cleft side to get adequate mobilization of the advancement flap and medicalization of the cleft side alar base for nasal sill closure. Few surgeons also advocate subperiosteal or supraperiosteal dissection, through the intraoral incision at the pyriform region. However, in the author's experience, the need for this vestibular incision is not always necessary. An "L" flap can be designed from the mucosa of the cleft side as shown in the figure. This flap is continued upwards into the nasal mucosa and not towards the alveolar mucosa. The importance of this lies in the fact that, once harvested, the flap is retracted upwards into the nasal base and is thus used for closure of nasal sill. Moreover, due to this upward pull, the abnormal alar base attachment that leads to flattening of the alar rim is corrected. Thus, it helps in reducing the nasal symmetry (Fig. 72.28).

- Incision starts from the deepest point of the Cupid's bow till the columella base. The plane of dissection is just above the muscle. On the mucosa the incision continues till the junction of the dry and wet mucosa to expose the muscle. Insert a skin hook which will stretch the lip and aid in further dissection. Note: The superior labial artery can be encountered at this point and may need cauterization (Fig. 72.29).

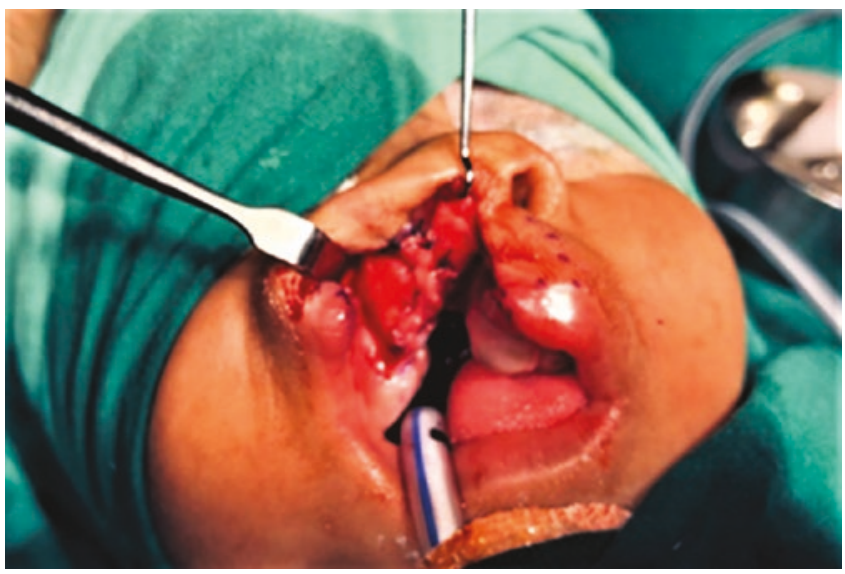

CAssociation of Oral and Maxillofacial Surgeons of India

Fig. 72.30 Nasal layers are now sutured from both the cleft and noncleft sides and sutured using a 4.0 Vicryl

- Begin the incision from the point where the white roll diminishes, and carry it along the marking between the skin and mucosa to reach the junction between the nasal skin and mucosa.

- A small mucosal triangle containing the dark mucosa is maintained, and incision is then carried out to raise the $\mathrm{L}$ flap.

- Once the L flap is raised, the muscle of the cleft side element is exposed.

- Incision is made between the mucosa and muscle similar to the non-cleft side in the plane of existing minor salivary glands.

- The incision between the skin and muscle is similar to the lateral element.

- The abnormal muscle attachments on this side are at the base of the alar and the pyriform region that would require subperiosteal dissection to release the attachment.

- Insertion of Flaps and Suturing.

- The final step of closing the flaps into desired position begins with insetting the $\mathrm{L}$ and $\mathrm{M}$ flaps.

- Step 1

- Using the M flap is optional. The author generally discards the M flap but occasional uses it to reduce tension while doing the nasal floor repair in very wide clefts.

- The L flap is used to create the nasal layer on the cleft side by lining it between the nasal skin and the nasal floor.

- Step 2

- Creating the Nasal Floor: Nasal layers are now sutured from both the cleft and non-cleft sides and sutured using a 4.0 Vicryl (Fig. 72.30).

- At this point of time, the septum is exposed. When the nasal layer is being raised, if required the septum can be straightened.

- Step 3 
- Suturing the Oral Mucosa: Begin at the point where the wet and dry mucosae meet. The alignment of these two points from both elements is crucial for good mucosal repair. The rest is completed till the alveolar base. The suture material used here is 4.0 Vicryl. The dry mucosa will be closed last (Fig. 72.31).

- Muscle Suturing: The preference is to suture the muscle at the junction of white roll and Cupid's bow. The suture allows reassessment of adequate rotation of the flap to create equal length of the philtral columns. A back cut can now be placed to accommodate for discrepancies. The back cut is made parallel to the existing philtral column at the base of the columella.

- Muscle layer suturing is then completed carefully reorienting the fibres at equal height and bites from both elements. At this stage the lip anatomy should

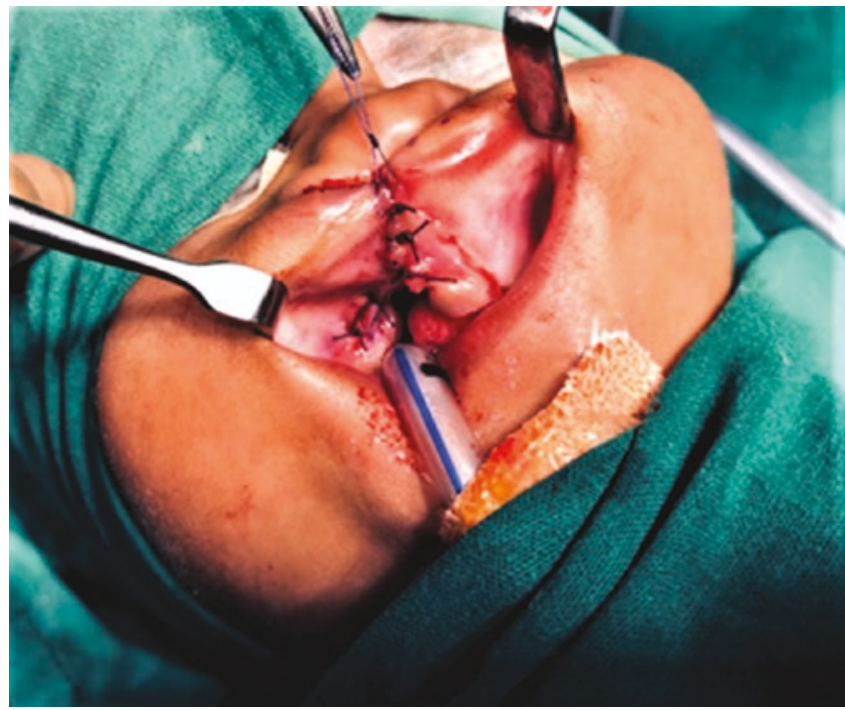

CAssociation of Oral and Maxillofacial Surgeons of India

Fig. 72.31 Suturing of the oral mucosa

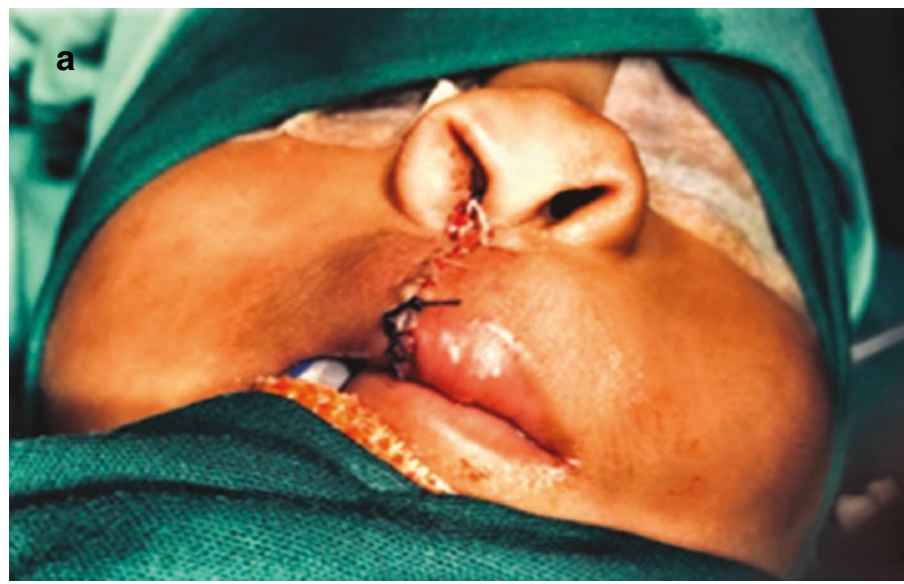

CAssociation of Oral and Maxillofacial Surgeons of India

Fig. 72.33 (a) Skin suturing. (b) Note the matching of the white roll correspond to final anatomy, and the skin should be passively seated over the muscle layer. The suturing is completed using 4.0 Vicryl, and the knots are cut flush to prevent any extrusion of sutures on the skin surface (Fig. 72.32).

- Skin Suturing: The first step in suturing the skin is to evaluate the area where the $\mathrm{C}$ flap is going to be utilized and also the dimension of the flap needed. The excess flap can be trimmed or in some instances completely discarded (Fig. 72.33a).

- The preference of the $\mathrm{C}$ flap is to use it as a hemi-columella or nasal sil. Using the $\mathrm{C}$ flap into the back cut defect creates an unnatural scar across the cutaneous lip and columella junction.

- Once the C flap is tucked beneath the skin, excess skin tissue if any is trimmed, and suturing begins from the base of the columella down to the vermilion. The suture

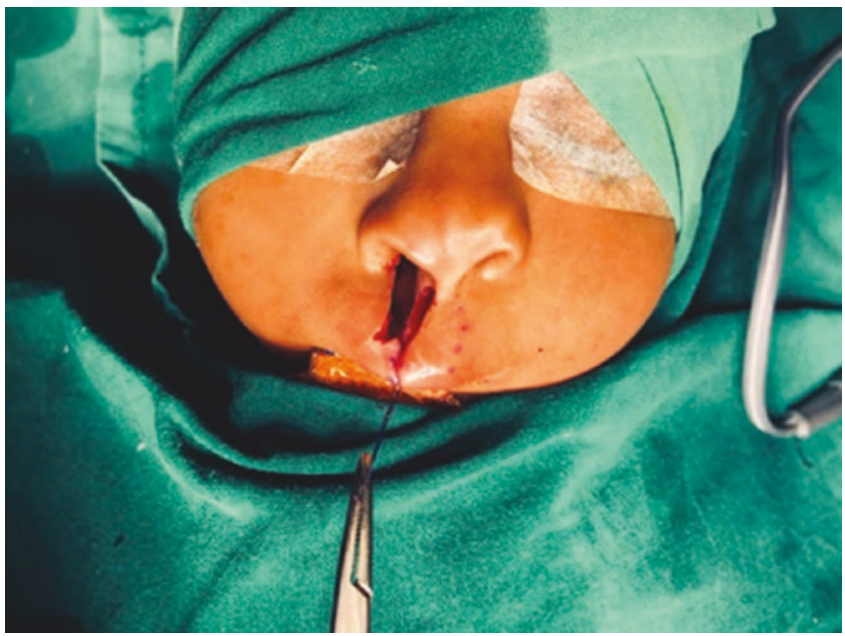

CAssociation of Oral and Maxillofacial Surgeons of India

Fig. 72.32 Muscle suturing

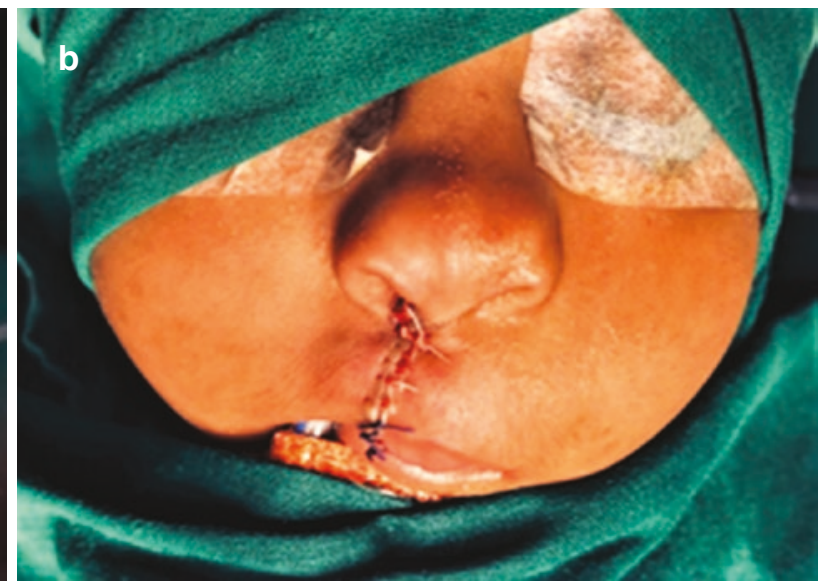




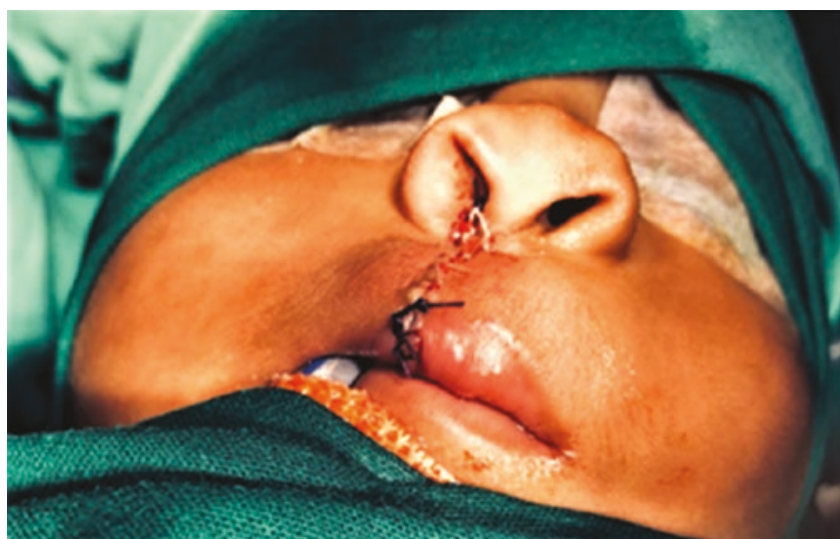

CAssociation of Oral and Maxillofacial Surgeons of India

Fig. 72.34 Dry mucosa suturing

used here is 5.0 Vicryl Rapide or 6.0 Vicryl Rapide (Fig. 72.33b).

- Dry Mucosa Suturing: At the end of skin suturing, the vermilion continuity is established by using the V-shaped mucosal flap established from the cleft segment tucked into the non-cleft mucosa. At this stage care should be taken to secure a suture beneath the vermilion for muscle repair, and the mucosal stitch should be passive to reduce necrosis of the mucosal tip (Fig. 72.34).

- A good repair depends upon minimal handling of the tissues and a tension-free closure of all layers especially the skin as the muscle bears the stress of tension forces.

\subsection{Bilateral Lip Repair}

James Barrett Brown said "Bilateral clefts are twice as hard as unilateral clefts, and the results are less than half as good" [69]. Bilateral cleft lip repair can be one-stage or two-stage. Proponents of one-stage repair stress on creating a symmetric, balanced lip. This is indicated in cases of complete or incomplete symmetric bilateral clefts or where the premaxilla is within the arch. Two-stage repair is indicated in the presence of a small prolabium, an asymmetric cleft or a protruded premaxilla. Proponents of two-stage repair advocate this technique for conversion of a bilateral into unilateral cleft, to encourage the growth of prolabium and to avoid excessive lip tension. In earlier techniques of bilateral lip repair, excision of the prolabium was made mistakenly assuming it to be a displaced columella. This was because surgeons failed to recognize the potential of the prolabium to grow in width and height when attached to the dynamic lateral lip elements.
Principles of Bilateral Cleft Lip Repair: Certain key points and landmarks need to be kept in mind while considering a bilateral cleft lip repair. The following principles of bilateral cleft lip repair should be adhered to:

1. Symmetry must be established. In case of staged repairs, this is hindered which lead to asymmetrical results.

2. The surgeon should anticipate a fourth dimensional changes that occur with growth. Failure to account for this may result in a widened philtrum. This is attributable to slower-growing areas such as the lengthening columella and projection of the nasal tip, compared with faster-growing areas such as the philtral width [70] Thus, there is a need to undercorrect fast-growing areas and overcorrect the slow-growing structures.

3. Prolabium: No matter how small it is, the prolabium is always sufficient for reconstruction. It should always be used for reconstruction of the midportion and not used for partial reconstruction of the philtrum and columella. When white line is present in the prolabium, it must be used, however, a short prolabium pulls down nasal tip creating a secondary nasal deformity.

4. Premaxilla: Presurgical orthopaedic treatment should be done only to expand the maxillary segments. Closure and joining the muscle at the midline create enough pressure to retroposition the protruding premaxilla. Sometimes, resection of the vomer behind the vomerine-premaxillary suture can be done, and the premaxilla can be repositioned using plating or K-wire with or without bone graft.

5. Vermillion: There is a very narrow strip of vermillion present in a bilateral cleft lip. A vermillion flap from lateral lip elements should be taken for fullness and protrusion of the lip.

6. Muscle repair: As the prolabium is without muscle fibres, muscle continuity under the prolabium is necessary for a functional lip. There is a need to release the abnormal attachment at the base of the ala from the vertical to horizontal and functional attachment.

7. The nasal deformity can be addressed either primarily or secondarily.

\subsubsection{Techniques of Bilateral Cleft Lip Repair (Video 72.2)}

\subsubsection{Straight Line Repair}

Bardach used a straight line repair. The prolabium was used for the entire central portion of the lip. This caused a problem in case of a short prolabium or a protruded premaxilla [71]. Salyer also used a straight line repair. In his repair, no tissue is discarded, the entire prolabium is lengthened and philtral and skin flaps are used for vestibular lining [72]. 

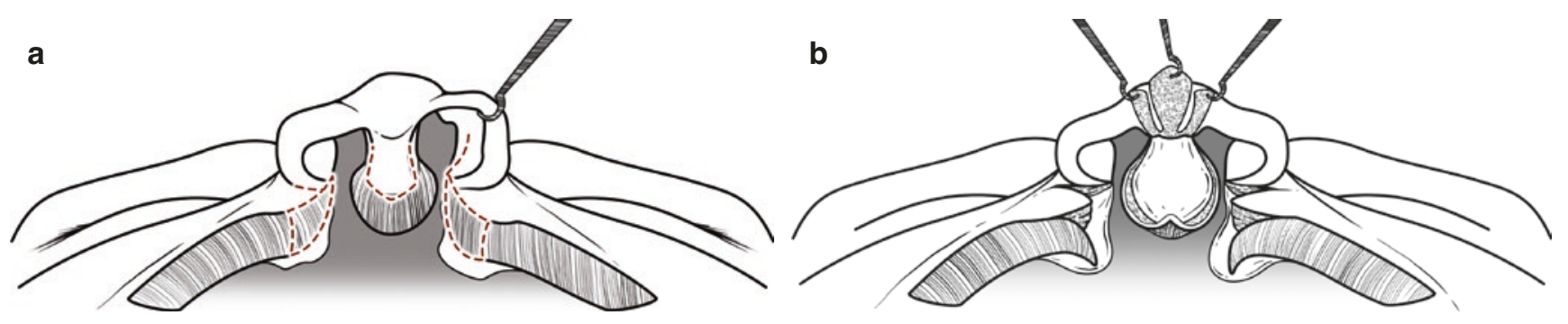

C
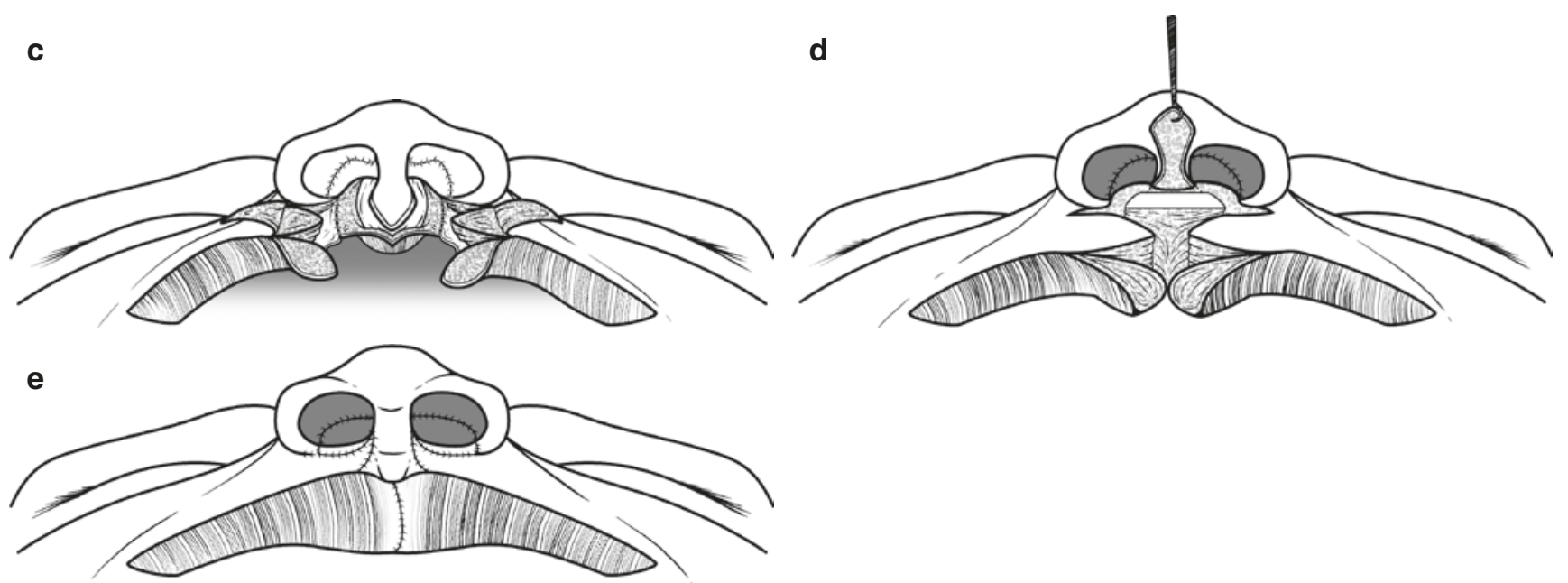

CAssociation of Oral and Maxillofacial Surgeons of India

Fig. 72.35 (a-e) Millard's technique of bilateral lip repair

\subsubsection{Millard's Repair}

Millard's repair allowed rotation of the Cupid's bow with the gap filled from skin advanced from the lateral element [73]. It allowed complete elevation of the prolabium and suturing of the orbicularis across the premaxilla. In addition, Millard created lateral segments of the prolabium as "forked flaps". These flaps were banked to add columellar height at a later stage, thus addressing the vertical height deficiency, and it also corrected the wide alar bases (Fig. 72.35a-e). The key elements of bilateral lip repair are given in Box 72.6.

\subsubsection{Mulliken's Repair}

Mulliken designed a narrow prolabial flap with slightly concave sides; $2 ; 2.5 \mathrm{~mm}$ at base and $3.5-4 \mathrm{~mm}$ between Cupid s bow peak. The surgical stratagem is symmetrical labial

\section{Box 72.6 Key Elements of Bilateral Lip Repair}

- Bringing in a new white roll from the lateral lip elements.

- The prolabium parings are banked for future columella lengthening.

- Bringing lateral vermilion flaps beneath the prolabium.

- Reconstructing the orbicularis muscle beneath the elevated prolabium. repair and synchronous anatomic positioning of the alar cartilages with sculpturing/draping of the nasal soft tissues. It consists of following elements:

- Suture of the orbicularis oris in the midline.

- Fixation to anterior nasal spine.

- Positioning dislocated lower lateral cartilages: interdomal suture.

- Suspension over ipsilateral upper lateral cartilage with intercartilaginous suture.

- Suture of the orbicularis oris in the midline.

- Fixation to the anterior nasal spine.

- Positioning dislocated lower lateral cartilages: interdomal suture.

- Suspension over the ipsilateral upper lateral cartilage with intercartilaginous suture.

\subsubsection{Bilateral Lip Repair: Author's Technique}

Markings: Fig. 72.36 shows the marking of the prolabial flap and the lateral flaps.

- Once all incisions are designed, the lip is infiltrated with 1:100.000 epinephrine. We can start with either the prolabium or lateral flaps. Grab the lip between fingers for better control during incision and bloodless field. 
- Incision starts on the prolabium following the previous markings, the medial flap is for philtral reconstruction, and two laterals segments of the skin are discarded (Fig. 72.37a).

- The philtral flap is dissected, leaving a generous amount of deeper soft tissues attached. The flap is raised in a preperiosteal plane off the premaxilla and up to the base of the columella (Fig. 72.37b).

- Next step is creation of mucosal flap from the prolabium for sulcus reconstruction and exposure of anterior nasal spine.

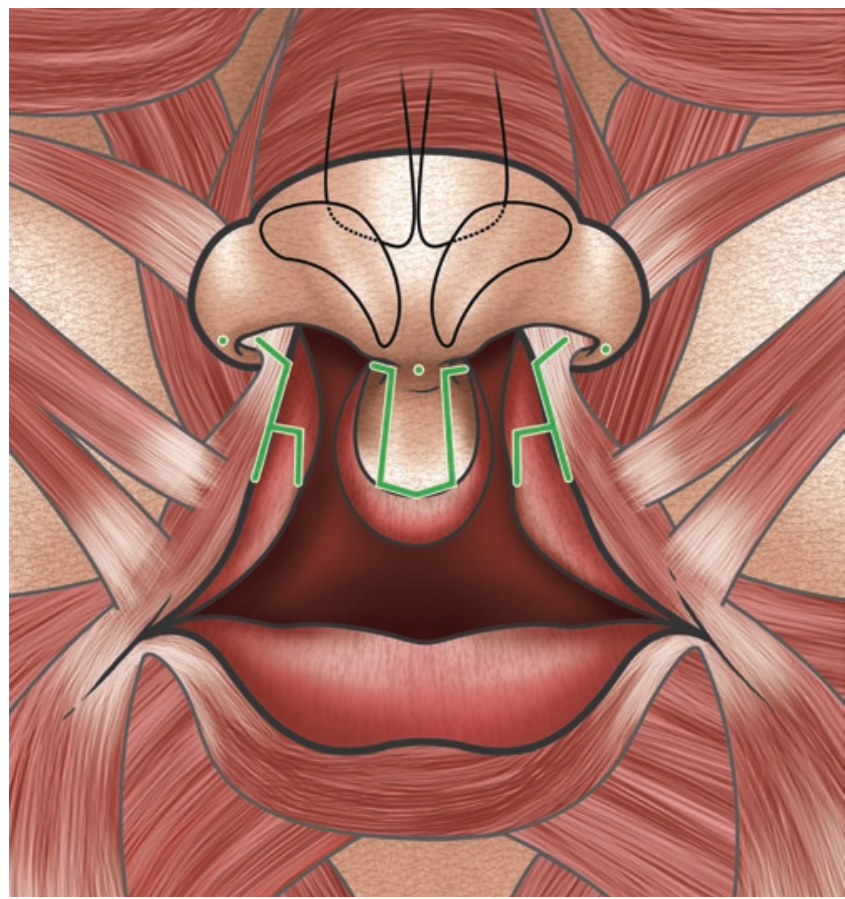

CAssociation of Oral and Maxillofacial Surgeons of India

Fig. 72.36 Markings for bilateral lip repair
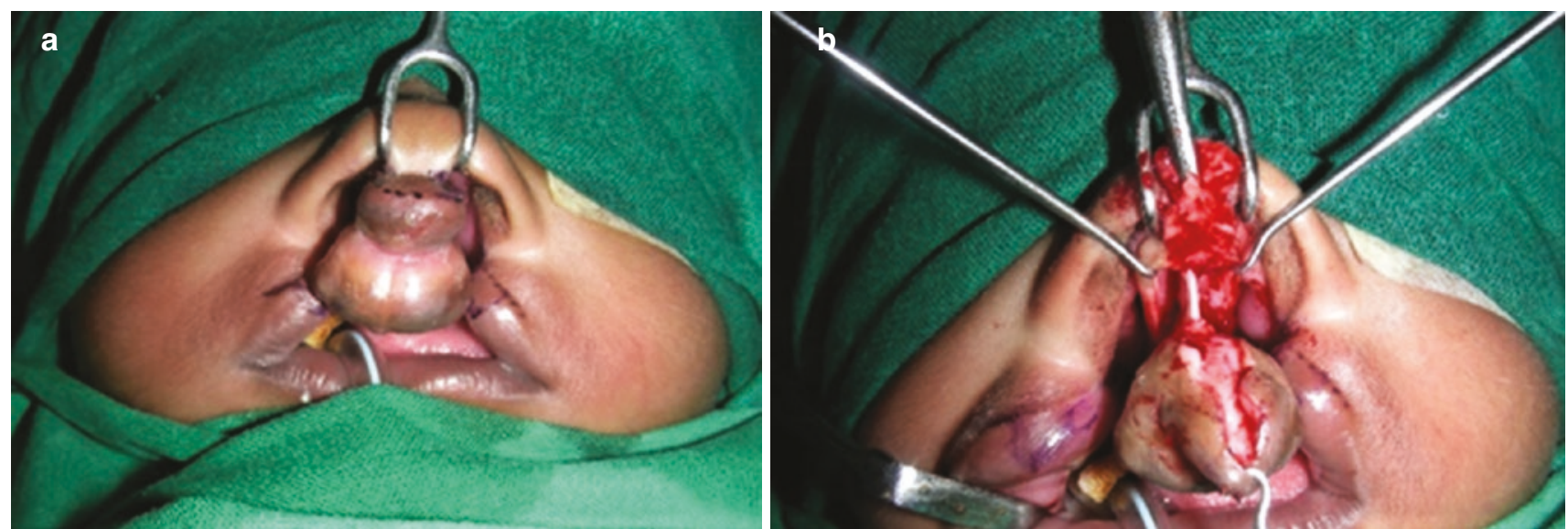

(C)Association of Oral and Maxillofacial Surgeons of India
- Incision in lateral lip following the marks in the skin and mucosa of the vermillion is made (Fig. 72.38).

- Incision is carried on the vermilion-cutaneous junction, dissecting the vermilion to the point where the peak of the Cupid's bow is marked.

- Full thickness cuts are made through the orbicularis oris and the oral mucosa of the upper lip.

- Incision in the sulcus to aid in the detachment of the abnormal lateral lip element, especially the muscle.

- Those incisions facilitate mobilization of the lateral lip elements so they can be brought up and over the premaxilla which aids in decreasing tension.

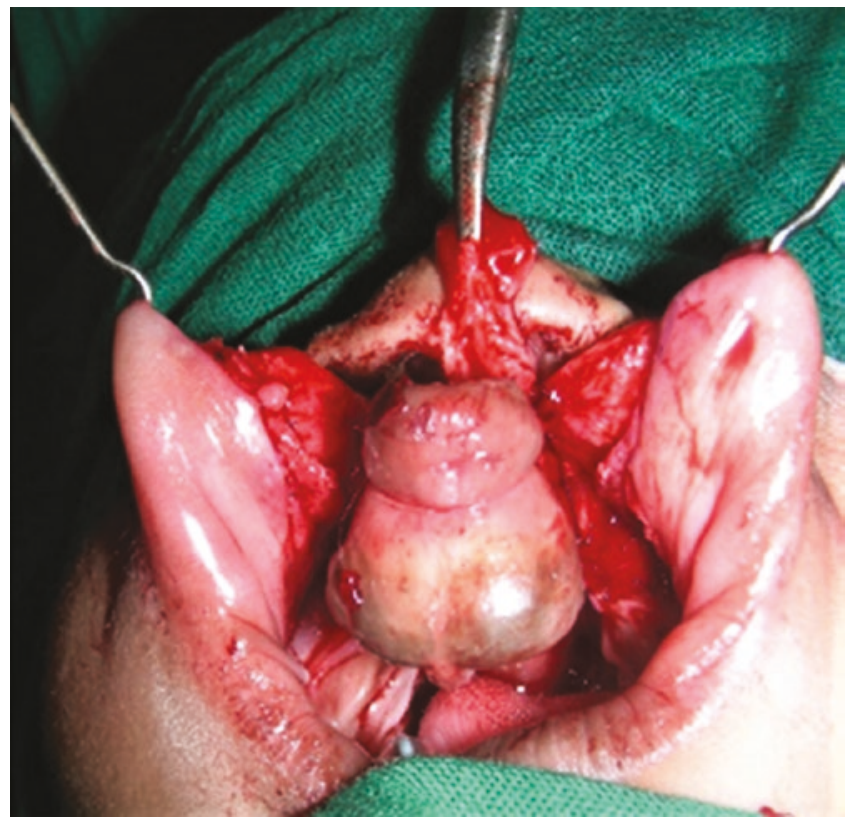

CAssociation of Oral and Maxillofacial Surgeons of India

Fig. 72.38 Dissection of the lateral flaps

Fig. 72.37 (a) Marking of the prolabium flap and lateral flap. (b) The prolabium flap dissected 
- The muscle is dissected as a separate layer from the mucosa not from the skin. Undermining of the soft tissue, dissection and release are carried up to the inferior orbital nerve.

- Subperiosteal dissection of the pyriform aperture towards the frontomaxillary pillar, to release the ala from its abnormal insertions.

Release and repositioning of the following structures from their abnormal attachment:

- Alar base.

- Muscular, ligamentous and lining attachments.

- Fibrous attachments with the accessory chain of the lateral crus.

- Full-thickness cut is made along the nasal lining at the pyriform aperture. This release creates a lining defect that will be filled with the septal flap.

- Dissection of mucoperiosteal flap from lateral nasal wall.

- Liberation of the orbicularis oris, freeing it from its abnormal attachment around the base of the nose.

- Reposition of the orbicularis from vertical to horizontal position with retrograde dissection without dissection of the muscle and the skin in the free border.

\section{Suturing}

(a) Nasal Floor

- Mucoperiosteal flap from lateral nasal wall and mucoperichondrial flap from the nasal septum are sutured to form the nasal floor. This helps to bring the base of the ala medially, thus narrowing the width of the nostril.

(b) Recreating the Sulcus

- Advance prolabial mucosal flap superiorly to establish the lining of the labial sulcus, trimmed as needed, and fixing it to the periosteum inferiorly to the nasal spine.

- Medial advancing of mucosal flaps and fixation to the mucosal flap of the prolabium, previously fixed. Then they are sutured together in the middle line from inferior to superior, starting in the red line (key stitch).

(c) Muscle Repair

- Medial advanced musculocutaneous flaps from the lateral lips.

- Muscle is brought across the midline below the prolabium.

- Apposition of the muscle is done from distal (key stitch) to proximal area (Fig. 72.39).

- Proximal segment fixed to the periosteum of the anterior nasal spine in the middle line.

(d) Vermillion Repair

- The midportion of the vermilion is reconstructed by bringing lateral vermilion flaps below the philtrum flap (Fig. 72.40).

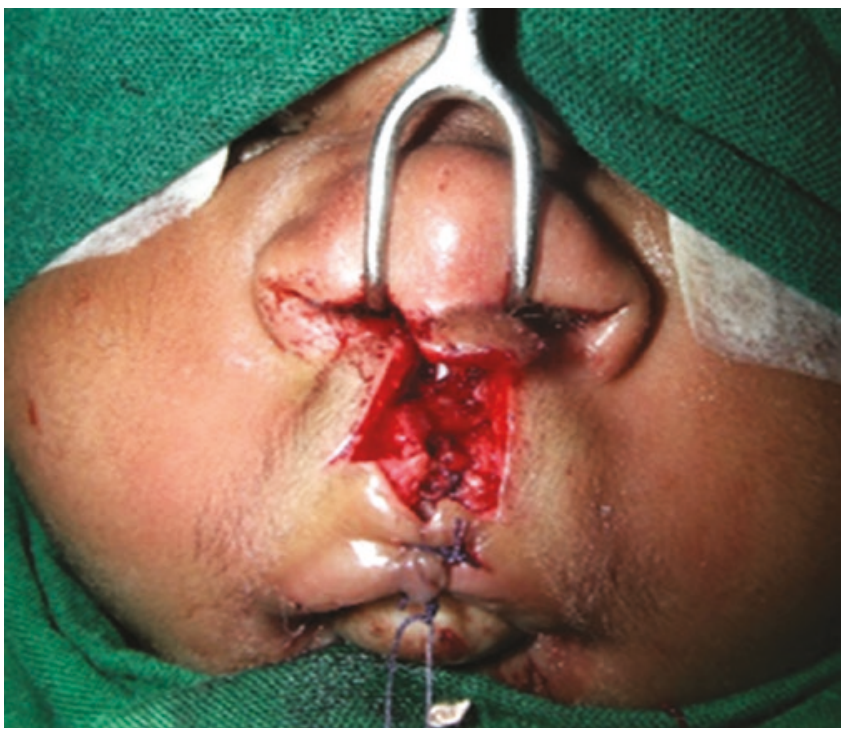

CAssociation of Oral and Maxillofacial Surgeons of India

Fig. 72.39 Lateral flaps sutured beneath the prolabium. Muscle sutured to create the continuity

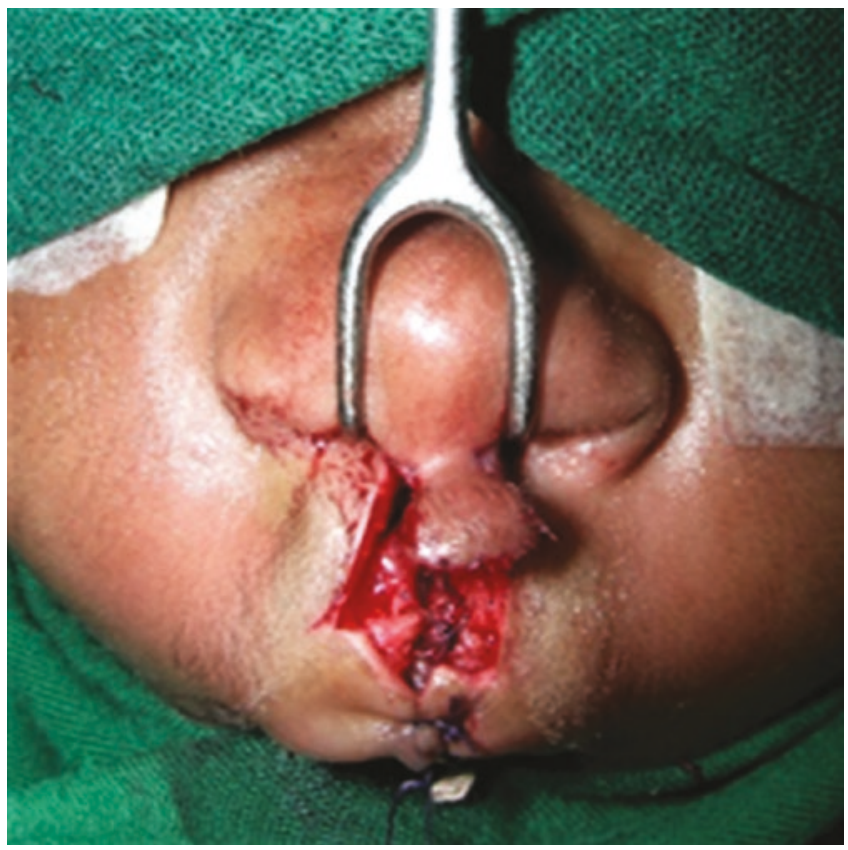

CAssociation of Oral and Maxillofacial Surgeons of India

Fig. 72.40 Position of the prolabium to create the future philtral column

(e) Skin

- Preventing or minimizing lip tension is the key to successful bilateral cleft repair (Fig. 72.41).

- Excessive tension: tethering of the columella, increased scarring and facial growth problems.

- Attention is given to construction of the Cupid's bow. 


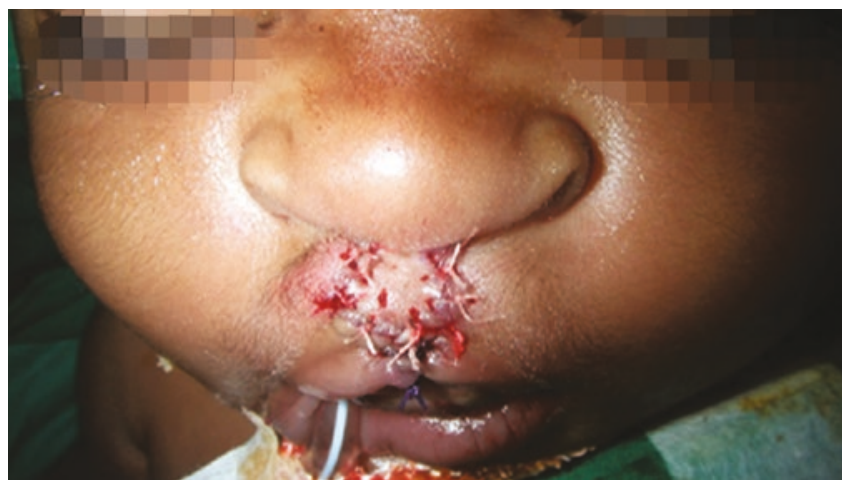

(C)Association of Oral and Maxillofacial Surgeons of India

Fig. 72.41 Skin suturing done

\subsection{Primary Chielorhinoplasty}

A variety of options exists to address the nasal deformity with cleft lip. These include preoperative nasoalveolar moulding, overcorrection of the nostril width and alar cartilage at the time of lip repair and postoperative use of nasal conformers. Primary treatment of the nose at the time of lip repair has become popular, in order to gain early restoration of the symmetry by repositioning the alar cartilage and lengthening the columella. However, relapse is frequent due to the elastic deformed alar cartilage. Various theories and opinions have been popularized regarding correction of the septum, to either straighten the septum or leave for later correction. A study done by Mancini et al. involves three-dimensional analysis of unilateral cleft lip and palate patients treated with PNAM and primary rhinoplasty, which demonstrated significant improvements in nasal projection, columellar length, nasal symmetry and nasal width [74].

\subsection{Postoperative Wound Care and Outcome Assessment}

Postoperative wound care is extremely important in determining the results of lip repair and is often a factor resulting in the need of a lip revision.

1. Suture area should be cleaned daily with saline and baby soap twice; topical application of antibiotics is recommended for 10 days.

2. 3 weeks post-op, we recommend to massage the scar towards the mucosa to prevent scar contracture.

3. Massage can be done with vitamin E cream/silicone gel/ oil. It is recommended to massage for at least 6 months.

\subsubsection{Outcomes}

Improper surgical technique and tissue dissection can lead to certain undesirable outcomes. Other factors such as wide deformities, severely displaced premaxilla, inadequate postoperative care, poor healing and infection can also lead to aesthetic results. Understanding the process and severity of the outcome helps in addressing the problem in secondary lip repair or lip scar revisions. The outcomes can be divided into the following types:

- Mucosal notching-As pointed above, the mucosal dissection should always be in the plane between the muscles and the mucosa plus minor salivary glands. Failure to maintain that results in a thin mucosa that inverts after suturing. This leads to mucosal notching. As a trainee, one can also give mattress sutures to achieve mucosal eversion. In case of very mild mucosal notching presenting at 3 weeks, it is advised to continue the massage. If notching persists after 6 months of lip repair, it can be treated by surgically improving placement of muscle; thus we recommend a lip revision.

- Scarring-A scar can present in various forms. A scar can be linear but hypertrophic in appearance. Such scars can be avoided if proper massaging is done in the postoperative phase. If the scar has keloid tendency, triamcinolone injections are to be given at an interval of 15 days followed by vigorous massage.

- Contracture-A scar can also present as a gross or mild vertical contracture. This usually results due to inadequate rotation, thus pulling the lip towards the nose resulting in vertical shortening of cleft side philtral column. Improper muscle closure or overzealous separation of the skin from the muscle can lead to scarring of the skin.

- Inadequate philtral column matching-This again results due to lack of a proper design and improper mobilization of the rotation flap.

- Complete breakdown of the surgical wound may be the most severe adverse outcome in the immediate post-operative phase.

\subsection{Indications for Lip Revision}

Scarred fibrous tissues with poor vascularity always make secondary surgery more challenging. Dissection and reapproximation of surgical landmarks are difficult in such cases. The basic surgical principles that should be followed are identification and preservation of all the vital anatomic structures. 
The basic indications for a lip revision surgery are:

1. Unilateral.

- The scar is not in line with the natural philtral column.

- The lip length is short.

- There is a mucosal notching.

- There is a white roll to Cupid's bow mismatch.

- There is a nasolabial fistula.

2. Bilateral.

- There is a wide philtral column.

- Mucosal notching.

- Whistling defect.

- No sulcus depth.

\subsection{Conclusion}

In our course of learning of cleft, we often understand embryology, anatomy and the surgical technique as separate concepts. In this chapter, we have tried to integrate them and tried to explain the rationale behind the surgical steps. Embryological basis of normal anatomy and then of cleft is pivotal to understand the arrangements of muscles, the vascular supply and thus the basis of incisions. We have described our surgical technique of cleft lip repair with longterm follow-ups. In the congenital deformity of cleft where there is paucity and deformation of tissues, preserving the tissues during surgery is one of the important principles of lip repair.

\subsection{Case Scenarios}

Figures $72.42,72.43,72.44,72.45$ and 72.46 represent cases of operated unilateral and bilateral cleft lip with long-term follow-ups.

Figures $72.47,72.48,72.49$ and 72.50 represents cases of lip revisions with follow-ups.

Disclosure: Authors have no financial conflicts to disclose.
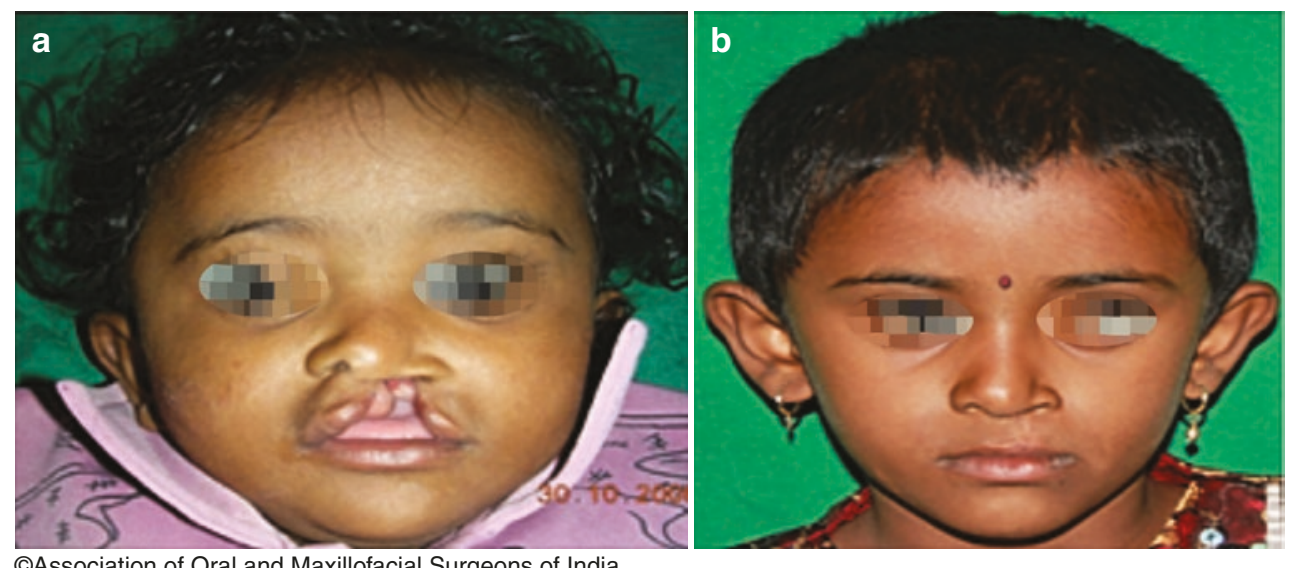

Fig. 72.42 (a, b) Pre operative (a) and postoperative (b) Photograph of repair of unilateral cleft lip using author's technique of lip repair [7-year follow-up] 


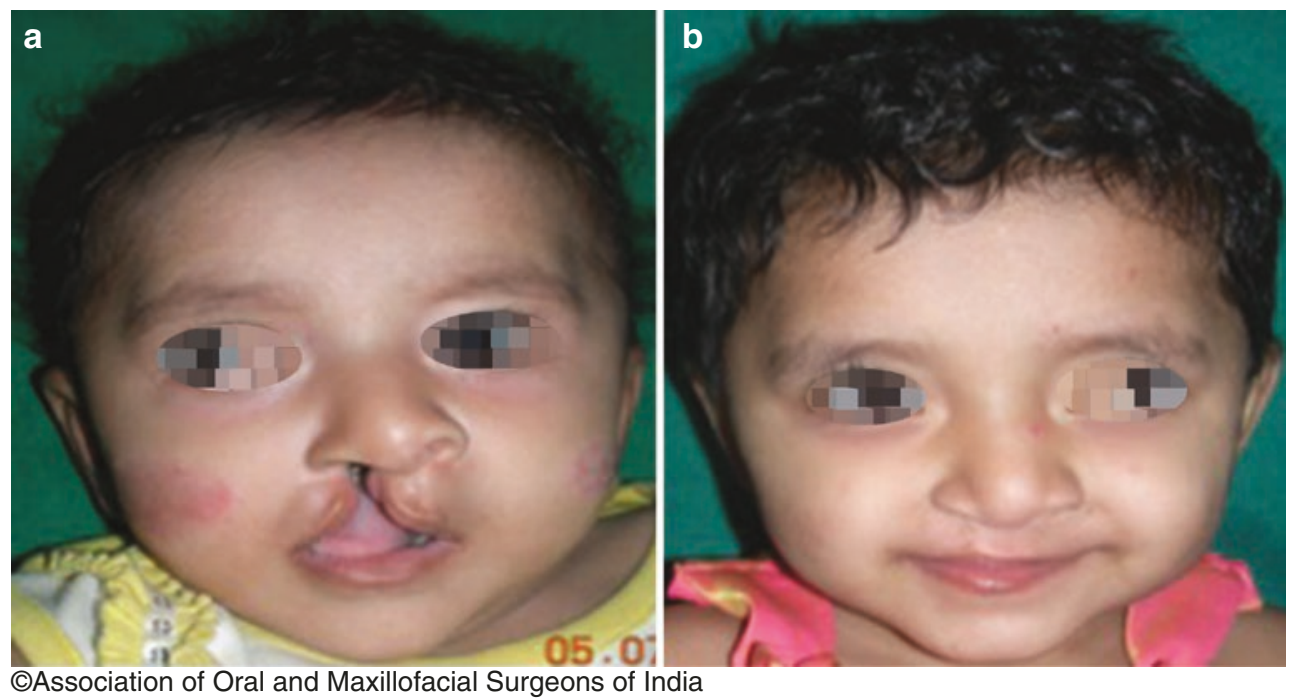

Fig. 72.43 (a, b) Another case of a 3-month-old female of complete unilateral cleft lip repaired. Left, preoperative; right, postoperative after a 4-years follow-up

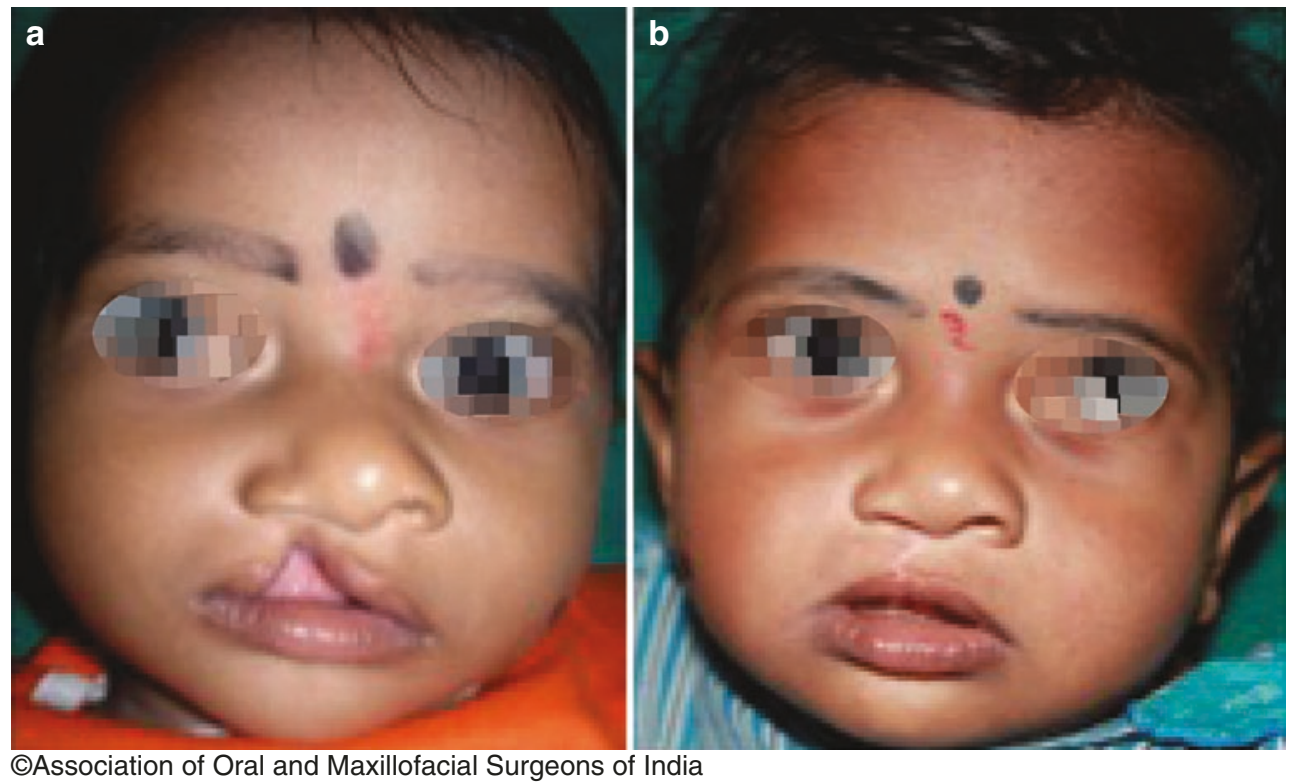

Fig. 72.44 (a, b) Operated case of an incomplete cleft lip, 2-year follow-up 


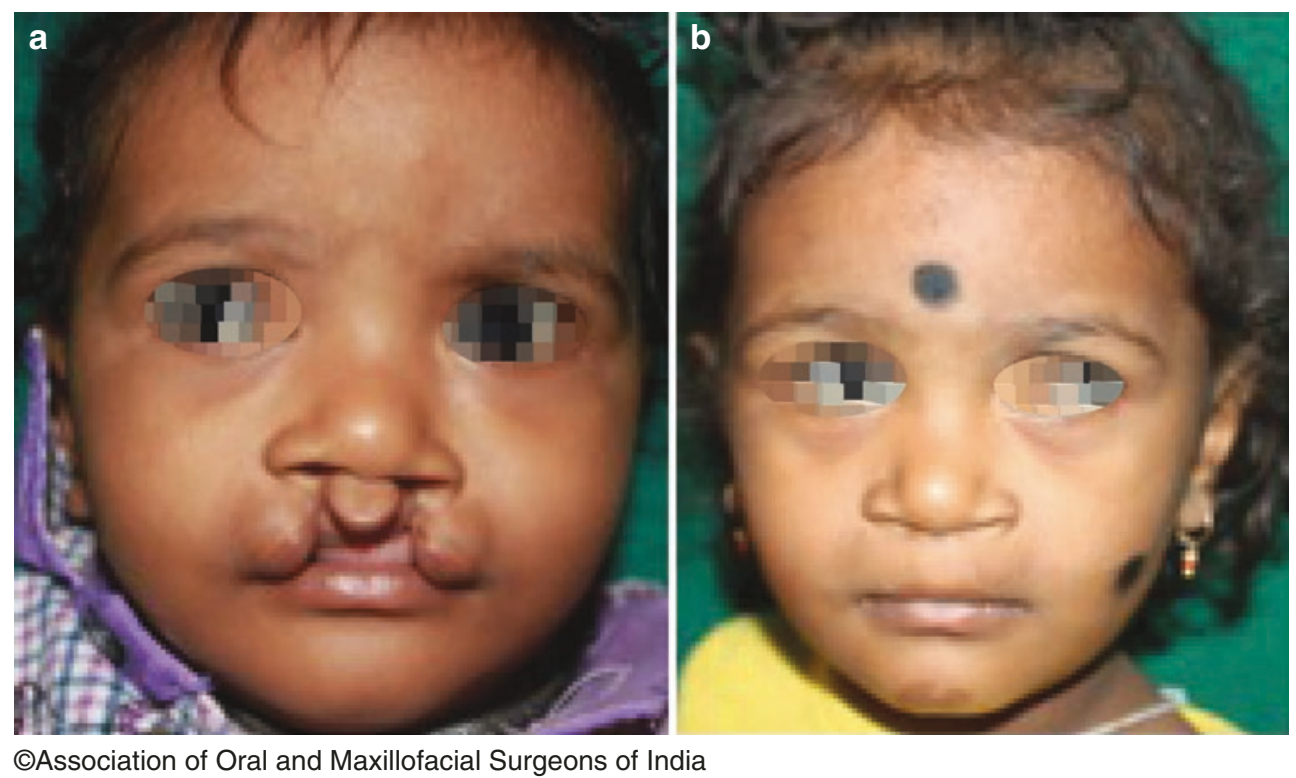

Fig. 72.45 (a, b) Pre-op and post-op photograph of a case of bilateral cleft lip repair, 5-year follow-up

Fig. 72.46 (a, b) Another case of operated bilateral cleft $\operatorname{lip}$

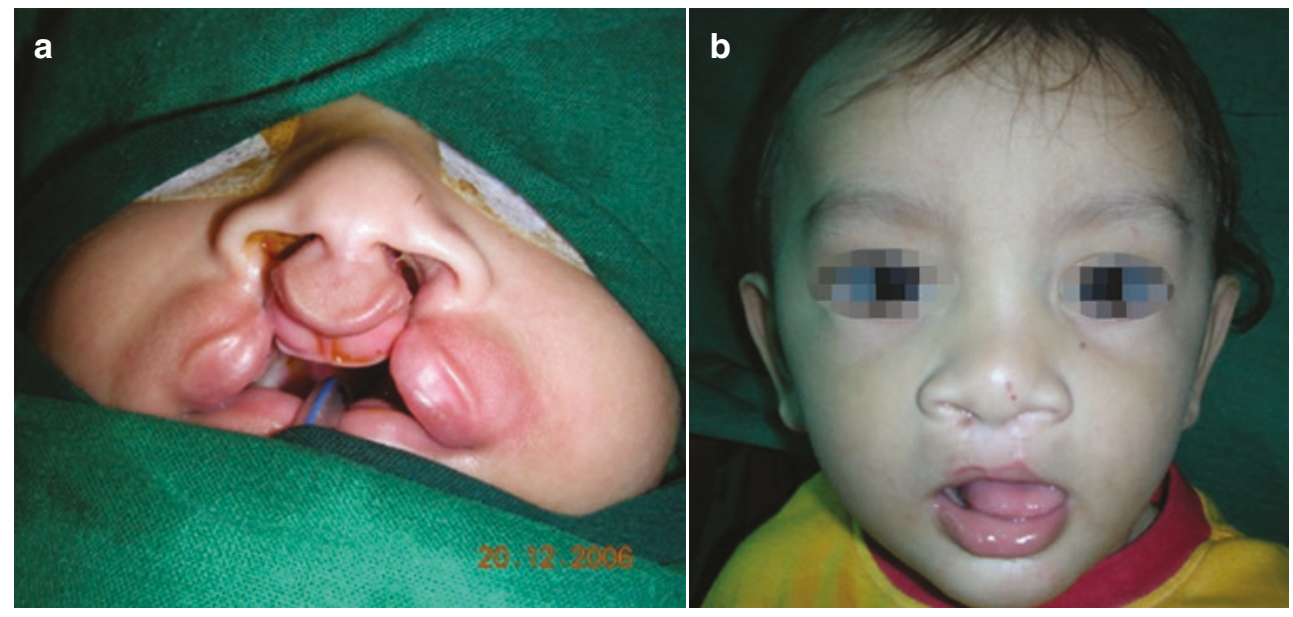

(CAssociation of Oral and Maxillofacial Surgeons of India 


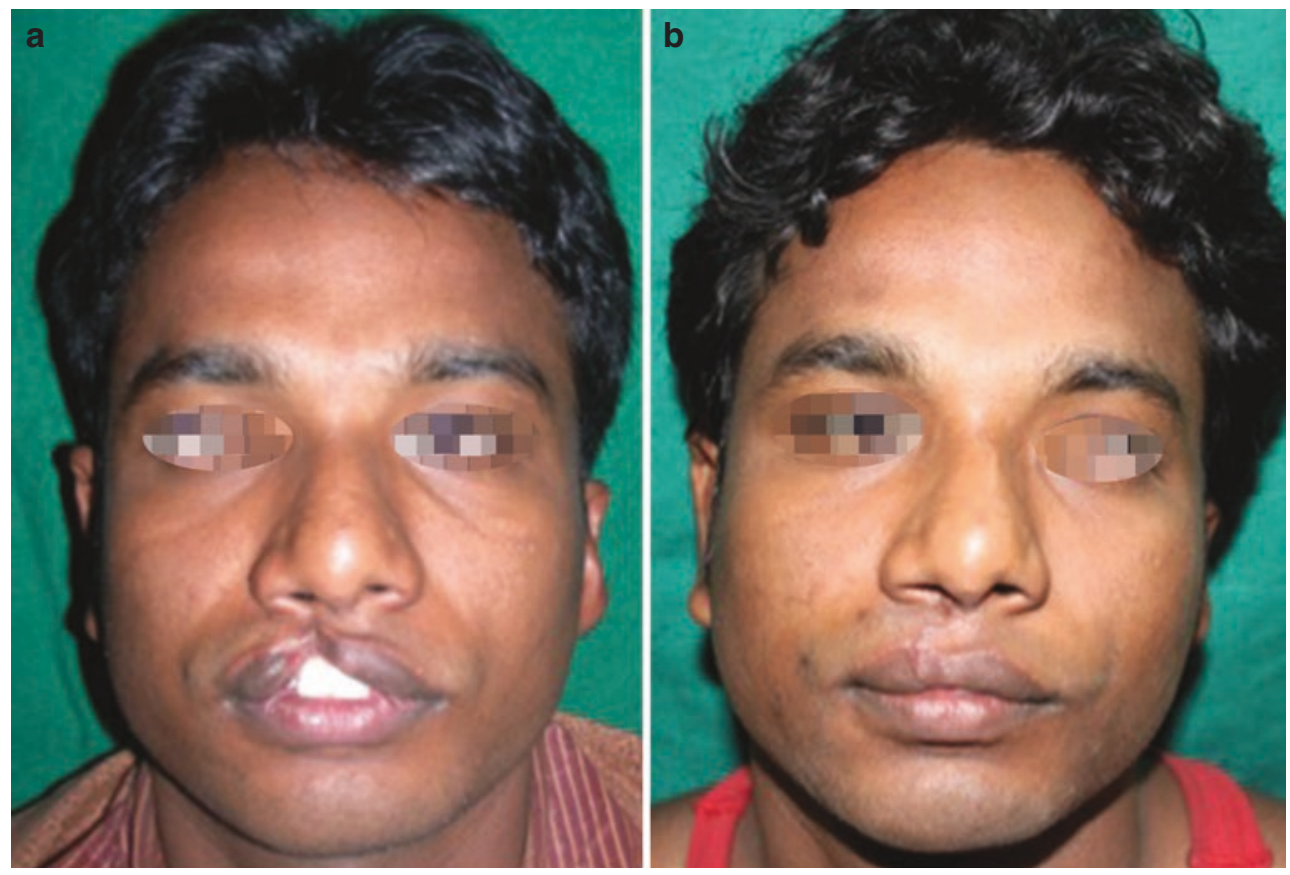

CAssociation of Oral and Maxillofacial Surgeons of India

Fig. 72.47 (a, b) A case of mucosal notching in an adult lip (a) Postoperative image after a 2-year follow-up (b)
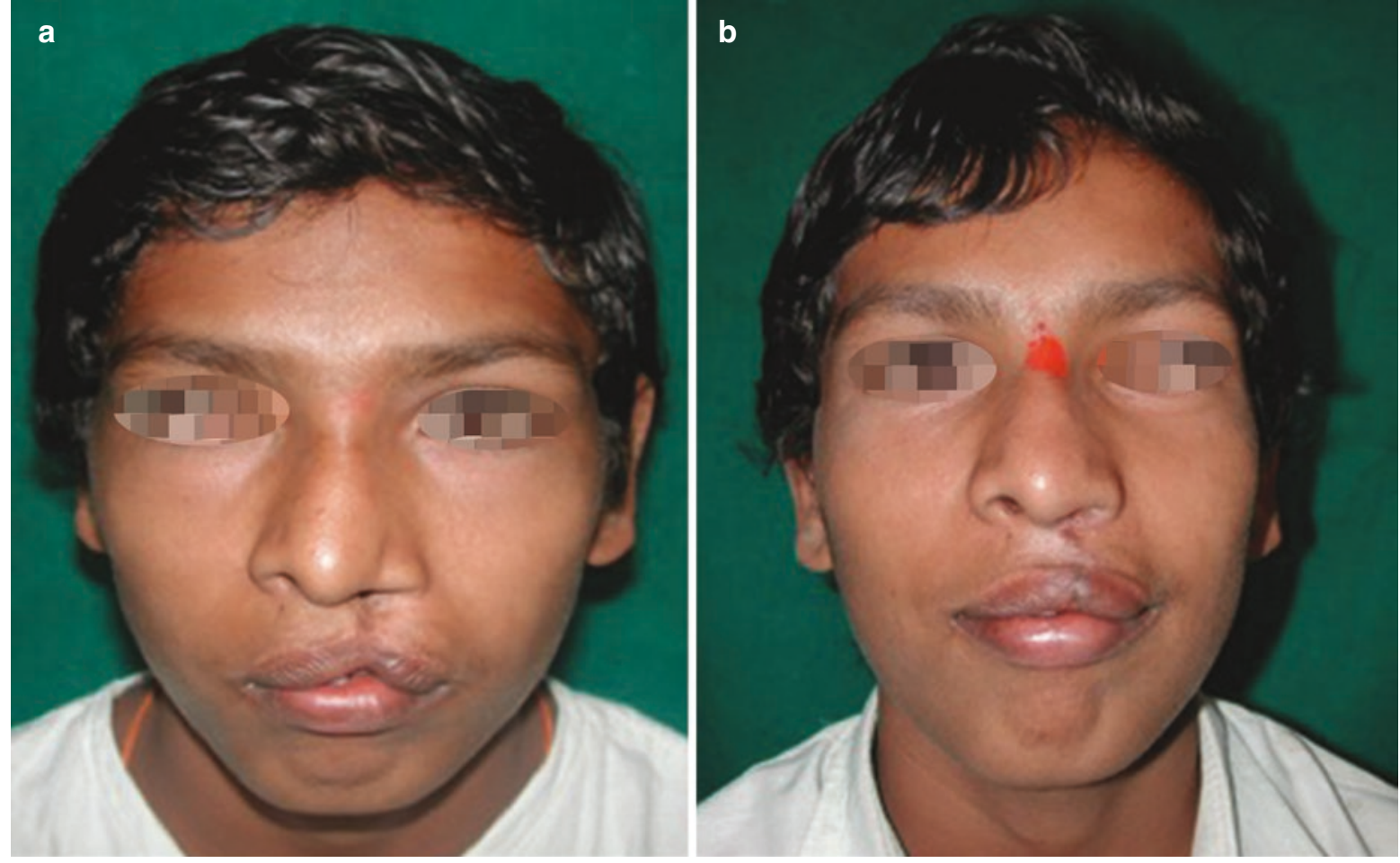

(c)Association of Oral and Maxillofacial Surgeons of India

Fig. $72.48(a, \mathbf{b})$ A case of operated unilateral cleft lip with mucosal notching and vertical scar contracture (a) Postoperative image after lip revision (b) 


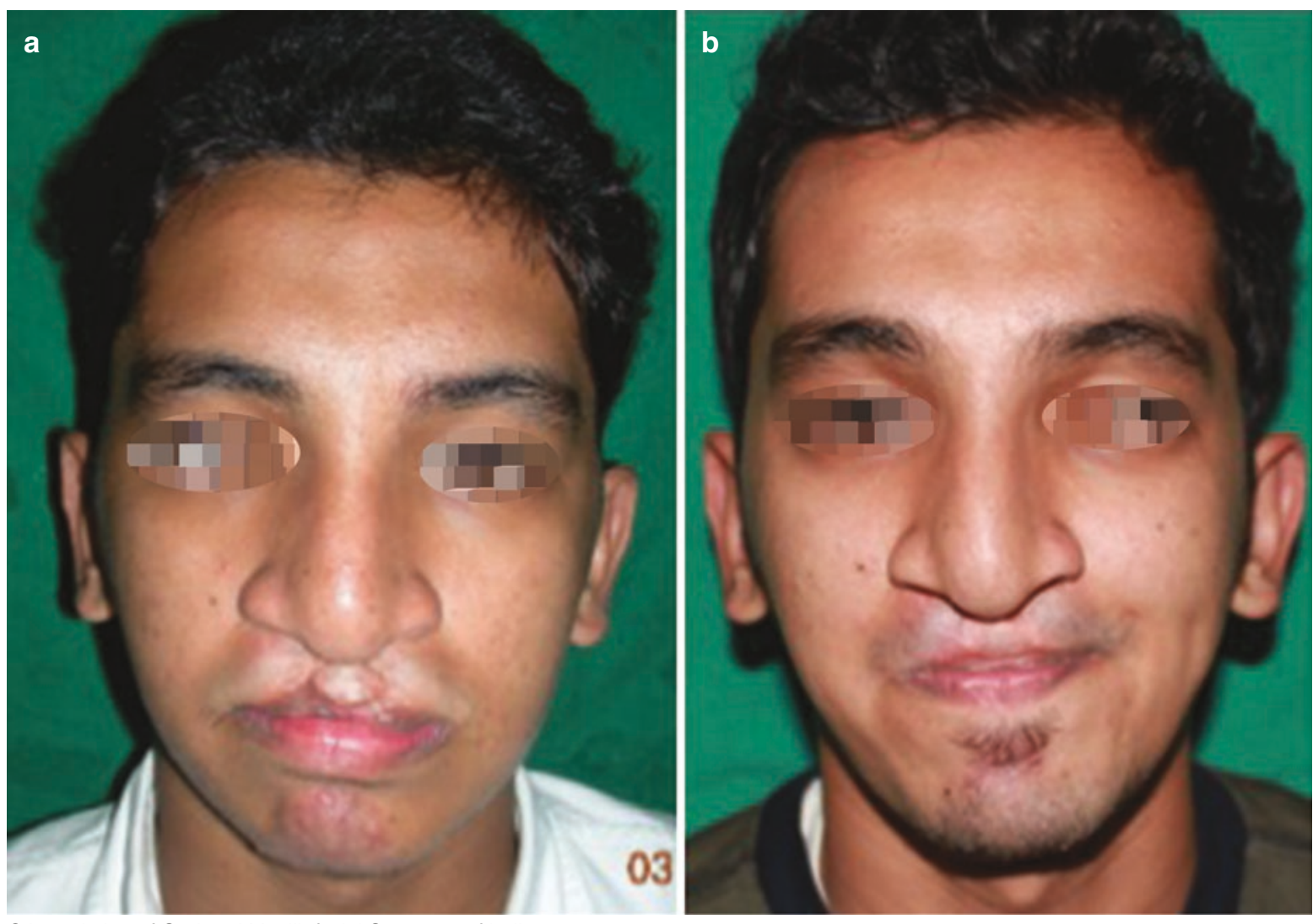

CAssociation of Oral and Maxillofacial Surgeons of India

Fig. 72.49 (a, b) An operated case of bilateral cleft lip before (a) and after (b) lip revision
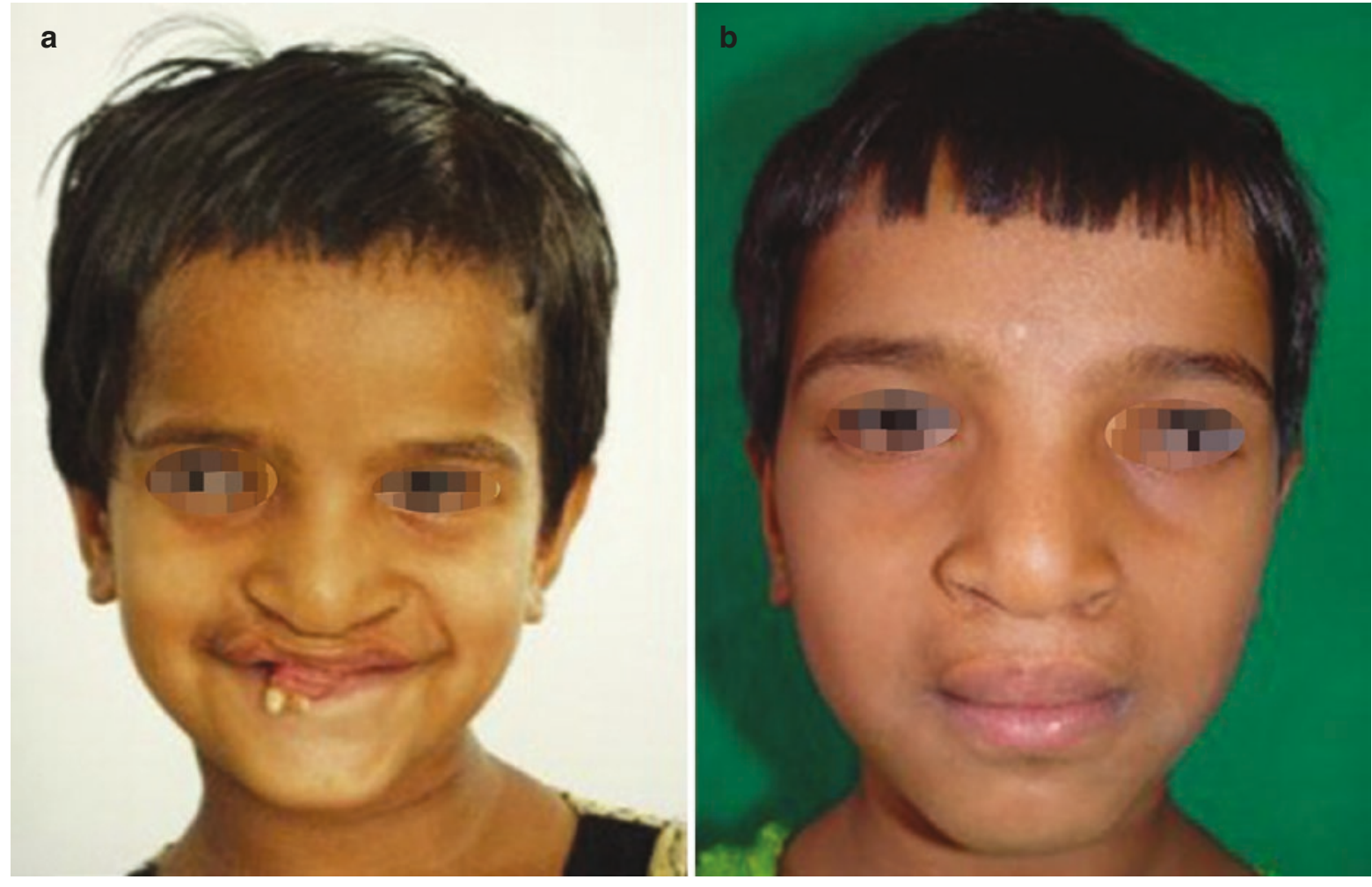

CAssociation of Oral and Maxillofacial Surgeons of India

Fig. 72.50 (a, b) A case of an operated bilateral cleft lip with protruding premaxilla and a wide lip (a) Postoperative image (b) after lip revision and premaxillary repositioning 


\section{References}

1. Kadir A, Mossey PA, Blencowe H, Moorthie S, Lawn JE, Mastroiacovo P, et al. Systematic review and meta-analysis of the birth prevalence of orofacial clefts in low- and middle-income countries. Cleft Palate Craniofac J. 2017;54:571-81.

2. Millard DR Jr. Cleft craft: evolution of its surgery. In: The unilateral deformity, vol. 1. Boston: Little, Brown; 1976.

3. Sadler TW, Langman J. Langman's medical embryology. 12th ed. Philadelphia: Wolters Kluwer Health/Lippincott Williams \& Wilkins; 2012.

4. Millard DR Jr. Cleft craft: evolution of its surgery. In: Embroyological theories, vol. 1. Boston: Little, Brown; 1976.

5. Millard DR Jr. Cleft craft: evolution of its surgery. In: Anatomy in multiple dimensions, vol. 1. Boston: Little, Brown; 1976.

6. Ghi T, Perolo A, Banzi C, et al. Two-dimensional ultrasound is accurate in the diagnosis of fetal craniofacial malformation. Ultrasound Obstet Gynecol. 2002;19:543-51.

7. Drake RL, Vogl W, Mitchell AWM, Gray H. Gray's anatomy for students. Philadelphia: Elsevier/Churchill Livingstone; 2005.

8. Davis JS, Ritchie HP. Classification of congenital clefts of the lip and palate. JAMA. 1922;79:1323-7.

9. Brophy TW. Cleft palate and harelip procedures. Int J Orthod Oral Surg. 1921;7:319-30.

10. Veau V. Division Palantine. Paris: Masson et Cie; 1931.

11. Kernahan DA, Stark RB. A new classification for cleft lip and cleft palate. Plast Reconstr Surg Transplant Bull. 1958;22:435-41.

12. Harkins CS, Berlin A, Harding RL, Longacre JJ, Snodgrasse RM. A classification of cleft lip and cleft palate. Plast Reconstr Surg Transplant Bull. 1962;29:31-9.

13. Kernahan DA. The striped Y - a symbolic classification for cleft lip and palate. Plast Reconstr Surg. 1971;47:469-70.

14. Spina V. A proposed modification for the classification of cleft lip and cleft palate. Cleft Palate J. 1973;10:251-2.

15. Elsahy NI. The modified striped $Y-$ a systematic classification for cleft lip and palate. Cleft Palate J. 1973;10:247-50.

16. Millard DR Jr. Cleft craft, vol. I. Boston: Little, Brown and Company; 1977. p. 41-55.

17. Friedman HI, Sayetta RB, Coston GN, Hussey JR. Symbolic representation of cleft lip and palate. Cleft Palate Craniofac J. 1991;28:252-9.

18. Kernahan DA. On cleft lip and palate classification. Plast Reconstr Surg. 1973;51:578.

19. Smith AW, Khoo AK, Jackson IT. A modification of the Kernahan "Y" classification in cleft lip and palate deformities. Plast Reconstr Surg. 1998;102:1842-7.

20. Balakrishnan C. Indian classification of cleft lip and palate. Indian J Plast Surg. 1975;8:23.

21. Kriens O. Lahshal: a concise documentation system for cleft lip, alvolus and palate diagnoses. In: Kriens O, editor. What is cleft lip and palate? A multidisciplinary update workshop, Bremen 1987. Stuttgart: Thieme; 1989.

22. Yuzuriha S, Mulliken JB. Minor-form, microform, and minimicroform cleft lip: anatomical features, operative techniques, and revisions. Plast Reconstr Surg. 2008;122(5):1485-93.

23. Bhuskute AA, Tollefson TT. Cleft lip repair, Nasoalveolar molding, and primary cleft rhinoplasty. Facial Plast Surg Clin North Am. 2016;24(4):453-466.

24. Cutting C, Grayson B, Brecht L, Santiago P, Wood R, Kwon $\mathrm{S}$. Presurgical columellar elongation and primary retrograde nasal reconstruction in one-stage bilateral cleft lip and nose repair. Plast Reconstr Surg. 1998;101:630-9.

25. Smith KS, Henry BT, Scott MA. Presurgical Dentofacial orthopedic management of the cleft patient. Oral Maxillofac Surg Clin North Am. 2016;28(2):169-176.
26. Santiago PE, Grayson BH, Cutting CB, et al. Reduced need for alveolar bone grafting by presurgical orthopedics and primary gingivoperiosteoplasty. Cleft Palate Craniofac J. 1998;35(1):77-80.

27. Wood RJ, Grayson BH, Cutting CB. Gingivoperiosteoplasty and midfacial growth. Cleft Palate Craniofac J. 1997;34(1):17-20.

28. Bennun RD, Perandones C, Sepliarsky VA, et al. Nonsurgical correction of nasal deformity in unilateral complete cleft lip: a 6-year follow-up. Plast Reconstr Surg. 1999;104(3):616-30.

29. Ezzat CF, Chavarria C, Teichgraeber JF, et al. Presurgical nasoalveolar molding therapy for the treatment of unilateral cleft lip and palate: a preliminary study. Cleft Palate Craniofac J. 2007;44(1):8-12.

30. Yang C, Huang N, Shi B. [Clinical research of presurgical orthodontic treatment of complete cleft lip and palate infant.] Hua Xi Kou Qiang Yi Xue Za Zhi. 2011;29(4):396-399. Chinese.

31. Ross RB. Growth of the facial skeleton following the Malek repair for unilateral cleft lip and palate. Cleft Palate Craniofac J. 1995;32(3):194-8.

32. Bonanthaya K, Nayak T, Bitra S, Rachwalski M, Shetty PN. An assessment and comparison of nasolabial aesthetics in bilateral clefts using the anatomical subunit-based scale: a nasoalveolar moulding versus non-nasoalveolar moulding study. Int J Oral Maxillofac Surg. 2019;48(3):298-301.

33. de Ladeira PR, Alonso N. Protocols in cleft lip and palate treatment: systematic review. Plast Surg Int. 2012;2012:562892.

34. https://medicine.uiowa.edu/iowaprotocols/cleft-lip-and-palateprotocols

35. Salyer KE, Xu H, Genecov ER. Unilateral cleft lip and nose repair; closed approach Dallas protocol completed patients. J Craniofac Surg. 2009;20 Suppl 2:1939-1955.

36. Dudkiewicz Z. Ocena jednoetapowego chirurgicznego leczenia jednostronnych rozszczep_ow podniebienia pierwotnego i wt_ornego. Probl Chir Dziec. 1991;18:8e19. [in Polish]

37. Åbyholm F. Primary closure of cleft lip and palate. In: Turvey TA, KWL V, Fonseca RJ, editors. Facial clefts and craniosynostosis. Philadelphia: WB Saunders; 1996. p. 370-83.

38. Ross RB. Growth of the facial skeleton following the Malek repair for unilateral cleft lip and palate. Cleft Palate Craniofac J. 1995 May;32(3):194-8.

39. Russell K, Long RE Jr, Hathaway R, Daskalogiannakis J, Mercado A, Cohen M, et al. The Americleft study: an inter-center study of treatment outcomes for patients with unilateral cleft lip and palate part 5. General discussion and conclusions. Cleft Palate Craniofac J. 2011;48:265-70.

40. http://www.wch.sa.gov.au/services/az/divisions/psurg/craniofacial/ documents/management_cleft_lip_palate.pdf.

41. Shaw WC, Brattström V, Mølsted K, Prahl-Andersen B, Roberts CT, Semb G. The Eurocleft study: intercenter study of treatment outcome in patients with complete cleft lip and palate. Part 5: discussion and conclusions. Cleft Palate Craniofac J. 2005;42:93-8.

42. Shaw WC, Semb G, Nelson P, Brattström V, Mølsted K, PrahlAndersen B. The Eurocleft project 1996-2000. Standards of care for cleft lip and palate in Europe. Amsterdam: IOS Press; 2000.

43. Lehman JA Jr, Douglas BK, Ho WC, Husami TW. One-stage closure of the entire primary palate. Plast Reconstr Surg. 1990;86:675-81.

44. Farina R: Total unilateral harelip: correction of severe deformity of the palate and lips in a single operation; Le Mesurier's cheiloplasty \& Veau-Ernst's gnathourano- staphyloplasty. Ann Chir Plast. 3:199-205. 1958 In French.

45. Fudalej P, Surowiec Z, Offert B, Dudkiewicz Z, Katsaros C. Craniofacial morphology in complete unilateral cleft lip and palate patients consecutively treated with 1-stage repair of the cleft. J Craniofac Surg. 2010;21:1468-73.

46. Rose W. On harelip and cleft palate. London: H.K. Lewis; 1891.

47. Thompson JE. An artistic and mathematically accurate method of repairing the defect in cases of hairlip. Surg Gynecol Obstet. 1912;14:498-504. 
48. Veau V. Le role tubercle median dans la constitution de la face. Ann Anat Pathol (Paris). 1926;3:305-48.

49. Pfeifer G. Lip corrections following earlier cleft surgery by way of wave-line incisions. Dtsch Zahnarztl Z. 1970;25:569-76.

50. Delaire J. Primary cheilorhinoplasty for congenital unilateral labiomaxillary fissure. Trial schematization of a technic. Rev Stomatol Chir Maxillofac. 1975;76:193-215.

51. Chait L, Kadwa A, Potgieter A, et al. The ultimate straight line repair for unilateral cleft lips. J Plast Reconstr Aesthet Surg. 2009 Jan; 62:50-55. [Epub 2007 Nov 26].

52. Mirault G. Deux lettres sur l'operation du bec-de-lievre. J Chir Paris. 1844:1-12.

53. Blair VP, Brown JB. Mirault operation for single harelip. Surg Gynecol Obstet. 1930;51:81.

54. Brown JB, McDowell F. Simplified design for repair of single cleft lip. Surg Gynecol Obstet. 1945;80:12.

55. LeMesurier AB. The quadrilateral mirault flap operation for harelip. Plast Reconstr Surg (1946). 1955;16:422-33.

56. Hagedorn W. Uber eine Modifikation der Hasenschartenoperation. Zentralbl Chir. 1884;11:756.

57. Tennison CW. The repair of unilateral cleft lip by the stencil method. Plast Reconstr Surg. 1952;9:115.

58. Randall P. A triangular flap operation for the primary repair of unilateral clefts of the lip. Plast Reconstr Surg Transplant Bull. 1959;23:331-47.

59. Millard DR Jr. A primary camouflage of the unilateral Harelook. In: Skoog T, editor. Transactions of the first international congress of plastic surgery, stockholm, 1955. Baltimore: Williams \& Wilkins; 1957. p. 160-6.

60. Millard DR. Complete unilateral clefts of the lip. Plast Reconstr Surg. 1960;25:595-605.

61. Millard DR. A radical rotation in single harelip. Am J Surg. 1958;95:318-22.

62. Millard DR. Refinements in rotation-advancement cleft lip technique. Plast Reconstr Surg. 1964;33:26-38.
63. Stal S, Brown RH, Higuera S, Hollier LH Jr, Byrd HS, Cutting $\mathrm{CB}$, Mulliken JB. Fifty years of the Millard rotation-advancement: looking back and moving forward. Plast Reconstr Surg. 2009;123(4):1364-77.

64. Mohler LR. Unilateral cleft lip repair. Plast Reconstr Surg. 1987;80:511-7.

65. Fisher DM. Unilateral cleft lip repair: an anatomical subunit approximation technique. Plast Reconstr Surg. 2005;116:61-71.

66. Noordhoff MS. Reconstruction of vermilion in unilateral and bilateral cleft lips. Plast Reconstr Surg. 1984;73:52.

67. Cutting CB, Dayan JH. Lip height and lip width after extended Mohler unilateral cleft lip repair. Plast Reconstr Surg. 2003;111:17-23.

68. Mulliken JB, Martinez-Perez D. The principle of rotation advancement for repair of unilateral complete cleft lip and nasal deformity: technical variations and analysis of results. Plast Reconstr Surg. 1999;104:1247-60.

69. Wolfe SA. Repair of bilateral incomplete cleft lip: techniques and outcomes. Plast Reconstr Surg. 2014;134(1):166e-168e.

70. Zhang JX, Arneja JS. Evidence-based medicine: the bilateral cleft lip repair. Plast Reconstr Surg. 2017;140(1):152e-165e. Review.

71. Bardach J, Cutting C. Anatomy of the unilateral and bilateral cleft lip and nose. In: Bardach J, Morris HL, editors. Multidisciplinary Management of Cleft lip and Palate. Philadelphia: Saunders; 1990. p. 150-9.

72. Salyer KE, Bardach J. Salyer \& Bardach's atlas of craniofacial \& cleft surgery: craniofacial surgery. Philadelphia: Lippincott-Raven Publishers; 1999.

73. Trier WC. Repair of bilateral cleft lip: Millard's technique. Clin Plast Surg. 1985 Oct;12(4):605-25.

74. Mancini L, Gibson TL, Grayson BH, Flores RL, Staffenberg D, Shetye PR.Three-dimensional soft tissue nasal changes after Nasoalveolar molding and primary Cheilorhinoplasty in infants with unilateral cleft lip and palate. Cleft Palate Craniofac J. 2019;56(1):31-38.

Open Access This chapter is licensed under the terms of the Creative Commons Attribution 4.0 International License (http://creativecommons. org/licenses/by/4.0/), which permits use, sharing, adaptation, distribution and reproduction in any medium or format, as long as you give appropriate credit to the original author(s) and the source, provide a link to the Creative Commons license and indicate if changes were made.

The images or other third party material in this chapter are included in the chapter's Creative Commons license, unless indicated otherwise in a credit line to the material. If material is not included in the chapter's Creative Commons license and your intended use is not permitted by statutory regulation or exceeds the permitted use, you will need to obtain permission directly from the copyright holder. 